$(2)$ IMPACTO del COVDD-19

3 desde la PERSPECTIVA SOCIOECONONICN 3. en CONTEXTO GLOBAL

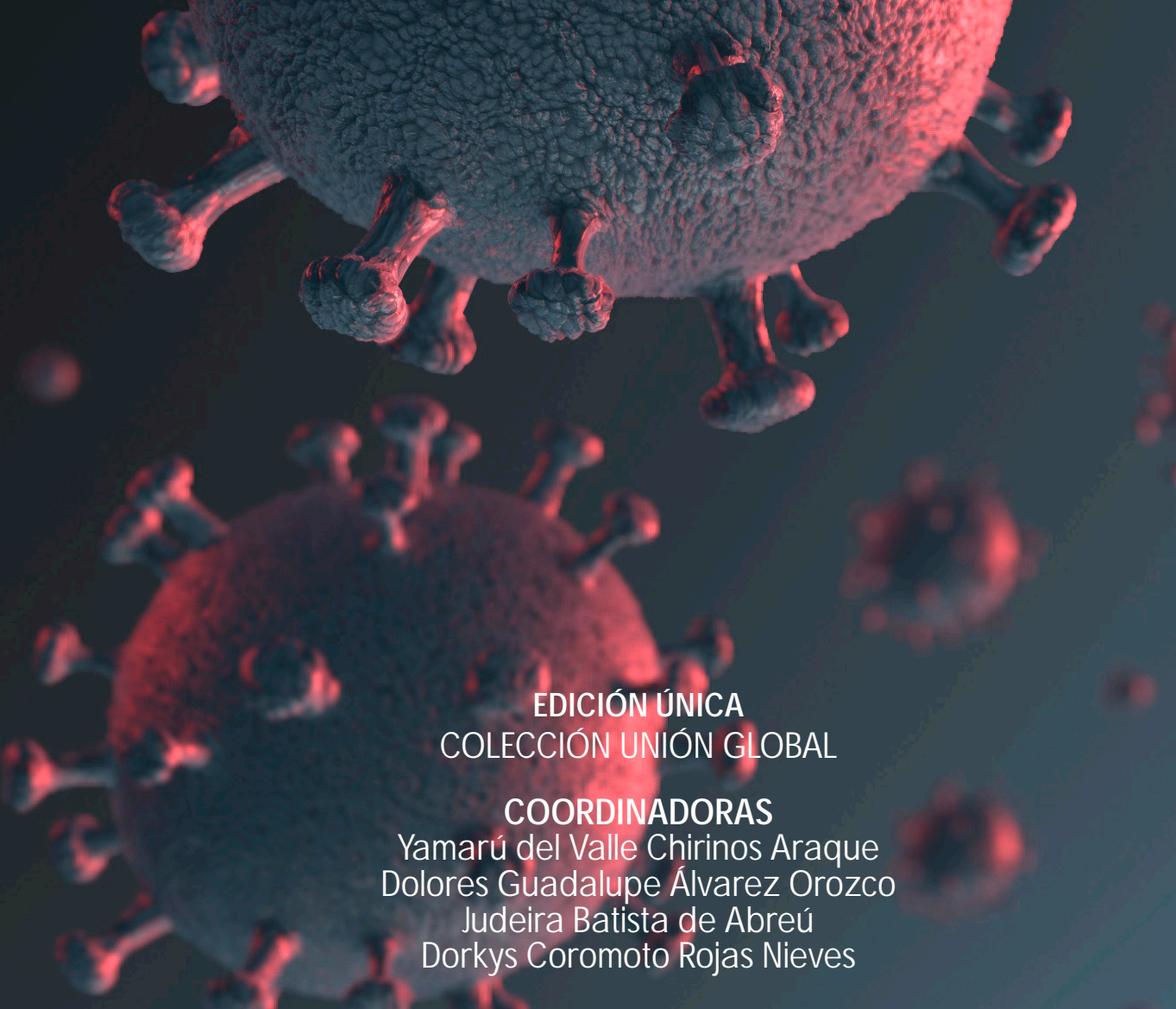




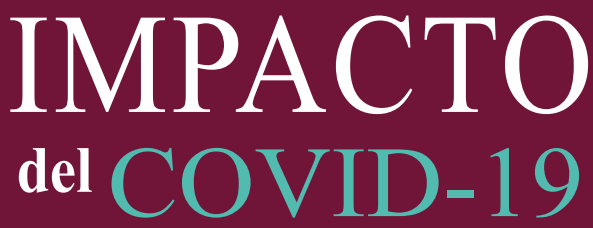

\section{desde la PERSPECTIVA SOCIOECONÓMICA en el CONTEXTO GLOBAL}

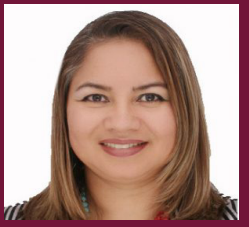

\section{Dra. Yamarú del Valle Chirinos Araque}

Dra En Gestión de la Innovación, Directora General de la Alianza de Investigadores Internacionales S.A.S. ALININ. Docente investigadora de la Universidad Católica Luis Amigó en Colombia Investigadora Senior categorizada por Minciencias. Profesora de pregrado y Postgrado en la UNERMB Venezuela. Ponente en eventos nacionales e internacionales, conferencista magistral en eventos internacionales, Directora de tesis de pregrado y postgrado, investigadora reconocida por el programa de estímulo al investigador PEll nivel A2 en Venezuela Editora de libros de investigación, par evaluador de revistas científicas indexadas a nivel nacional e internacional, autora de artículos publicados en revistas científicas, responsable de proyectos de investigación internacionales en ejecución, profesora invitada en aliversas Universidades en Latinoamérica.

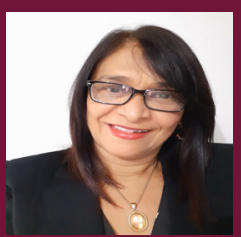

\section{Dra. Judeira Batista de Abreú}

Estudios Postdoctorales en Gerencia en las organizaciones. Doctora en Ciencias Gerenciales. Master en Ingeniería Química e Ingeniera Química. Especialista en PNL y en Destrezas de Coach ontológico. Docente investigador en la Universidad de la Guajira, Colombia, miembro activo del grupo de Investigación GEPINCAT de la misma universidad y de la Red de Investigadores Internacionales ALININ. Autora de más de 50 artículos en las áreas de Neuroliderazgo, Gestión Tecnológica, Innovación, Resolución de conflicto, Planificación estratégica y Toma de decisiones en el sector público y privado. Conferencista nacional e internacional y autora del libro Liderazgo congruente desde la PNL.

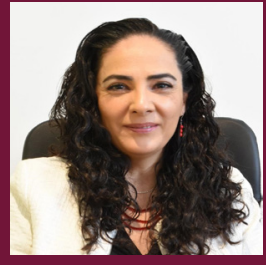

Dra. Dolores Álvarez
Doctora en Administración por la
Universidad de Celaya. Directora
de Vinculación en la Universidad
Politécnica de Guanajuato.
Exdirectora de Carrera de la
Licenciatura en Administración
y Gestión de PyMES. 17 años de experiencia como Profesora Investigadora a nivel Maestría y Doctorado en instituciones públicas y privadas. Integrante del Cuerpo Académico en Consolidación "Desarrollo de las organizaciones" reconocido por PRODEP nivel CAEF. Miembro del Sistema Nacional de investigadores nivel candidato. Certificada por CONOCER en los estándares impartición de cursos de formación del capital humano de manera presencial grupal y Evaluación de la competencia de los candidatos con base en estándares de competencia. Autoras de diversos artículos en revistas arbitradas e indexadas, libros y capítulos de Libro sobre temas de Responsabilidad Social y Recursos Humanos.

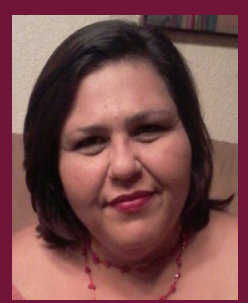

\section{Dra. Dorkys Coromoto Rojos Nieves}

Dra. En Ciencias Gerenciales, Profesora de Pregrado y Postgrado en UNERMB Venezuela Profesora de Postgrado en UNIOJEDA. Coordinadora de ALININ en el Estado Zulia, Venezuela. Tutora de tesis de Pregrado y Postgrado. Investigadora en el Centro de Estudios Administrativos y Políticas Públicas (CEAPP). Ex - Coordinadora de Servicio Comunitario. 



\title{
IMPACTO del COVID-19 desde la PERSPECTIVA SOCIOECONÓMICA en el CONTEXTO GLOBAL
}

\author{
EDICIÓNÚNICA
}

COLECCIÓN UNIÓN GLOBAL

\section{Coordinadores}

Yamarú del Valle Chirinos Araque Dolores Guadalupe Álvarez Orozco Judeira Batista de Abreú Dorkys Coromoto Rojas Nieves 
Este libro está conformado por documentos de trabajo denominados por documentos cientificos propios de las reflexiones de los autores que lo constituyen, todos los capítulos incluidos en él son producto de investigaciones desarrolladas por sus autores. Fueron arbitrados bajo el sistema doble ciego por expertos externos en el área, bajo la supervisión de los grupos de investigación de: la Universidad Politécnica Territorial de Falcón Alonso Gamero (UPTAG), Falcón, Venezuela, la Alianza de Investigadores Internacionales (ALININ), Antioquia, Colombia. Los planteamientos y argumentaciones presentadas en los capítulos del libro Impacto del COVID-19 desde la perspectiva socioeconómica en el contexto global, son responsabilidad única y exclusiva de sus autores, por lo tanto, los coordinadores, las Universidades e instituciones que respaldan la obra actúan como un tercero de buena fe.

Edición: Fondo Editorial Universitario Servando Garcés de la Universidad Politécnica Territorial de Falcón Alonso Gamero. Santa Ana de Coro, estado Falcón, Venezuela. Coeditor: Alianza de Investigadores Internacionales S.A.S. ALININ. Itagüí, Antioquia, Colombia.

(C) 2020. Impacto del COVID-19 desde la perspectiva socioeconómica en el contexto global.

Coordinadoras:

Yamarú del Valle Chirinos Araque

Dolores Guadalupe Álvarez Orozco

Judeira Batista de Abreú

Dorkys Coromoto Rojas Nieves

Autores:

(C) Douglas Adolfo García Gómez; (C Yamarú Del Valle Chirinos Araque; (c) Naybi Salas Vargas; (C) Sergio Madero; (C) Lisbeth Molero; (C) Allyson Vanegas; (C) Andrea Andrade; (c) Luis Guillermo Molero Suárez; (C) Leidi Yoana Zamudio Garnica; (C) José De Jesús Freyle Gómez; (C) Nayiris Marcela López Calleja; (C) Rafael Paredes Carrasco; (C) Mauricio Alejandro Bedoya Jimenez; (C) Julián David Colorado Agudelo; (C) Osmany Pérez Barral; (C) Mónica del Rocío Alarcón Quinapanta; (C) Jorge Vladimir Núñez Grijalva; (C) Yazmín Alejandra Quintero Hernández; (C) Perla Shiomara del Carpio Ova; (C) Sergio Luis Mondragón Duarte; (C) Efraín de Jesús Hernández Buelvas; (C) Arney Alfonso Vega Martínez; (C Nataliya Barbera de Ramírez; (C María de Lourdes Tiburcio Sánchez; (C) Roberto Godínez López; (C) Gustavo Adolfo Rubio-Rodríguez; (C Alexander Blandón López; (C) Guillermo Meza Salcedo; (C) Carolina González; (C) Noemi Vega Lugo; (C) Nancy Testón; (C Josnel Martínez Garcés; (C) Jacqueline Garcés Fuenmayor; (C Lesbia Rosa Tirado Amador; (C) Carlos Arturo Leal Acosta; (C) Fernando Xavier Rosas Salas; (C) Myrian Patricia Rubio Díaz; (C) Walter Serna Borja; (C César Alveiro Trujillo Solarte; (C Mario Francisco Sosa González; (C) Ángel Acevedo-Duque C Martín Cano Contreras; (C) María Susana Acosta Navarrete; C Héctor Cuevas Vargas; (C) Yeimy Mireya Cuellar Medina; (C) Paula Andrea Jaramillo García; (C) Feibert Alirio Guzmán Pérez; (C Leibniz Huxlay Flórez Guzmán; C Elvigia Cardona Zuleta; (C María Isabel Uribe López; (C) Judeira Batista; (C) Judith Batista; ( C Edison Perozo; (C Juan José Quintero Rivera; (C) Leydi Daniela Rodríguez Díaz; (C) Marino Valencia R; (C) Verena González C; (C) Luis Ferney Bonilla B; (C) Robinson Escobar Soto; (C) Albano Alexander Rojas-Britto; (c) José Obdulio Curvelo-Hassán; ( Mario Heimer Flórez-Guzmán; (c) Mónica Alexandra Zarta Campos; (C) Alexander Beltrán Echeverry; (C) Jesús David Vera Galicia; (C) Kimberly Cortes Buitrago; (C) Alejandro Sánchez Quiñones; (c) Gilberto Lázaro Galloso Cueto; (C) Alejandro Leoner Galloso 
Machín; (C) David Rincón Ávila; (C) Irsa Daniela Botello Arredondo; (C) Dolores Guadalupe Álvarez Orozco; (C) Carlos Alberto Moncada Sierra; (C) Julián Ferrer Guerra; (C Jorge SánchezMaldonado; (C) Yully Rodríguez Garzón; (C) Jairo Alberto Olarte Cabana; (C) Mario Samuel Rodríguez Barrero; (C) Aracelly Buitrago Mejía; (C Gustavo Adolfo Rubio Rodríguez; ( F Federico José Jiménez Varón; (C Ingrid Eliana Gómez; @ Sandra Milena Malavera Pineda; @ Paula Andrea Malavera Pineda; (c) Valentina Colorado Bedoya; (C) María José Osorio Villa; (C) Luísa Cagica Carvalho; (C) Rui Dias; (C) João Pereira; (C) Adriana Backx; (C) Francieli Iung Izolani.

\section{Edición Única}

Versión digital

Depósito legal: FA2020000022

ISBN: 978-980-7857-35-2

www.doi.org/10.47212/impactocovid19.1

Evaluación de contenido: Esta obra ha sido aprobada por el Consejo Editorial de la Universidad Politécnica Territorial de Falcón Alonso Gamero (UPTAG) y editada bajo procedimientos que garantizan su normalización.

Declaración conflictos de interés: los autores de esta publicación declaran la inexistencia de conflictos de interés de cualquier índole con instituciones o asociaciones comerciales.

Hecho en Venezuela

Coordinadora Editorial: Lic. Gabriela Castillo.

Portada: Imagen propiedad de freepik.es

Maquetación, revisión y corrección de estilo, gramática, presentación y ortografía: Lcda. Ana Pirela. Quito, Ecuador. Correo electrónico: anarelyspirela@gmail.com.

\section{(c)}

Esta obra está bajo una Licencia CreativeCommons Atribución-No Comercial-Compartir Igual 4.0 Internacional.

Para citar este libro siguiendo las indicaciones de la sexta edición en español de APA: Chirinos, Y., Álvarez, D., Batista, J. y Rojas, D. (2020). (Eds.), Impacto del Covid-19 desde la perspectiva socioeconómica en el contexto global. Fondo Editorial Servando Garcés. 


\section{CATALOGACIÓN DE LA FUENTE}

304 IM34

Impacto del COVID-19 desde la perspectiva socioeconómica en el contexto global: Edición Única / Yamarú del Valle Chirinos Araque, Dolores Guadalupe Álvarez Orozco, Judeira Batista de Abreú, Dorkys Coromoto Rojas Nieves, coordinadoras. Santa Ana de Coro, estado Falcón, Venezuela; Fondo Editorial Universitario Servando Garcés de la Universidad Politécnica Territorial de Falcón Alonso Gamero (UPTAG), 2020. (Colección Unión Global). 162 páginas.

Versión digital, ISBN: ISBN: 978-980-7857-35-2

INVESTIGACIONES - AMÉRICA LATINA; IMPACTO SOCIOECONÓMICO CORONAVIRUS, COVID-19 - PANDEMIA - SALUD - EDUCACIÓN - ECONOMÍAPOLÍTICAS PÚBLICAS - EFECTOS AMBIENTALES - RESPONSABILIDAD SOCIAL; Grupos de investigación de: Universidad Politécnica Territorial de Falcón Alonso Gamero (UPTAG), Falcón, Venezuela, y Alianza de Investigadores Internacionales (ALININ), Medellín, Colombia.

Disponible en:

https://investigacionuptag.wordpress.com/

www.alinin.org

www.academia.edu

www.doi.org/10.47212/impactocovid19.1 


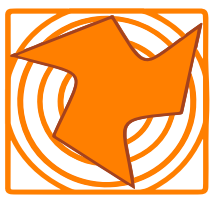

REPÚBLICA BOLIVARIANA DE VENEZUELA EOUCACIÓN UNIVERSITARIA, CIENCIA Y TECNOLOGÍA

SANTAANA DE CORO - ESTADO FALCON

UNIVERSIDAD POLITÉCNICA

TERRITORIAL DE FALCÓN

ALONSO GAMERO

Universidad Politécnica Territorial de Falcón

Alonso Gamero

UPTAG

Ing. Rafael Pineda Piña

Rector

MSc. Emma Paola García

Vicerrectora Académica

Ing. Víctor Piñero Cruz

Vicerrector de Desarrollo Territorial

MSc. Eugenio Petit

Secretario General

Dra. Oneida Jordán

Coordinadora de Creación Intelectual y

Desarrollo Socioproductivo 


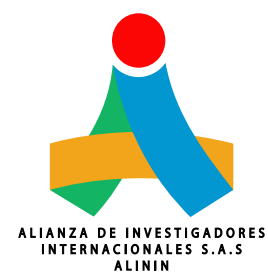

Alianza de Investigadores Internacionales

\author{
ALININ \\ Dra. Yamarú del Valle Chirinos Araque \\ Directora General \\ Dra. Nataliya Barbera Alvarado \\ Coordinadora de Investigación \\ Dra. Lyneth Haymara Camejo López \\ Coordinadora del Comité de Arbitraje \\ Dra. Dorkys Coromoto Rojas Nieves \\ Coordinadora Ejecutiva - Venezuela \\ Dr. Roberto Godínez López \\ Coordinador Ejecutivo Guanajuato - México. \\ Dr. Adán Guillermo Ramírez García \\ Coordinador Ejecutivo Estado de Sonora - México
}




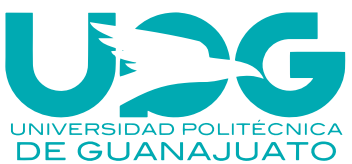

Universidad Politénica de Guanajuato

UPG

\section{Dr. Hugo García Vargas}

Rector

Juan Fernando Rivera Meza

Secretario Académico

Gabriela Médina Ramos

Subdirectora de investigación e internacionalización 
Aliados Institucionales de ALININ
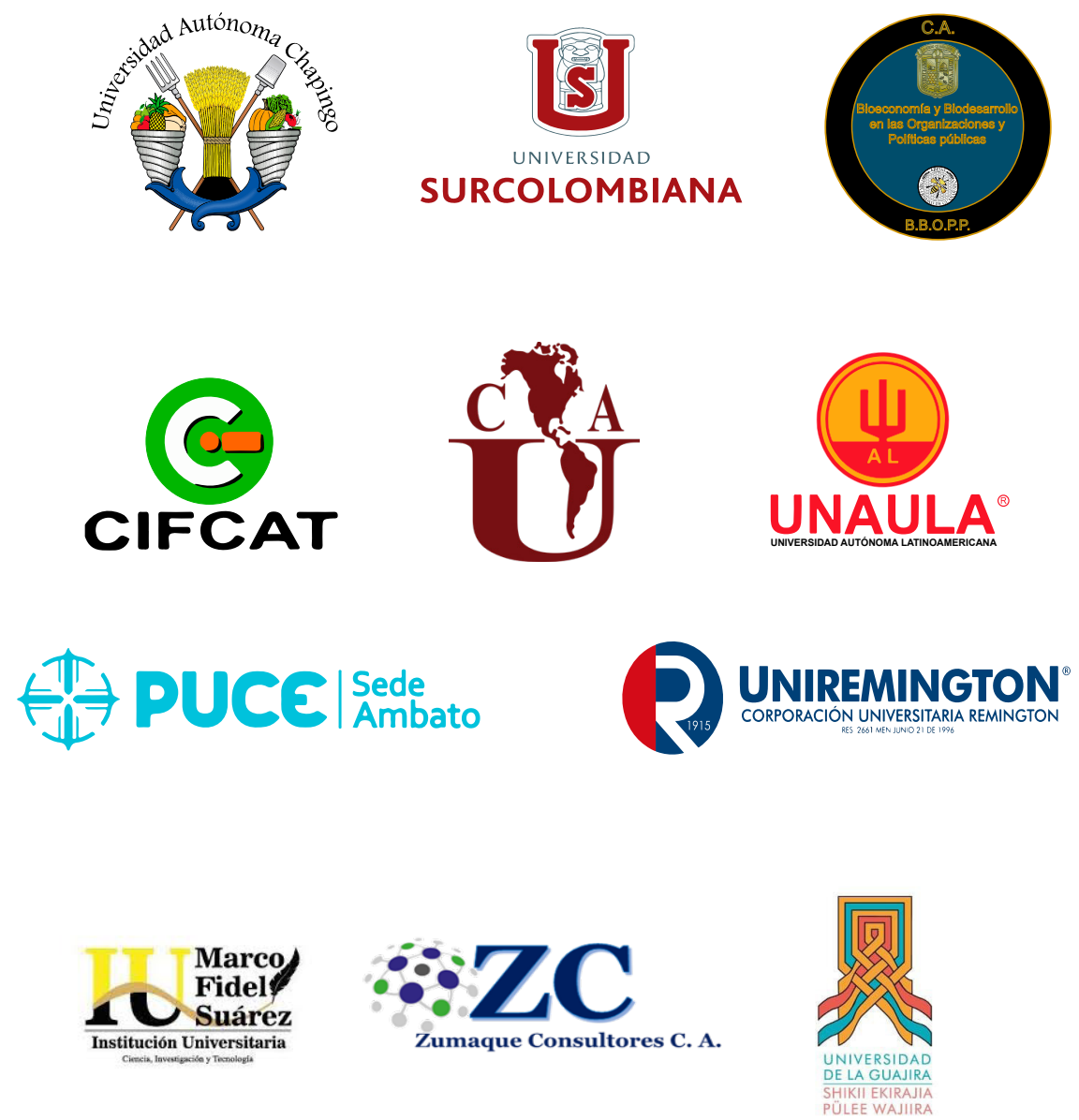
Adriana Backx

Universidade de São Pau

Francieli Iung Izolani

Universidad Federal de Santa Maria

Bolivia

Gilberto Lázaro Galloso Cueto

Universidad Aquinino de Bolivia

Alejandro Leoner Galloso Machín

Universidad Aquinino de Bolivia

Colombia

Yamarú del Valle Chirinos Araque

Universidad Católica Luis Amigó

Lisbeth Molero

Universidad Politécnico Grancolombiano

Allyson Vanegas

Universidad Politécnico Grancolombiano

Andrea Andrade

Universidad La Salle

Luis Guillermo Molero Suarez

Fundación Universitaria Panamericana

Leidi Yoana Zamudio Garnica

Corporación Universitaria Iberoamericana

José De Jesús Freyle Gómez

Centro Etno-educativo rural Mapuain

Nayiris Marcela López Calleja

Centro Etno-educativo rural Mapuain

Mauricio Alejandro Bedoya Jimenez

Universidad Católica Luis Amigó

Julián David Colorado Agudelo

Universidad Católica Luis Amigó

Sergio Luis Mondragón Duarte

Universidad Autónoma Latinoamericana

Efraín de Jesús Hernández Buelvas

Universidad de Córdoba

Arney Alfonso Vega Martínez

Universidad de Caldas 
Nataliya Barbera de Ramírez

Universidad del Sinú

Gustavo Adolfo Rubio-Rodríguez

Corporación Universitaria Minuto de Dios

Alexander Blandón López

Universidad del Tolima

Guillermo Meza Salcedo

Corporación Universitaria Minuto de Dios

Josnel Martínez Garcés

Corporación Universitaria Autónoma de Nariño

Jacqueline Garcés Fuenmayor

Corporación Universitaria Autónoma de Nariño

Lesbia Rosa Tirado Amador

Universidad del Sinú

Carlos Arturo Leal Acosta

Corporación Universitaria Rafael Núñez

Walter Serna Borja

Corporación Universitaria Autónoma de Nariño

César Alveiro Trujillo Solarte

Universidad del Cauca

Yeimy Mireya Cuellar Medina

Corporación Universitaria Remington

Paula Andrea Jaramillo García

Corporación Universitaria Remington

Feibert Alirio Guzmán Pérez

Corporación Universitaria Remington

Leibniz Huxlay Flórez Guzmán

Colegio Miguel Antonio Caro

Elvigia Cardona Zuleta

Universidad Católica Luis Amigó

María Isabel Uribe López

Universidad Católica Luis Amigó

Judeira Batista

Universidad de La Guajira

Edison Perozo

Universidad de la Guajira

Juan José Quintero Rivera

Corporación Universitaria Remington

Leydi Daniela Rodríguez Díaz

Corporación Universitaria Remington

Marino Valencia R.

Universidad de San Buenaventura

Verena González C.

Universidad de San Buenaventura

Luis Ferney Bonilla B.

Universidad de San Buenaventura

Robinson Escobar Soto

Corporación Universitaria Autónoma de Nariño 


\author{
Albano Alexander Rojas-Britto \\ Corporación Universitaria Autónoma de Nariño \\ José Obdulio Curvelo-Hassán \\ Universidad Cooperativa de Colombia \\ Mario Heimer Flórez-Guzmán \\ Fundación Universitaria María Cano \\ Mónica Alexandra Zarta Campos \\ Corporación Universitaria Minuto de Dios \\ Alexander Beltrán Echeverry \\ Corporación Universitaria Minuto de Dios \\ Jesús David Vera Galicia \\ Corporación Universitaria Minuto de Dios \\ Kimberly Cortes Buitrago \\ Corporación Universitaria Remington \\ Alejandro Sánchez Quiñones \\ Corporación Universitaria Remington \\ Jorge Sánchez-Maldonado \\ Corporación Universitaria del Meta \\ Yully Rodríguez Garzón \\ Jairo Alberto Olarte Cabana \\ Fundación Universitaria Unipanamericana \\ Mario Samuel Rodríguez Barrero \\ Universidad Cooperativa de Colombia \\ Aracelly Buitrago Mejía \\ Universidad del Tolima \\ Gustavo Adolfo Rubio Rodríguez \\ Universidad Minuto de Dios \\ Federico José Jiménez Varón \\ Universidad Minuto de Dios \\ Ingrid Eliana Gómez \\ Corporación Universitaria Remington \\ Sandra Milena Malavera Pineda \\ Universidad Católica Luis Amigó \\ Paula Andrea Malavera Pineda \\ Institución Universitaria Remington \\ Valentina Colorado Bedoya \\ Fundación Universitaria María Cano \\ María José Osorio Villa \\ Fundación Universitaria María Cano
}

Douglas Adolfo García Gómez

Universidad de Sancti Spíritus "José Martí Pérez"

Naybi Salas Vargas

Universidad de Sancti Spíritus "José Martí Pérez" 
Chile

Rafael Paredes Carrasco

Universidad Autónoma de Chile

Ángel E. Acevedo-Duque

Universidad Autónoma de Chile

Ecuador

\section{Osmany Pérez Barral}

Pontificia Universidad Católica del Ecuador

Mónica del Rocío Alarcón Quinapanta

Universidad Regional Autónoma de Los Andes

Jorge Vladimir Núñez Grijalva

Pontificia Universidad Católica del Ecuador

Fernando Xavier Rosas Salas

Pontificia Universidad Católica del Ecuador

Myrian Patricia Rubio Díaz

Pontificia Universidad Católica del Ecuador

Mario Francisco Sosa González

Universidad Nacional Autónoma de Honduras

México

\section{Sergio Madero}

Tecnológico de Monterrey

Yazmín Alejandra Quintero Hernández

Universidad de Guanajuato

Perla Shiomara del Carpio Ova

Universidad de Guanajuato

María de Lourdes Tiburcio Sánchez

Universidad de Guanajuato 


\section{Roberto Godínez López}

Universidad de Guanajuato

Carolina González

Universidad Autónoma del Estado de Hidalgo

Noemi Vega Lugo

Universidad Autónoma del Estado de Hidalgo

Nancy Testón

Universidad Autónoma del Estado de Hidalgo

Martín Cano Contreras

Universidad Tecnológica del Suroeste de Guanajuato

María Susana Acosta Navarrete

Universidad Tecnológica del Suroeste de Guanajuato

Héctor Cuevas Vargas

Universidad Tecnológica del Suroeste de Guanajuato

David Rincón Ávila

Universidad de Guanajuato

Irsa Daniela Botello Arredondo

Universidad de Guanajuato

Dolores Guadalupe Álvarez Orozco

Universidad Politénica de Guanajuato

Carlos Alberto Moncada Sierra

Tecnológico Nacional de México

Julián Ferrer Guerra

Tecnológico Nacional de México

\section{Luísa Cagica Carvalho}

Instituto Politénico de Setúbal

Rui Dias

Instituto Politénico de Setúbal

João Pereira

Instituto Politécnico de Lisboa

Venezuela

Judith Batista

Universidad del Zulia 


\section{ÍNDICE}

Introducción 1

La universidad cubana su accionar ante la presencia del corona virus (COVID-19) Douglas Adolfo García Gómez / Yamarú del Valle Chirinos Araque / Naybi Salas Vargas.

Perspectivas de investigación como consecuencias del COVID-19

Sergio Madero.

Prospectiva de las barreras no arancelarias para Colombia ante una economía en tiempos de pandemia (COVID-19)

Lisbeth Molero / Allyson Vanegas / AndreaAndrade .11

Estrategia de negocios disruptiva como consecuencia de eventos globales: caso economía informal en Colombia

Luis Guillermo Molero Suarez / Leidi Yoana Zamudio Garnica. 14

EI COVID-19 una pandemia o crisis mundial? El pueblo Wayuu discriminado por el gobierno de Colombia

De Jesús Freyle Gómez / Nayiris Marcela López Calleja.

Oportunidades del cuadro de mando integral, después de que se levanten las restriccines del Coronavirus

Rafael Paredes Carrasco.

EI COVID-19 y sus efectos en torno a la desigualdad en América Latina

Mauricio Alejandro Bedoya Jimenez / Julián David Colorado

Agudelo

Impacto de la economía en tiempos emergentes

Osmany Pérez Barral / Mónica del Rocío Alarcón Quinapanta / Jorge Vladimir Núñez

Grijalva.

Encuentros y desencuentros en la familia tras el COVID-19

Yazmín Alejandra Quintero Hernández / Perla Shiomara del Carpio Ova 
La suspensión de los contratos de prestación de servicios estatales por el COVID-19 en Colombia

Sergio Luis Mondragón Duarte.

Tendencias neurocognitivas emergentes de un proceso de transformación socioeconómica ante la crisis del COVID-19

Efraín de Jesús Hernández Buelvas / Arney Alfonso Vega Martínez / Nataliya Barbera de Ramírez

Análisis de la planeación de prospectiva estratégica como herramienta para visualizar el futuro

María de Lourdes Tiburcio Sánchez / Roberto Godínez López........................ 42

La responsabilidad social universitaria: una herramienta de gestión organizacional centrada en el ser humano

Gustavo Adolfo Rubio-Rodríguez / Alexander Blandón López / Guillermo Meza

Salcedo.

Impacto del COVID-19 en el turismo de la ciudad de Pachuca de Soto, Hidalgo, México

Carolina González / Noemí Vega Lugo / Nancy Testón 48

Competencias TIC para implementar la educación virtual ante la pandemia de la COVID-19

Josnel Martínez Garcés / Jacqueline Garcés Fuenmayor

51

Impacto enfermedad COVID-19 en la organización social a partir de la dinámica y función familiar

Lesbia Rosa Tirado Amador / Carlos Arturo Leal Acosta

COVID-19 y la educación superior en América Latina: una aproximación hacia los efectos sobre docentes y alumnos y posibles respuestas

Fernando Xavier Rosas Salas / Myrian Patricia Rubio Díaz

Medidas económicas para lograr la reactivación de la economía colombiana ante la pandemia de la COVID-19

Walter Serna Borja / César Alveiro Trujillo Solarte... 61 
Inversión en capital humano en la manufactura intermedia, de la industria automotriz hondureña, y el efecto del COVID-19

Mario Francisco Sosa González / Ángel E. Acevedo-Duque.

La evolución educativa mexicana, antes y después del COVID-19: una transformación emergente

Martín Cano Contreras / María Susana Acosta Navarrete / Héctor Cuevas

Vargas.

Impacto del COVID-19 sobre la industria del café en el Tolima, Colombia

Yeimy Mireya Cuellar Medina. 71

Impacto de la RSE en Colombia ante la presencia del corona virus (COVID-19)

Paula Andrea Jaramillo García / Feibert Alirio Guzmán Pérez / Leibniz Huxlay Flórez

Guzmán

Agudización de la violencia intrafamiliar por el COVID-19: el caso de la ciudad de Medellín, Colombia

Elvigia Cardona Zuleta / María Isabel Uribe López

Efectos vinculantes post COVID-19: una mirada globalizante

Judeira Batista / Judith Batista / Edison Perozo. ... 81

Producto Interno Bruto (PIB) del departamento del Tolima, Colombia afectado por el COVID-19

Juan José Quintero Rivera / Leydi Daniela Rodríguez Díaz.... 85

El teletrabajo contra la interrupción del mercado laboral en Colombia debido a la crisis del COVID-19

Marino Valencia R / Verena González C / Luis Ferney Bonilla B

Desafíos de enseñar y aprender virtualmente. La academia en cuarentena Robinson Escobar Soto....

Injerencia del COVID-19 en la contabilidad de las empresas colombiana Albano Alexander Rojas-Britto.

Una educación que permita la adaptación al cambio, la gran enseñanza de la pandemia del SARS-CoV-2

José Obdulio Curvelo-Hassán / Mario Heimer Flórez-Guzmán .98 
La responsabilidad social empresarial en época de pandemia

Mónica Alexandra Zarta Campos / Alexander Beltrán Echeverry / Jesús David Vera Galicia

Impacto económico en la región del Tolima, Colombia debido al COVID-19

Kimberly Cortes Buitrago / Alejandro Sánchez Quiñones.

Impacto psicológico de la pandemia de la COVID-19 en los profesionales y la familia

Gilberto Lázaro Galloso Cueto / Alejandro Leoner Galloso Machín 108

La economía y la pandemia del virus SARS-COV2 (COVID-19) perspectiva mexicana

David Rincón Ávila / Irsa Daniela Botello Arredondo / Dolores Guadalupe Álvarez

Orozco

Análisis del tecnoestrés y diferencias de percepciones entre los modelos educativos presencial y en línea durante el aislamiento del coronavirus

Carlos Alberto Moncada Sierra / Julián Ferrer Guerra...

Una aproximación al COVID-19 como actor-red y las mutaciones del consumo

Jorge Sánchez-Maldonado / Yully Rodríguez Garzón.

Niñez y mujer durante la pandemia del COVID-19. Una mirada al caso latinoamericano

Jairo Alberto Olarte Cabana

Capacidad de respuesta del sistema de salud colombiano para afrontar el COVID-19 Mario Samuel Rodríguez Barrero / Aracelly Buitrago Mejía / Gustavo Adolfo Rubio Rodríguez

Acción de los gobiernos locales en la atención a la pandemia como expresión de la tensión entre representaciones sociales contradictorias

Federico José Jiménez Varón.....

Impacto económico en el transporte público del Tolima ante la presencia del corona virus (COVID-19)

Ingrid Eliana Gómez. 
Incidencia del COVID-19 en el contexto económico latinoamericano

Sandra Milena Malavera Pineda.

Efectos del COVID-19 en los sistemas contables y administrativos en Colombia Paula Andrea Malavera Pineda................................................. 138

Relación entre la contaminación ambiental y el COVID-19 en Medellín y su impacto económico

Valentina Colorado Bedoya / María José Osorio Villa....

Tempestade perfeita? Instituições de ensino superior presenciais em transição para o ensino a distância em tempos de COVID-19: um estudo preliminar

Luísa Cagica Carvalho / Rui Dias / João Pereira / Adriana Backx. ...

Responsabilidad social empresarial vs situación excepcional por el COVID-19 en los países latinoamericanos

Osmany Pérez Barral / Jorge Vladimir Núñez Grijalva / Mónica del Rocío Alarcón Quinapanta..... 151

Corona Virus (Covid-19): Reflejos Socioeconómicos en Brasil

Francieli Iung Izolani. 


\section{INTRODUCCIÓN}

El libro "Impacto del COVID-19 desde la perspectiva socioeconómica en el contexto global”, es resultado del I Encuentro Internacional de Investigación, organizado por la Alianza de Investigadores Internacionales ALININ, donde participaron investigadores, académicos y científicos presentando reflexiones acerca del fenómeno desde distintas áreas del conocimiento, con una mirada inter y transdisciplinar de la ciencia.

En tal sentido, este libro representa un medio científico que permite la difusión y transmisión de conocimientos significativos para la comprensión de la situación desde diversos puntos de vista, puesto que tras la declaración del virus COVID-19 como pandemia, por parte Organización Mundial de la salud (OMS) el día 11 de marzo de 2020 y la confirmación de que este flagelo sanitario ha desencadenado una crisis social y humana a nivel global, que ha generado caos e incertidumbre en todos los aspectos de la dinámica diaria del desempeño social, el mundo ahora es diferente de cómo lo conocíamos y ha entrado a un escenario de nueva normalidad en el desarrollo de las actividades diarias de los ciudadanos y los sistemas de salud, económicos, políticos, educativos, culturales, entre otros.

Ante estos acontecimientos es necesario estar a la vanguardia y buscar oportunidades para hacer frente a los devastadores efectos que esta pandemia está ocasionando en todos los niveles de la vida humana, es por ello, que las investigaciones presentadas en este libro constituyen un referente para la comprensión de la problemática generada a causa del COVID-19, dichas investigaciones tienen como fin promover el intercambio científico en tiempos de crisis, utilizando parámetros de fuentes fidedignas de organismos nacionales e internacionales y el análisis crítico reflexivo de los investigadores que intentan dar respuesta a tan grave problemática que representa una amenaza para la humanidad.

Por otra parte, es importante visualizar este escenario de crisis e incertidumbre, como un espacio de reflexión y oportunidad, y no, como un obstáculo, es en este momento donde la investigación puede aportar y contribuir, como instrumento vital, o como el arma más valiosa, y finamente elaborada para la defensa ante cualquier guerra, 
es por ello, que la investigación, la academia y la ciencia, deben ser utilizadas para la construcción de un nuevo paradigma humanístico y científico, que permita impactar positivamente en el desarrollo del conocimiento que conduzca a una sociedad más justa.

En tal sentido, es un privilegio desarrollar actividades científicas y socialmente responsables al servicio de los pueblos, como es este libro, el cual representa un icono para la historia de la humanidad, todos los capítulos que conforman este libro demuestran el compromiso de cada uno de los autores con las generaciones futuras, para cumplir con la tarea de formar talento humano en el ámbito investigativo, generando conocimientos científicamente fiables y socialmente pertinentes. Es relevante destacar que, en esta era digital, donde la ciencia, la tecnología y la innovación convergen en una acelerada dinámica, ha permitido que las comunicaciones impulsen la participación global entre investigadores, científicos y académicos, generando espacios de participación para el debate, la crítica y la acción.

En este libro se encuentran plasmadas los resultados de investigaciones, ideas y opiniones de investigadores, profesionales, académicos a nivel mundial sobre la situación que ha provocado la pandemia por la que se está atravesando, pero también hace un llamado a la reflexión para examinar la manera como se viene llevando a cabo los procesos de formación académica y científica al interior de las instituciones educativas, esta realidad que se vive actualmente ha trastocado la vida de muchas maneras, como sociedad no se estaba preparada para estar aislados, como docentes se tienen algunas dificultades para el uso de las herramientas tecnológicas en la educación virtual, la carga de trabajo se han incrementado considerablemente, pero ante todo se puede ver con satisfacción cómo la humanidad se ha adaptado al drástico cambio que llegó sin previo aviso, es por ello, que ante las adversidades es importante la reflexión y actuación positiva.

En este sentido es propicio citar las palabras del padre rector de la Universidad Católica Luis Amigó. Presbítero Carlos Enrique Cardona Quiceno: "esto no se ha acabado y que esta realidad sea para vivir con una verdadera resiliencia, que nuestra actitud no se distancie del compromiso que todos tenemos y que no deslegitimemos lo que en esfuerzo han construido todos desde el primer día que nos montamos en 
esta barca", no debemos claudicar, es la única oportunidad con este cambio que el mundo nos puso, somos un presente que debe dejarle algo a las generaciones venideras, y que no trabajamos en una fábrica de chocolates; trabajamos con proyectos de vida que están en un marco referencial que es la Educación y desde ya la Vocación, nuestro convencimiento se pone a prueba..." por lo tanto los esfuerzos deben ir encaminados a entender esta realidad y sacar el mejor provecho de ella y sus enseñanzas en pro de las nuevas generaciones.

Dra. Yamarú del Valle Chirinos Araque. 


\title{
LA UNIVERSIDAD CUBANA Y SU ACCIONAR ANTE LA PRESENCIA DEL CORONA VIRUS (COVID-19)
}

\author{
THE CUBAN UNIVERSITY THEIR TO WORK \\ BEFORE THE PRESENCE OF THE CORONAVIRUS \\ (COVID-19)
}

\section{Douglas Adolfo García Gómez}

Master en Ingeniería Industrial, Docente Investigador de la Universidad de Sancti Spíritus "José Martí Pérez". Cuba. Correo electrónico: douglas@uniss. edu.cu.

\section{Yamarú del Valle Chirinos Araque}

Doctora en Ciencias, Mención Gerencia Universidad Dr. Rafael Belloso Chacín, Investigadora Senior categorizada por Colciencias. Docente investigadora del grupo GORAS y ECOSOL. Universidad Católica Luis Amigó, Medellín, Colombia. Correo electrónico: yamaruchirinosaramigo.edu.edu.co. Registro ORCID http://orcid.org/0000-0003-0471-9859.

\section{Naybi Salas Vargas}

Master en Administración de Empresas, Docente Investigadora de la Universidad de Sancti Spíritus "José Martí Pérez". Cuba. Correo electrónico: naybi@uniss. edu.cu.

\section{Oobjetivo}

Analizar las estrategias adoptadas por las instituciones universitarias en Cuba ante la presencia del (COVID-19).

\section{Descripción del contexto}

Desde comienzos de este año el mundo se ha visto bajo la terrible presión de la expansión de la pandemia (COVID-19), la cual según reportes de la Organización Mundial de la Salud (OMS, 2020), al cierre del 26 de abril de 2020, se tienen 182 países con casos de la enfermedad, con 2844712 confirmados y 201315 fallecidos, para una 
letalidad de 7.07 \%. Específicamente en la región de las Américas se precisan 1134686 casos confirmados, con 63649 fallecidos, para una letalidad de $5.62 \%$.

Cuba no escapa a esta realidad, la mayor de las Antillas representada por una población de 11338138 habitantes y densidad poblacional de 103 habitantes/Km². Que desarrolla su economía en un entorno muy difícil, agudizado profundamente por un bloqueo recio de más de 60 años y con tendencias de recrudecimiento desde el pasado año. Se ha visto obligada a ajustar su planificación económica para lograr enfrentar las condiciones actuales y poder vencer el nuevo reto que el mundo le ha impuesto.

Es cierto que la economía tendrá afectaciones en el turismo y en los precios de principales rublos exportables como el níquel, azúcar, tabaco y ron, pero se cuenta con fortalezas tales como: la industria biofarmacéutica, los servicios médicos, la aprobación de nuevos proyectos de inversión por montos millonarios, y con la convicción profunda de lucha del pueblo, la solidaridad y empeño del gobierno para lograr su objetivo sin desamparar a nadie. Además, del fuerte encadenamiento de los diferentes ministerios dentro de los cuales se encuentra el Ministerio de Educación Superior.

\section{Metodología}

La realización del estudio se enfocó en el paradigma cualitativo el cual trata identificar la naturaleza profunda de las realidades, su estructura dinámica, aquella que da razón plena de su comportamiento y manifestaciones (Martínez, 2012). Se utiliza como técnica para la recolección de datos la observación directa para el obtener el comportamiento de las variables implícitas en tiempo real y la revisión documental de la literatura.

\section{Hallazgos}

La universidad cubana ha jugado su rol significativo, evidencia de ello son las pesquisas realizadas a diario por los estudiantes de la Universidades de Ciencias Médicas un apoyo fundamental en la determinación y control de la situación epidemiológica producido por la enfermedad. La Universidad de las Ciencias Informáticas (UCI) creó una aplicación, una nueva herramienta Pesquisiador Virtual COVID-19, que permite captar 
información sobre el estado de salud de la población, como complemento al proceso de pesquisa activa que realiza el Sistema Nacional de Salud. Se encuentra disponible a través de la web y como aplicación de dispositivos móviles, dicha aplicación se basa en una encuesta epidemiológica, que cada persona puede responder y cuyo resultado se entrelaza con el sistema de salud, apoya al conocimiento de desarrollo de la pandemia. Sin costo alguno para la población.

Por otra parte, los demás centros de educación superior han ajustado el calendario para cerrar el curso, sin perder el año escolar y en septiembre comenzar con una actualización en los primeros 90 días, con algunos reajustes retomar el nuevo curso de esa manera no afectar a los estudiantes.

Otra estrategia de impacto desplegada por las universidades es la creación de consultorías por especialistas en psicologías, a través de las diferentes vías de comunicación.

Todo ello ha contribuido a que el país logre unos de los comportamientos más favorables a nivel mundial con respecto al desarrollo de la pandemia. La figura 1 y 2 representa lo antes expuesto al mostrar la relación entre las variables muestras realizadas - positivas y altas médicas - fallecidos durante el mes de abril 2020.

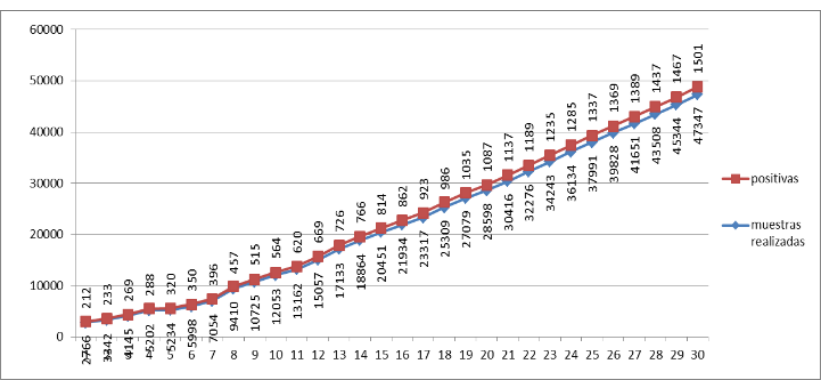

\section{Grafico 1. Relación de las variables muestras realizadas y positivas .}

Fuente: elaboración propia 2020. 


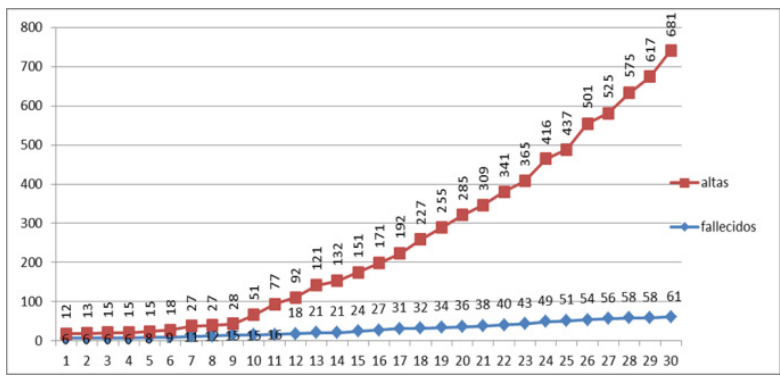

\section{Grafico 2. Relación de las variables altas médicas - fallecidos.}

Fuente: elaboración propia 2020.

El análisis de las figuras muestra que existe un promedio porcentual con relación a los casos contagiados de 20.65 de altas y 3.12 fallecidos. Resultados de las estrategias tarazadas y que ha logrado mantener en estos márgenes la evolución de la enfermedad, donde ha sido de alta contribución el apoyo realizado por la universidad cubana.

\section{Referencias bibliográficas}

Organización Mundial de la Salud. (15 de abril 2020). Infecciones por coronavirus World Health Organization. https://wwwwho.int/health topics

Martínez M., (2012). Nuevos fundamentos en la investigación cientifica. México. Trillas

Ministerio de Salud. (19 de abril 2020). Infecciones por coronavirus - nota informativa. https://www.temas.sld.cu/noticias/2020/04/19/nota informativa.

Ministerio de Ciencia y Tecnología. (21 abril 2020). Pesquisiador virtual para enfrentamientoCOVID-19 cecmed. https://www.cecmed.cu/ noticias/2020/04/21/pesquisiador virtual 


\title{
PERSPECTIVAS DE INVESTIGACIÓN COMO CONSECUENCIAS DEL COVID-19
}

\section{RESEARCH PERSPECTIVES RESULTING FROM THE COVID-19 OUTBREAK}

\author{
Sergio Madero \\ Doctor en Dirección y Economía de Empresas, Profesor Investigador de la \\ Escuela de Negocios, Tecnológico de Monterrey, México: Correo electrónico: \\ smadero@tec.mx.
}

\section{Objetivo}

Explorar y conocer la percepción de las personas sobre los efectos del coronavirus COVID-19, en los diversos procesos empresariales involucrando el comportamiento humano y organizacional.

\section{Descripción del contexto}

Ahora nos encontramos en una situación muy similar a la que se vivió en México en el año 2009 a causa de la influenza A H1N1, una contingencia inesperada y no planeada causada por el virus COVID-19, detectada por primera vez en diciembre de 2019 en Wuhan, China y que se ha esparcido en muchos países, ocasionando que la Organización Mundial de la Salud, OMS (2020) lo declarara como una pandemia, motivo por el cual ha tenido un impacto sin precedentes en el mundo, que involucra principalmente aspectos de sanitarios, económicos y empresariales.

\section{Metodología}

Considerando los instrumentos de medida utilizados por Madero y Flores (2009) y (2010), se diseñó un cuestionario que fue distribuido mediante las redes de contacto del autor durante el período del 10 al 17 de marzo de 2020, obteniendo un total de 289 respuestas, residentes en México, el 39.1\% son del género masculino y el $60.9 \%$ del femenino, en lo que respecta sus actividades, el $8.3 \%$ estudian, el $26.0 \%$ estudian y trabajan y el 65.7\% trabajan en una empresa. 


\section{Hallazgos}

En la tabla 1, se muestranla información descriptiva de los reactivos utilizados y que fueron considerados analizar para el desarrollo del presente documento.

Tabla 1. Lista de reactivos utilizados en la investigación.

\begin{tabular}{|c|c|c|c|c|c|}
\hline \multirow[b]{2}{*}{ Ítems } & \multicolumn{5}{|c|}{ Frecuencias de las Respuestas } \\
\hline & $\begin{array}{c}\text { Desacuerdo } \\
1-2\end{array}$ & $\begin{array}{c}\text { Indiferente } \\
\qquad 3\end{array}$ & $\begin{array}{c}\text { Acuerdo } \\
\text { 4-5 }\end{array}$ & Promedio & $\begin{array}{l}\text { Desv. } \\
\text { Est. }\end{array}$ \\
\hline $\begin{array}{l}\text { 1.- Estoy tenso o preocupado } \\
\text { por los efectos que pueda tener el } \\
\text { coronavirus }\end{array}$ & 83 & 87 & 119 & 3.15 & 1.25 \\
\hline $\begin{array}{l}\text { 2.- Cuando estoy en casa } \\
\text { me preocupan las actividades } \\
\text { relacionadas con el trabajo }\end{array}$ & 126 & 53 & 110 & 2.82 & 1.44 \\
\hline $\begin{array}{l}\text { 3.- Por motivos del } \\
\text { coronavirus he tenido que ajustar } \\
\text { mis rutinas de trabajo }\end{array}$ & 245 & 20 & 23 & 1.60 & 1.05 \\
\hline $\begin{array}{l}\text { 4.- Es una realidad y hay que } \\
\text { tener cuidado }\end{array}$ & 18 & 65 & 206 & 4.05 & .99 \\
\hline $\begin{array}{l}\text { 5.- Considero que el } \\
\text { coronavirus me ha ayudado a ser } \\
\text { más sensible ante los demás }\end{array}$ & 155 & 76 & 58 & 2.41 & 1.32 \\
\hline $\begin{array}{l}\text { 6.- Consideras que estás } \\
\text { preparado para la llegada del } \\
\text { coronavirus }\end{array}$ & 149 & 79 & 61 & 2.53 & 1.20 \\
\hline $\begin{array}{l}\text { 7.- Piensas que el coronavirus } \\
\text { vaya a afectar las actividades de } \\
\text { trabajo de las personas }\end{array}$ & 24 & 38 & 227 & 4.12 & 1.03 \\
\hline $\begin{array}{l}\text { 8.- En esta época de } \\
\text { contingencia por el coronavirus se } \\
\text { facilitan los procesos para trabajar } \\
\text { en casa * }\end{array}$ & 59 & 38 & 165 & 3.82 & 1.42 \\
\hline
\end{tabular}

Fuente: Elaboración propia a partir de los datos obtenidos.

* Para estos reactivos se tuvieron 27 sin respuesta.

Tomando en cuenta los resultados descriptivos surgen una serie de reflexiones para considerar en el diseño de nuevos modelos de investigación relacionados con el comportamiento humano y organizacional, teniendo como variables principales: 
flexibilidad organizacional, factores psicosociales, reacciones de comportamiento, salud emocional y balance vida trabajo.

Influencia de los estresores en el equilibrio emocional y mental de las personas al momento de estar realizando actividades a distancia forzados por el COVID-19 (Preguntas 1, 2 y 8 ).

Adaptación al cambio en situaciones de contingencia y los efectos psicosociales que afectan el comportamiento de la persona en la era del COVID-19 (Preguntas 3, 4 y 6).

Cambios de los Valores, Reglas, Principios y Medidas de convivencia en los lugares de trabajo o en casa en situaciones de aislamiento o distanciamiento (Preguntas 5, 7 y 8).

Es importante considerar también la perspectiva de investigación, teniendo en cuenta como unidad de estudio los diversos procesos empresariales que están afectados y forman parte de situaciones de crisis, como la disminución de los ingresos, las medidas de austeridad propuestas, el ausentismo y la rotación del personal, el aumento de la competencia global, el exceso de mano de obra y la necesidad de su formación entre muchos otros indicadores o métricas a analizar.

\section{Referencias bibliográficas}

Madero, S. y Flores, R. (2009). Predictores de la disposición de trabajadores mexicanos a aceptar el teletrabajo. Revista Investigación y Ciencia de la Universidad Autónoma de Aguascalientes. 43. 24-29.

Madero, S. y Flores, R. (2010). Forzados a trabajar a distancia por el virus A H1N1: Exploración del estrés por el trabajo a distancia y uso de tecnología, con la satisfacción con el trabajo y la disposición a realizar actividades a distancia.

XIV Congreso Internacional de Investigación en Ciencias Administrativas. ACACIA, Realizado en EGADE Business School, Monterrey NL, México.

OMS (2020) https://www.who.int/es/dg/speeches/detail/who-director-general-sopening-remarks-at-the-media-briefing-on-covid-19---11-march-2020 tomada el 7 de abril de 2020. 


\section{PROSPECTIVA DE LAS BARRERAS NO \\ ARANCELARIAS PARA COLOMBIA ANTE UNA \\ ECONOMÍA EN TIEMPOS DE PANDEMIA (COVID-19)}

\section{PROSPECTIVE OF NON-TARIFF BARRIERS FOR COLOMBIA IN THE FACE OF AN ECONOMY IN TIMES OF PANDEMIC (COVID-19)}

\section{Lisbeth Molero}

Doctora en Ciencias Gerenciales, Docente de la Universidad Politécnico Grancolombiano. Correo electrónico: 1molero@poligran.edu.co.

\section{Allyson Vanegas}

Magister en Educación, Docente de la Universidad Politécnico Grancolombiano. Correo electrónico: vcallynson@poligran.edu.co.

\section{Andrea Andrade}

Estudiante Finanzas y Comercio Internacional Universidad La Salle. Correo electrónico: aandrade11@unisalle.edu.co.

\section{Objetivo}

Analizar la prospectiva de las barreras no arancelarias para Colombia frente a los desafíos del (COVID-19).

\section{Descrpción del contexto}

La economía es uno de los sectores más expuesto en un escenario de Pandemia, en el caso específico de Colombia para el mes de febrero 2020, según el DANE, del 100\% de los productos exportados el 22,6\% corresponden al grupo de producción agropecuarios, alimentos y bebidas los cuales son afectados severamente por las barreras no arancelarias específicamente las medidas técnicas sanitarias y fitosanitarias debido a la naturaleza del fenómeno. La magnitud de la pandemia originada por la covid-19 tiene proporciones importantes en cuanto al comercio de estos productos tanto en el eje de los países de América Latina y el Caribe (ALC) como hacía el resto de las regiones, las exigencias sanitarias se intensifican convirtiéndose en uno de los garantes de la seguridad nacional. 
Lo que representa una contracción importante en este sector durante el desarrollo del ciclo pandémico. Todo lo antes expuesto infiere que la flexibilización de las medidas técnicas sanitarias y fitosanitarias dependerá del comportamiento del virus el cual hasta los momentos se mantiene exponencialmente elevado en comparación con otros por el nivel de contagio.

\section{Metodología}

Desde la perspectiva metodológica la investigación se tipifica como cualitativa de diseño documental hermenéutico, ya que a través del análisis de los recursos documentales se logra la descripción de las categorías y subcategorías presentes en la investigación para poder resumir de manera concluyente la naturaleza del fenómeno. La técnica utilizada fue la revisión documental textual construyendo una matriz de datos cualitativo (Hernández et al., 2010).

\section{Matriz de datos análisis cualitativo.}

\begin{tabular}{|c|c|c|c|c|}
\hline $\begin{array}{l}\text { Categoría } \\
\text { de análisis }\end{array}$ & $\begin{array}{c}\text { Sub } \\
\text { categoría }\end{array}$ & $\begin{array}{l}\text { Análisis de la } \\
\text { subcategoría }\end{array}$ & $\begin{array}{l}\text { Descriptores o } \\
\text { referentes de la } \\
\text { Subcategoría }\end{array}$ & $\begin{array}{c}\text { Resumen } \\
\text { Conclusivo }\end{array}$ \\
\hline $\begin{array}{l}\text { Barreras no } \\
\text { arancelarias }\end{array}$ & $\begin{array}{c}\text { Medidas } \\
\text { Técnicas } \\
\text { Sanitarias y } \\
\text { Fitosanitarias }\end{array}$ & $\begin{array}{l}\text { Esta subcategoría se } \\
\text { enfoca en las medidas } \\
\text { exigidas por los distintos } \\
\text { países en relación } \\
\text { con la manipulación, } \\
\text { empaque, embalaje, } \\
\text { cosecha, producción } \\
\text { y post producción, así } \\
\text { como certificaciones y } \\
\text { documentos requeridos } \\
\text { por parte de los entes para } \\
\text { el ingreso de todos los } \\
\text { productos agropecuarios, } \\
\text { alimentos y bebidas a } \\
\text { sus territorios. UNTAC } \\
\text { (2012). }\end{array}$ & $\begin{array}{l}\text { Según el Centro de } \\
\text { Comercio Internacional } \\
\text { (ITC) los acuerdos de la } \\
\text { Organización Mundial } \\
\text { del Comercio expresan } \\
\text { que el uso de las medidas } \\
\text { no arancelarias está } \\
\text { permitido bajo algunas } \\
\text { circunstancias. Como } \\
\text { la aparición de virus. } \\
\text { Por las características } \\
\text { sanitarias. }\end{array}$ & $\begin{array}{l}\text { La información } \\
\text { analizada es } \\
\text { concluyente, ya } \\
\text { que las medidas } \\
\text { técnicas sanitarias } \\
\text { y fitosanitarias son } \\
\text { las más afectadas } \\
\text { en los escenarios de } \\
\text { pandemias debido a } \\
\text { las características de } \\
\text { los productos por lo } \\
\text { que ellas representan } \\
\text { un elemento } \\
\text { fundamental para } \\
\text { evitar la exportación } \\
\text { de los virus. }\end{array}$ \\
\hline
\end{tabular}

Fuente: Elaboración propia (2020). 


\section{Hallazgos}

El estudio de las categorías planteadas en el análisis mostrado en el cuadro anterior indica como las medidas técnicas sanitarias y fitosanitarias pueden convertirse en barreras importantes en un escenario como el que vive el mundo por la propagación de un virus como el COVID-19 el boletín técnico emitido por el DANE refleja que las exportaciones del grupo agropecuarios, alimentos y bebidas para febrero del 2020 representaron el $22,6 \%$ del porcentaje total de las exportaciones del país. Por lo que el impacto comercial es representativo para el sector.

\section{Referencias bibliográficas}

INTRACEN.ORG. Análisis de mercados medidas no arancelarias. (2012). http://www. intracen.org/itc/analisis-mercados/medidas-no-arancelarias/identificandolas-medidas-no-arancelarias/

DANE. (2020). https://www.dane.gov.co/files/investigaciones/boletines/exportaciones/ bol_exp_feb20.pdf

Dinero.com. Regulaciones aduaneras y de comercio exterior durante la cuarentena. (2020). https://www.dinero.com/economia/articulo/regulaciones-aduanerasy-de-comercio-exterior-durante-cuarentena/283816 


\section{ESTRATEGIA DE NEGOCIOS DISRUPTIVA COMO \\ CONSECUENCIA DE EVENTOS GLOBALES: CASO \\ ECONOMÍA INFORMAL EN COLOMBIA}

\section{DISRUPTIVE BUSINESS STRATEGY AS A CONSEQUENCE OF GLOBAL EVENTS: CASE OF INFORMAL ECONOMY IN COLOMBIA}

\section{Luis Guillermo Molero Suarez \\ Doctor en Ciencias Gerenciales. Unipanamericana Fundación Universitaria Panamericana. Correo electrónico: 1molero@unipanamericana.edu.co. Avenida (Calle) 32 No. 17 - 30, Teusaquillo, Bogotá, Colombia.}

\section{Leidi Yoana Zamudio Garnica}

Magister en dirección y gestión de instituciones educativas. Corporación Universitaria. Iberoamericana. Correo electrónico: leidi.zamudio@ibero.edu. co. Cl. 67 \# 5 - 27, Bogotá, Colombia.

\section{Objetivo}

Analizar desde la perspectiva del emprendimiento la estrategia de negocios disruptiva como consecuencia de eventos globales: caso economía informal en Colombia.

\section{Descripción del contexto}

Colombia ocupa una posición importante en Latinoamérica en temas de emprendimiento, por lo cual, eventos globales como el COVID-19 que precisan instaurar medidas sanitarias, económicas y sociales para mitigar su propagación y en consecuencia evitar el colapso del sistema sanitario, ejercen presiones disímiles que socaban el aparato productivo. Estas consideraciones, han permeado súbitamente el mercado nacional, donde se estima que la paralización temporal podría costar alrededor del 10\% del PIB mensual según información ofrecida por la Facultad de Economía de la Universidad de Los Andes (Facultad de Economía Universidad de Los Andes, 2020), dato sumiso, en comparación a los indicadores compuestos avanzados de la Organización para la Cooperación y el Desarrollo Económicos (OCDE, 2020) y la Organización Mundial 
del Comercio (OMC, 2020). En consecuencia, se debe analizar el desarrollo de nuevas estrategias de negocios disruptivas ante las prácticas tradicionales, que pasa, por la capacitación efectiva desde las organizaciones que hacen vida en Colombia, para hilar positivamente en nuevas formas de emprendimiento menos susceptibles a catástrofes de escala mundial.

\section{Metodología}

La metodología empleada en la presente investigación se desarrolló bajo el paradigma cualitativo el cual trata de identificar la naturaleza profunda de las realidades, su estructura dinámica, aquella que da razón plena de su comportamiento y manifestaciones; asimismo, la investigación se llevó a cabo alrededor de un estudio bibliográfico con un diseño documental (Tamayo y Tamayo, 2006), que emplea la hermenéutica para proyectar un análisis desde donde poder establecer las relaciones de los tópicos de acuerdo a diferentes autores.

\section{Hallazgos}

Colombia concentra el tercer ecosistema con mayor emprendimiento de Latinoamérica, según datos suministrados por Américas Society/Council of the Américas (AS/ COA, 2015), Global Entrepreneurship and Development Institute (GEDI, 2018) y la Organización Internacional del Trabajo (Banco Mundial, 2019). Estos datos, coinciden con el Departamento Administrativo Nacional de Estadística de Colombia, donde la proporción de ocupados informales para el trimestre móvil noviembre 2019 - enero 2020 fue 47,7\% (DANE, 2020). Es así, como el Estado colombiano, en su condición de órgano rector y ante eventos a escala global que han demostrado susceptibilidades en lo económico, social y político, debe en consecuencia, accionar nuevas estrategias donde la empresa pública y privada a través de su competencia como organizaciones socialmente responsables, involucre sus capitales intelectuales para garantizar la capacitación efectiva que amalgame eficazmente este conglomerado de emprendimientos, muchas veces, población vulnerable, para fomentar el despliegue de nuevos modelos de negocio que permita sortear positivamente catástrofes de índole nacional o mundial. 


\section{Referencias biblográficas}

AS/COA, A. (2015). AS/COA/AMERICAS SOCIETY COUNCIL OF THE AMERICAS. Recuperado el 07 de 04 de 2020, de https://www.as-coa.org/

Banco Mundial. (2019). Banco Mundial: Empleo informal (\% del total del empleo no agrícola). Obtenido de https://datos.bancomundial.org/indicador/SL.ISV. IFRM.ZS

DANE. (2020). Boletín Técnico-Gran Encuesta Integrada de Hogares (GEIH) Noviembre 2019 - Enero 2020. Boletín, DANE, Bogota, Colombia. Recuperado el 09 de 04 de 2020, de https://www.dane.gov.co/files/investigaciones/boletines/ech/ ech_informalidad/bol_ech_informalidad_nov19_ene20.pdf

Facultad de Economía Universidad de Los Andes. (02 de 04 de 2020). Dinero. Recuperado el 08 de 04 de 2020, de https://www.dinero.com/economia/ articulo/cuanto-cuesta-la-cuarentena-en-colombia/283814

GEDI. (2018). The GEDI, The Global Entrepreneurship and Development Institute. Recuperado el 07 de 04 de 2020, de https://thegedi.org/2018-globalentrepreneurship-index-data/

OCDE. (26 de 03 de 2020). Organización para la Cooperación y el Desarrollo Económicos (OCDE). Recuperado el 09 de 04 de 2020, de http://www.oecd. org/coronavirus/en/

OMC. (8 de 4 de 2020). Organización Mundial del Comercio OMC. Recuperado el 9 de 4 de 2020, de https://www.wto.org/spanish/news_s/pres20_s/pr855_s.htm

Tamayo y Tamayo, M. (2006). El proceso de la investigación cientifica. México: Limusa. 


\title{
LA COVID-19 ¿UNA PANDEMIA O CRISIS MUNDIAL? EL PUEBLO WAYUU DISCRIMINADO POR EL GOBIERNO DE COLOMBIA
}

\section{COVID-19 A PANDEMIC OR WORLD CRISIS, THE WAYUU PEOPLE DISCRIMINATED BY THE GOVERNMENT OF COLOMBIA}

\author{
José De Jesús Freyle Gómez \\ Profesional en Negocios Internacionales. Correo electrónico: josefreylegomez@ \\ hotmail.com y docente del Centro Etno-educativo rural Mapuain.

\section{Nayiris Marcela López Calleja} \\ Licenciada en Ciencias Naturales. Correo electrónico: nayimarceklleja@gmail. \\ com y docente del Centro Etno-educativo rural Mapuain.
}

\section{Objetivo}

Analizar la crisis generada por la pandemia (COVID-19), en las comunidades wayuu en Colombia.

\section{Descripción del contexto}

La crisis mundial generada por la pandemia Covid-19, ha demostrado la deficiencia que presenta el mundo para controlar un virus y que un mundo cada día más globalizado facilita su expansión. Las diferencias culturales, sociales y económicas de los países y de sus regiones contemplan planes de acciones y estratégicas diferentes, que se deben segmentar y adaptar a las situaciones coyunturales de cada país y región. La Organización Mundial de la Salud (OMS, 2020), presenta un trabajo articulado con otras organizaciones internacionales con el fin de mitigar los riesgos, entre ellas el Fondo de las Naciones Unidas para la Infancia (UNICEF), los cuales están muy preocupados por los efectos secundarios de la pandemia y las acciones de control relacionadas con los infantes, incluido el cierre de escuelas, la carga sobre los sistemas de salud locales y las presiones económicas que sienten algunas familias. 


\section{Metodología}

Esta investigación se basa en el paradigma cualitativo, el cual como expone Pulido (citado por Quecedo y Castaño, 2002) los estudios cualitativos, aportan datos valiosos descriptivos de los contextos, actividades y creencias de los participantes y constituye un enfoque de los problemas y procesos educativos.

\section{Hallazgos}

Steinberg (2020), manifiesta que, las noticias económicas por culpa del virus se han centrado en la especulación y generó la caída de las bolsas, lo que ha provocado un caos de manera mundial, la población se encuentra en incertidumbre radical. El informe del Programa de las Naciones Unidas para el Desarrollo (PNUD) en América Latina y el Caribe (2020), manifiestan la imposibilidad de utilizar el aislamiento y en especial de los grupos contagiados, lo cual genera un costo económico y social excesivamente alto. En el caso específico del departamento de La Guajira, donde presenta altos índices de pobreza, analfabetismo y escasez de los servicios básicos, la pandemia si se expande estaría fuera de control.

La Comisión Económica para América Latina y el Caribe (CEPAL, 2020) manifiesta que, en América Latina, la estrategia para detener la propagación; es el desarrollo del ámbito digital. Las tecnologías ayudan a disminuir la propagación del virus. Situación que en muchas regiones puede ser eficiente, pero en el Departamento de La Guajira, no, ya que en las zonas rurales son dispersas y no cuentan con los servicios públicos básicos, mucho menos con elementos digitales. Los infantes en los centros educativos reciben ayuda alimentaria y de cuidado, y es en ese tiempo que los padres aprovechaban para trabajar. Es por ello, que la suspensión de las clases tendrá repercusiones negativas, en especial en las comunidades indígenas, la mayoría de sus estudiantes, los únicos alimentos que consumen son los otorgados en sus instituciones. Se requiere desarrollar un plan de acción claro y enmarcado en las condiciones y necesidades de la población wayuu, que es muy diferente al resto del pueblo colombiano. 


\section{Referencias bibliográfícas}

CEPAL NACIONES UNIDAS. (03 de Abril de 2020). INFORME ESPECIAL COVID-19 \# 1. Recuperado el 06 de Abril de 2020, de América Latina y el Caribe ante la pandemia del COVID-19 "Efectos económicos y sociales": http:// www.obela.org/system/files/Am\%C3\%A9rica\%20Latina\%20y\%20e1\%20 Caribe\%20ante\%201a\%20pandemia.pdf

Organización Mundial de la Salud (OMS) . (11 de Marzo de 2020). NOTICIAS DE LA ONU. Recuperado el 05 de Abril de 2020, de Mirada global Historias humanas: https://news.un.org/es/story/2020/03/1470991

PNUD América Latina y el Caribe. (Marzo de 2020). El Programa de las Naciones Unidas para el Desarrollo (PNUD). Recuperado el 06 de Abril de 2020, de Evidencia, experiencia, y pertinencia en busca de alternativas de: https:// www.undp.org/content/dam/rblac/Policy\%20Papers\%20COVID\%2019/ UNDP-RBLAC-CD19-PDS-Number0-ES-final.pdf

Quecedo, R., y Castaño, C. (2002). Revista de Psicodidactica. Recuperado el 03 de Abril de 2020, de Introducción a la metodología de investigación cualitativa: https://www.redalyc.org/revista.oa?id=175

Steinberg, F. (12 de Marzo de 2020). Real Instituto Elcano. Recuperado el 05 de Abril de 2020, de Coronavirus: amenaza económica, respuesta política e implicaciones: http://www.realinstitutoelcano.org/wps/portal/rielcano_es/ contenido?WCM_GLOBAL_CONTEXT=/elcano/elcano_es/zonas_es/ ari22-2020-steinberg-coronavirus-amenaza-economica-respuesta-politicae-implicaciones 


\title{
OPORTUNIDADES DEL CUADRO DE MANDO INTEGRAL, DESPUÉS DE LEVANTARSE LAS RESTRICCIONES DEL CORONAVIRUS
}

\section{BALANCED SCORECARD OPPORTUNITIES, AFTER CORONAVIRUS RESTRICTIONS ARE LIFTED}

\author{
Rafael Paredes Carrasco \\ Doctorando en Administración y Dirección, Universidad Pablo de Olavide \\ (ESP), Magíster en Ingeniería Industrial. Profesor Instructor, Universidad \\ Autónoma de Chile Correo electrónico: lparedes57@hotmail.com.
}

\section{Objetivo}

Analizar la aplicación de un Sistema de Cuadro de Mando Integral en un organismo del sector de la salud en Chile.

\section{Descripción del contexto}

El uso del Cuadro de Mando Integral es una potente herramienta de gestión para las organizaciones puesto que ayuda al cumplimiento de los objetivos de las instituciones. Según lo que señalan Flórez y Ramón (2014), el Cuadro de Mando Integral de Riesgos permite gestionar la generación de valor en su doble perspectiva, riesgo y rendimiento, promoviendo la correcta alineación de la estrategia con las incertidumbres del entorno y facilitando una toma de decisiones proactiva. Carreño (2012) menciona que las técnicas de gestión de riesgos no son algo nuevo; han estado disponibles para empresas por mucho tiempo. Es la creciente presión regulatoria y su impacto, junto con la crisis económica actual, lo que ha elevado la gestión de riesgos como un factor clave en la gestión empresarial moderna, no solo en las instituciones financieras en particular, sino también en las empresas públicas en general.

Actualmente se atraviesa por un extenso aislamiento en los hogares a nivel mundial, debido a la pandemia que se está viviendo, es por esto, por lo que se procedió a estudiar esta problemática desde la perspectiva de la administración. En concreto, se procedió a analizar las dificultades que se presentarán en las organizaciones para 
seguir midiendo la gestión del rendimiento de las áreas que la componen en el objeto de estudio; los cuales serán los riesgos/oportunidades que se detectarán post COVID-19.

En ausencia de estudios que busquen oportunidades del CMI, después de que se levanten las restricciones de la pandemia en las organizaciones, es que en este trabajo se proponen algunas recomendaciones al respecto.

\section{Metodología}

Análisis documental basada en la revisión de artículos publicados en la última década.

\section{Hallazgos}

A modo de resumen, se listan los resultados que se desprenden de este trabajo:

El análisis del FODA matemático no se complementa con la definición de la estrategia del sector de la salud.

No se asocian los objetivos estratégicos del sector de la salud con los riesgos sociales.

Los Indicadores Claves de Desempeño (KPI) no se leen en conjunto con los Indicadores Claves de Riesgos (KRI).

H1: El estudio de las fortalezas, oportunidades, debilidades y amenazas, pero cuantificado con porcentajes de importancia para la organización, no son integrados con la descripción de las acciones de una organización con el fin de cumplir sus objetivos.

H2: Los objetivos de una organización para lograr determinadas metas y a largo plazo la posición de una organización en un mercado, no se relacionan con los factores de riesgos que se desprenden del COVID-19.

H3: Los KPI y los KRI de las organizaciones no se vinculan en una organización al momento de gestionar los riesgos organizacionales de la perspectiva sanitaria. 
Una limitación presente en este trabajo corresponde a que no se buscaron artículos del COVID-19, desde marzo 2020 a abril 2020. En base a los tres hallazgos mencionados anteriormente, se cree que abrirá el apetito de los futuros investigadores de doctorados y los directivos de la salud. Para culminar, se propone el siguiente mini-modelo, de carácter académico, para unificar un SCG:

\begin{tabular}{cccccc}
\hline $\begin{array}{c}\text { Objetivos } \\
\text { estratégicos }\end{array}$ & Riesgo & Impacto & Ocurrencia & $\begin{array}{c}\text { Tipo de } \\
\text { control }\end{array}$ & $\begin{array}{c}\text { Plan de } \\
\text { acción }\end{array}$ \\
\hline $\begin{array}{c}\text { Fortalecimiento } \\
\text { del sector de la } \\
\text { salud }\end{array}$ & $\begin{array}{c}\text { Fortalecer la } \\
\text { investigación para } \\
\text { aplanar la curva de }\end{array}$ & $\begin{array}{c}\text { Alto }(109.000 \\
\text { defunciones) }\end{array}$ & $\begin{array}{c}\text { Baja } \\
(3 \%-10 \%)\end{array}$ & $\begin{array}{c}\text { Medio } \\
\text { (Medir los }\end{array}$ & $\begin{array}{c}\text { Asignar } \\
\text { recursos }\end{array}$ \\
& contagiados & & & & públicos \\
& & & & \\
\hline
\end{tabular}

Fuente: elaboración propia (2020).

\section{Referencias bibliográficas}

Flórez, R., Ramón, J. (2014). El cuadro de mando integral de riesgos o la cara B de la gestión empresarial: alineando la estrategia para la generación sostenible de valor. Revista de la Asociación Española de Contabilidad y Administración de Empresas, ISSN 1577-2403. 


\title{
EL COVID-19 Y SUS EFECTOS EN TORNO A LA DESIGUALDAD EN AMÉRICA LATINA
}

\section{COVID-19 AND ITS EFFECTS AROUND INEQUALITY IN LATIN AMERICA}

\author{
Mauricio Alejandro Bedoya Jimenez \\ Magister en Administración Económica y Financiera, Docente Investigador \\ Universidad Católica Luis Amigó. Correo electrónico: mauricio.bedoyaji@ \\ amigo.edu.co.

\section{Julián David Colorado Agudelo} \\ Magister en Salud Pública, Docente Investigador Universidad Católica Luis \\ Amigó. Correo electrónico: julian.coloradoag@amigo.edu.co.
}

\section{Objetivo}

Establecer las relaciones del COVID-19 con el aumento de las desigualdades sociales y de género en Latinoamérica.

\section{Descripción del contexto}

El COVID-19 es una enfermedad respiratoria infectocontagiosa originada por el virus SARSCOV-2, virus que se manifestó en Wuhan, provincia de China en diciembre de 2019 (Ghinai et al., 2020). En cuestión de tres meses se propagó al resto del mundo. La Organización Mundial de la Salud (OMS) dada la situación de contagio del virus lo declaró pandemia el pasado 11 de marzo de 2020, (Wu y McGoogan, 2020). En las Américas, la Organización Panamericana de la Salud (OPS) ha documentado la existencia de 536664 casos confirmados, y 19294 personas fallecidas, con presencia en 54 países o territorios de esta región, Estados Unidos ha sido el país con más afectados con 461275 contagios y 16596 muertes (Organización Panamericana de la Salud, 2020). Los Gobiernos Latinoamericanos en respuesta, han implementado estrategias de cuarentena y el asilamiento social, ocasionado presiones a la desigualdad, ya presente 
en la región, es importante entender que la categoría de desigualdad, según D’Amico, (2016) está relacionada con el acceso de los diferentes grupos poblacionales a bienes y capacidades. Los ingresos, el acceso a los sistemas de salud, la seguridad alimentaria y la violencia han sido algunas de las variables más afectadas por las estrategias implementadas; donde la población con pocos ingresos, así como la de ingresos medios, se han visto afactadas, (Lustig y Birdsall, 2020).

\section{Metodología}

A partir de un enfoque cualitativo, se llevó a cabo una investigación documental hermenéutica, se utiliza como técnica de recolección de datos la revisión de informes realizados por organismos oficiales y ONG's, como también artículos publicados en bases de datos de ELSEVIER y Scielo. Para la sistematización de la información recolectada se utilizó una matriz que relaciona la fuente y el planteamiento sobre la categoría desigualdad (ver tabla 1).

Tabla1. Covid-19 y desigualdad.

\begin{tabular}{|c|c|}
\hline Origen & Planteamiento \\
\hline $\begin{array}{l}\text { Organización de Estados Americanos } \\
\text { (Botero et al., 2020, p. } 10-17 \text { ) }\end{array}$ & $\begin{array}{l}\text { Con una región marcada por la desigualdad, las afectaciones en } \\
\text { derecho la salud y esferas de los DD.HH se acrecientan de forma } \\
\text { diferenciada en poblaciones vulnerables. }\end{array}$ \\
\hline $\begin{array}{l}\text { Review The Lancet (Wenham et al., } \\
\qquad 2020 \text {, p. } 2 \text { ) }\end{array}$ & $\begin{array}{l}\text { Las políticas de salud pública no abordan impactos de género. } \\
\text { Las mujeres se exponen a mayor impacto al atender sus familias, } \\
\text { limitando su trabajo y economía. }\end{array}$ \\
\hline OXFAM $^{1}($ OXFAM, 2020) & $\begin{array}{l}\text { En sociedades fragmentadas como las latinoamericanas el COVID-19 } \\
\text { ha causado distinciones en las respuestas de los distintos Gobiernos } \\
\text { al hacerle frente. Afectando más a las poblaciones vulnerables. }\end{array}$ \\
\hline
\end{tabular}

Fuente: elaboración propia (2020).

\section{Hallazgos}

Tras la pandemia declarada por la OMS se dejan al descubierto las desigualdades existentes en las regiones menos desarrolladas, en las que existe mayor desigualdad al 
existir más población vulnerable. Los efectos en Latinoamérica han sido mayores que en regiones como España o Italia, debido a que medidas básicas como lavarse las manos no son posibles porque cerca del $21 \%$ de la población de la región vive en Barrios marginales (Comisión Económica para América Latina y el Caribe, 2020) en los que no tienen acceso al agua. Por otra parte, se presenta una ausencia de estudios de género entorno al diseño de las políticas dispuestas para contener la epidemia, las cuales no tienen enfoque de género, con lo que se deja como uno de los grupos poblacionales más expuestos ante la pandemia, a las mujeres, que a su vez aparecen como centro de la familia, limitando su actuar dentro de la sociedad. En respuesta a ello se debe garantizar la existencia de sistemas de salud inclusivos que sean oportunos y eficientes, así como la elaboración de políticas para enfrentar la pandemia con perspectiva de género que permitan el acceso a la protección de grupos vulnerables. La respuesta de los gobiernos a través de sus políticas deberá ser alejada de los sistemas de protección social que hasta ahora han sido ejecutados por los gobiernos para atender su población.

\section{Referencias bibliográficas}

Botero, Á., Melo, R., Molina, P., Mora, A., Muñoz, B., Noguera, S., Pérez, R., Rojas, R., Rovira, A., Sánchez, D., Salvia, A., Scagliola, A., \& Tuiñon, I. (2020). Guía Práctica de respuestas inclusivas y con enfoque de derechos ante el COVID-19.

CEPAL. (2020). Población urbana que vive en barrios marginales, asentamientos informales o viviendas inadecuadas. https://cepalstat-prod.cepal.org/ cepalstat/tabulador/ConsultaIntegradaProc_HTML.asp

D’Amico, M. (2016). La definición de la desigualdad en las agendas recientes de los organismos internacionales para América Latina. Rev. Colomb. Soc, 39, 20. https://doi.org/10.15446/rcs.v39n1.56348

Ghinai, I., McPherson, T. D., Hunter, J. C., Kirking, H. L., Christiansen, D., Joshi, K., Rubin, R., Morales-Estrada, S., Black, S. R., Pacilli, M., Fricchione, M. J., Chugh, R. K., Walblay, K. A., Ahmed, N. S., Stoecker, W. C., Hasan, N. F., Burdsall, D. P., Reese, H. E., Wallace, M., ... Layden, J. E. (2020). First known person-to-person transmission of severe acute respiratory syndrome coronavirus 2 (SARS-CoV-2) in the USA. The Lancet. https://doi. org/10.1016/S0140-6736(20)30607-3 
Lustig, N., y Birdsall, N. (2020). La nueva desigualdad y la protección social entre personas | PNUD en América Latina y el Caribe. https://www.latinamerica. undp.org/content/rblac/es/home/blog/2020/la-nueva-desigualdad-y-laproteccion-social-entre-personas.html

Organización Panamericana de la Salud. (2020). Cumulative COVID-19 cases reported by countries and territories in the Americas. https://who.maps.arcgis.com/ apps/webappviewer/index.html?id=2203b04c3a5f486685a15482a0d97a87 \&extent $=-20656313.6818 \% 2 \mathrm{C}-3596894.4332 \% 2 \mathrm{C} 1611932.8945 \% 2 \mathrm{C} 7390$ $469.7606 \% 2 \mathrm{C} 102100 \&$ site $=$ paho

OXFAM. (2020). El CORONAVIRUS no discrimina, las desigualdades sí Vencer la pandemia requiere enfrentar las desigualdades. www.oxfam.org

Wenham, C., Smith, J., Morgan, R., y Group, W. (2020). COVID-19: the gendered impacts of the outbreak. The Lancet, 395, 846-848. https://doi.org/10.1016/ S0140-6736(19)32990-3

Wu, Z., y McGoogan, J. M. (2020). Characteristics of and Important Lessons from the Coronavirus Disease 2019 (COVID-19) Outbreak in China: Summary of a Report of 72314 Cases from the Chinese Center for Disease Control and Prevention. JAMA - Journal of the American Medical Association. https:// doi.org/10.1001/jama.2020.2648 


\section{IMPACTO DE LA ECONOMÍA EN TIEMPOS EMERGENTES}

\section{IMPACT OF THE ECONOMY IN EMERGING TIMES}

\section{Osmany Pérez Barral}

Doctor en Ciencias Económicas, docente de la Pontificia Universidad Católica del Ecuador Sede Ambato. Correo electrónico: operez@pucesa.edu.ec.

\section{Mónica del Rocío Alarcón Quinapanta}

Doctora en Ciencias Técnicas, docente de la Universidad Regional Autónoma de Los Andes

\section{Jorge Vladimir Núñez Grijalva}

Doctor en Ciencias Jurídicas, docente de la Pontificia Universidad Católica del Ecuador Sede Ambato. Correo electrónico: jnunez@pucesa.edu.ec.

\section{Objetivo}

Analizar el impacto de la economía del Ecuador en tiempos emergentes.

\section{Descripción del Contexto}

El contexto económico en Ecuador comenzó a tener repercusiones negativas desde el 29 de febrero del 2020, donde se detectó el primer caso del virus corona virus (COVID-19), por una persona procedente de un vuelo de Madrid con destino a la ciudad de Guayaquil (El Universal, 2020), principal foco de la pandemia en el país. El criterio expuesto, es la base del comienzo de una situación económica compleja, no solo para esta provincia sino para el país completo, dado el nivel de contagio acelerado que trajo consigo la población de manera exponencial, sumado a la ineptitud y demora de los dirigentes de la ciudad en no tomar medidas proactivas y preventivas a partir de la información que recorría el mundo desde China.

En tal sentido, la base económica del país (Ecuador), expuso su debilidad para enfrentar una situación emergente, dado el nivel de endeudamiento que había adquirido con el Fondo Monetario Internacional (FMI) y otras instituciones financieras, donde la economía se endeudó en aproximadamente 2000 millones de dólares desde el año 2019. 
Asimismo, esta situación es más preocupante, porque el desarrollo y productividad de sus empresas es lento, producto, por ciento, de empresas que clasifican entre pequeñas y medianas con bajo nivel tecnológico, sin esperanza de crecer y ser sostenible en el tiempo, lo cual, permite deducir que sus niveles productivos son insuficientes para una pronta recuperación de la economía global del país en situaciones de crisis.

\section{Metodología}

La metodología se basa en una investigación descriptiva-explicativa, con un paradigma cualitativo a partir del empleo del método de análisis documental, producto de los acontecimientos del COVID-19 en Ecuador y la necesidad de analizar el impacto de la economía en tiempos emergentes. Lo cual permite, plantear que el desarrollado limitado de las empresas en un país del tercer mundo como éste, difícilmente pueda hacer frente a la situación de endeudamiento que ha adquirido, destacándose las cifras de la Cámara Marítima del Ecuador (CAMAE, 2020), donde el titular de Finanzas anunció la solicitud de 2000 millones en financiamiento, desglosándose en: 500 millones del FMI y \$ 500 millones más a tres instituciones financieras: Banco Interamericano de Desarrollo, Banco Mundial y el Banco de Desarrollo de América Latina. A ello se suman, \$1000 millones de deuda bilateral con China.

\section{Hallazgos}

La situación descrita en la metodología y la aparición del COVID-19 en Ecuador, empeoró el escenario económico del país, pues los altos niveles de contagios en las ciudades más grandes como Quito, Guayaquil (más del 50\% de contagiado de todo el Ecuador) y Cuenca, condujeron a la aceleración del virus al resto del país, paralizándose en gran medida la mayorías de las empresas que generaban los ingresos más elevados del país, por ejemplo el sector petrolero) más las medianas y pequeñas empresas que en algo contribuían a la economía y el empleo en el Ecuador, haciéndose más difícil que se pueda pagar las deudas a las instituciones financieras internacionales, máxime cuando la generalidad de las empresas del país clasifican como medianas, pequeñas y micro empresas (MIPYME's) con una tecnología no muy avanzadas y con bajos niveles de producción como para sostener una economía en época de crisis o situación emergente. Esta percepción se sustenta en los datos del Instituto Nacional de Estadística y Censos 
(INEC, 2017) citado por EKO (2019), confirmándose, que las MIPYME‘s representan el $99,55 \%$, donde el segmento de mayor participación son las microempresas con un $90,78 \%$, las pequeñas con $7,22 \%$ y las medianas con $1,55 \%$.

En tal sentido, Ecuador se ha visto en la necesidad de renegociar los pagos de la deuda externa para enfrentar la situación de solvencia y liquidez que tiene en la actualidad, dado a diversos factores que afectan directamente al país, entre los que destacan: economía débil, incremento de presión financiera interna (estallidos sociales en el país) y externa (con organismos financieros FMI y Banco Mundial, por ejemplo), búsqueda de nuevos préstamos sin un respaldo productivo fuerte, lo cual, empeora el bienestar social del pueblo al no darse respuesta a las emergencias que demanda la situación del COVID-19. Por lo tanto, los retos económicos del país se hacen más grandes cuando se profundiza los problemas sociales, en cuanto a: especulación de precios en el mercado formal e informal, incremento del desempleo, endeudamiento de la población y empresas con los bancos, incremento de desalojo por no pronto pago de inquilinos, disminución de estudiantes en instituciones educativas por falta de financiamiento para pagar sus estudios, aumento de mendicidad, quiebre de medianas, pequeñas y micro empresas, sacrificio económico del pueblo para enfrentar la crisis económica del país, producto de los préstamos solicitados por el gobierno y por el impacto del COVID-19 en la economía del país, entre otros factores, que hoy son una realidad en el Ecuador y en otras partes del mundo.

\section{Referencias bibliográficas}

Cámara Marítima del Ecuador (2020). Ecuador renegociará pagos de deuda externa y suscribirá un nuevo acuerdo con el FMI. Disponible en: http://www.camae. org/economia-del-ecuador/ecuador-renegociara-pagos-de-deuda-externa-ysuscribira-un-nuevo-acuerdo-con-el-fmi/

El Comercio (2020). El FMI trabaja en un nuevo acuerdo económico con Ecuador $y$ analiza dar recursos emergentes. Disponible en https://www.elcomercio. com/actualidad/fmi-acuerdo-economico-ecuador-emergencia.html. 
El Universo (2020). Tres tareas inmediatas tienen el Ecuador en acuerdo con el Fondo Monetario Internacional Disponible en: https://www.eluniverso.com/ noticias/2020/02/14/nota/7738362/fmi-fondo-monetario-internacionalrevision-tareas-pendientes

El Universo (2020). Ecuador confirma primer caso de coronavirus. https://www. eluniverso.com/noticias/2020/02/29/nota/7760757/ecuador-confirmaprimer-caso-coronavirus

Revista EKO (2019). Mipymes representan el 99\% de negocios en Ecuador. Disponible en https://www.ekosnegocios.com/articulo/mipymes-representan-el-99-denegocios-en-ecuador 


\section{ENCUENTROS Y DESENCUENTROS EN LA FAMILIA TRAS EL COVID-19}

\section{ENCOUNTERS AND DISAGREEMENTS IN THE FAMILY DUE TO COVID-19}

\section{Yazmín Alejandra Quintero Hernández}

Doctora en Psicología, profesora investigadora de tiempo completo, Departamento de Enfermería Clínica Universidad de Guanajuato, Campus Celaya-Salvatierra. Correo electrónico: yazmin.quintero@ugto.mx.

\section{Perla Shiomara del Carpio Ovando}

Doctora en Psicología Social, profesora investigadora de tiempo completo, Departamento de Estudios Culturales, Demográficos y Políticos, Universidad de Guanajuato. Campus Celaya-Salvatierra. Correo electrónico: pdelcarpio@ ugto.mx.

\section{Objetivo}

El presente trabajo tiene el objetivo comprender y argumentar las posibles dinámicas involucradas en los espacios de convivencia familiar y las condiciones derivadas de la situación de contingencia relacionada con el COVID19.

\section{Descripción del contexto}

Se centra especial atención en el contexto mexicano. Se ha señalado que desde que inició el aislamiento por el COVID-19 han aumentado en México un 5\% los ingresos de mujeres a refugios, un $60 \%$ las orientaciones vía telefónica o electrónica, un $24 \%$ los reportes de violencia familiar y un 7.2\% las detenciones por violencia intrafamiliar (Galván, 2020). Lo anterior nos permite subrayar el aumento de la violencia durante la contingencia.

Estos datos obligan a reflexionar sobre cambios o afectaciones en la dinámica familiar durante este periodo de aislamiento. Al ser un tema nuevo, implica transitar por las reflexiones de algunos autores y sentar las bases para la investigación de otros momentos (antes, durante y después) de la contingencia. 


\section{Metodología}

Es un estudio cualitativo pues, como indica Mason (1996), está basada en métodos de generación de datos flexibles y sensibles al contexto social en el que se producen. Se acude aquí a la revisión y análisis de fuentes documentales (artículos, periódicos, páginas electrónicas, trípticos, otros), registro de información en diario y a la observación.

\section{Hallazgos}

La familia puede ser uno de los mayores espacios de convivencia (INEGI, 2014); sin embargo, en condiciones "normales" sus integrantes "salen", dando espacio a la liberación de tensiones. De acuerdo con la Encuesta Nacional del Uso del Tiempo 2014, los niños, adolescentes, así como adultos que trabajan y estudian, dedican al menos una tercera parte del día a actividades fuera del hogar (INEGI, 2014). En espacios de convivencia e interacción es natural que surjan conflictos (Domínguez y García, 2003), especialmente en culturas colectivistas como la mexicana, caracterizadas por la interdependencia entre personas y su grupo (Cienfuegos et al., 2016). En este tipo de culturas los espacios de convivencia se vuelven mucho más importantes y se tornan decisivos. Se vuelve primordial las reacciones que el otro tenga frente a los comportamientos, se permite menos la individualidad y la expresión de puntos de vista alternativos que no coinciden del todo con el que alguno otro miembro tenga. Se sabe que la realidad es única para cada persona; así, existen tantas realidades como personas (Watzlawick, 1994). El problema surge cuando las personas esperan que el otro piense o actúe como ellas lo hacen. Por lo que, opiniones diferentes que además tienen que ver con la supervivencia se convierten en espacios de discusión y conflicto. Además de que ha sido documentado que las relaciones en periodos de máxima convivencia generan rupturas, las cuales en su punto más extremo derivan en separaciones y violencia, estos datos se han reflejado en investigaciones que documentan el aumento de divorcios, por ejemplo, tras periodos vacacionales (Korstanje, 2015). En este sentido, durante la contingencia por COVID-19, temas como la manera en que cada integrante vive la pandemia, las creencias que tenga en torno a esta, la gravedad que le otorgue y los mecanismos que ejerce para protegerse, pueden derivar en espacios de conflicto que se traducirán en una expresión emocional de mayor intensidad. 
Además, la situación de aislamiento durante la COVID-19 tiene algunas condiciones particulares que hacen a la convivencia aún más complicada, como son que el "encierro" o confinamiento no es voluntario, existe un riesgo a la salud y a la economía, lo que puede incrementar el estrés y aumentar la intensidad de las emociones derivadas, el miedo, la angustia, el desánimo, la añoranza o nostalgia, la inestabilidad o el caos, el enojo y la frustración por los planes no realizados (vacaciones, celebraciones, etc.) y la alteración de las rutinas diarias, la necesidad de reorganización de las actividades o tareas domésticas, la convivencia con los niños y los atrasos en actividades laborales. Otros puntos de discusión que tienen que ver con las individualidades son los diferentes puntos de vista y estrategias que cada integrante de la familia utiliza para mantenerse seguros. La obsesión con la limpieza, o, por el contrario, la relajación en temas de higiene y confinamiento, los diferentes niveles de aislamiento social de los integrantes, los diferentes puntos de vista sobre recibir, o no, a otros familiares en casa, acudir, o no, a eventos familiares, son temas de decisión importantes.

Por otro lado, la funcionalidad de la familia tiene que ver con su flexibilidad y su capacidad para adaptarse al cambio y superar las crisis (Juárez, et al., 2016). Derivado de lo cual, consideramos que la familia puede generar aprendizajes importantes y descubrir recursos personales que pueden fortalecer su unión; así, los integrantes pueden desarrollar empatía, solidaridad, comprensión mutua, habilidades de comunicación y negociación, una mayor expresión afectiva positiva y la valoración y el reconocimiento por el otro y su labor. Es indudable que este periodo pondrá a prueba las herramientas y fortalezas de la familia y desarrollará nuevos aprendizajes en muchas de ellas, para lo cual puede ser útil, ante la imposibilidad de mantener una distancia física, tratar de buscar espacios individuales que permitan mantener, en ocasiones, una sana distancia emocional (necesaria) para permitir la reflexión y el tiempo que posibilite la atenuación de las emociones.

\section{Referencias bibliográficas}

Cienfuegos-Martínez, Y.I., Saldívar-Garduno, A., Díaz-Loving, R. y Avalos-Montoya, A.D. (2016). Individualismo y colectivismo: Caracterización y diferencias entre dos localidades mexicanas. Acta de Investigación Psicológica, 6, 2534-2543. 
Domínguez, R y García, S. (2003). Introducción a la Teoría del Conflicto en las Organizaciones. Madrid: Universidad Rey Juan Carlos de Madrid.

Galván, M. (2020). Otra contingencia: La violencia contra las mujeres va en aumento. Expansión Política. Periódico en Línea (5 de abril de 2020) https://politica. expansion.mx/mexico/2020/04/05/otra-contingencia-la-violencia-contralas-mujeres-va-en-aumento

Instituto Nacional de Estadística Geografía e Informática (2014). Encuesta Nacional de uso de tiempo (ENUT) 2014. Documento metodológico. México: INEGI http://internet.contenidos.inegi.org.mx/contenidos/productos//prod_serv/ contenidos/espanol/bvinegi/productos/nueva_estruc/702825075545.pdf

Juárez, M.C.L., Ponce, R.R.E., Rodríguez, L.J.L. (2016). Clasificación clínica de la familia en estadios funcionales: propuesta de un instrumento para su estudio. Medicina Familiar, 18(3), 65-75.

Korstanje, M.E. (2015). Cuando viajar no es un placer: El divorcio en vacaciones. Revista de Antropología Experimental, 15, 73-83.

Mason, J. (1996). Qualitative Researching. Londres: Sage.

Watzlawick, P. (1994). ¿Es real la realidad? Barcelona: Herder. 


\section{LA SUSPENSIÓN DE LOS CONTRATOS DE PRESTACIÓN DE SERVICIOS ESTATALES POR EL COVID-19 EN COLOMBIA ${ }^{2}$}

\section{THE SUSPENSION OF CONTRACTS FOR THE PROVISION OF STATE SERVICES BY COVID-19 IN COLOMBIA $^{2}$}

\section{Sergio Luis Mondragón Duarte}

Abogado, Magíster en Derecho Público, Doctorando en Seguridad Humana y Derecho Global. Docente Investigador de la Maestría en Derecho Administrativo de la Universidad Autónoma Latinoamericana. Correo electrónico: sergio. mondragondu@unaula.edu.co

\section{Objetivo}

Analizar el contenido del Decreto Legislativo $N^{\circ} 491$ del 28 de marzo de 2020 expedido por el Ministerio de Justicia y del Derecho colombiano, que decidió sobre la suspensión de los contratos de prestación de servicios estatales en el marco del COVID-19, a la luz de los derechos humanos.

\section{Descripción del contexto}

El Decreto 417 del 17 de marzo de 2020 decretó el Estado de Emergencia Económica, Social y Ecológica ${ }^{3}$ en todo el territorio colombiano, debido a la aparición del Coronavirus COVID-19 ${ }^{4}$ en el país (MinSalud, 2020), el día 05 de marzo de 2020 (El Colombiano, 2020), lo cual implicó una cuarentena de aislamiento preventivo obligatorio por el término inicial de 19 días, contados a partir del 25 de marzo de 2020 hasta el 13 de abril de 2020 (MinInterior, Decreto 457 de 2020). Ahora bien, los contratos de prestación de servicios estatales son una modalidad de selección directa, que pueden ser suspendidos por mutuo acuerdo entre las partes contratantes "cuando situaciones de fuerza mayor, caso fortuito o de interés público impidan temporalmente cumplir el objeto de las obligaciones a cargo de los contratantes" (Colombia Compra Eficiente, 
2018) (Consejo de Estado, Concepto 2016-00001-00 de 2016) (Consejo de Estado, Sentencia 1996-07799-01, 2012), por lo que valdría la pena cuestionar la suspensión de los mismos durante la vigencia de este periodo de aislamiento preventivo obligatorio o de sus prórrogas.

\section{Metodología}

El presente opúsculo corresponde a una pesquisa de tipo cualitativo con enfoque descriptivo, basada en un método de revisión documental hermenéutico, que da cuenta de la interpretación normativa existente en torno a la regulación de la crisis de salud pública ocasionada por la pandemia del Coronavirus COVID-19 en el país colombiano, circunscrita a los contratos de prestación de servicios estatales.

\section{Hallazgos}

El Ministerio de Justicia y del Derecho emitió el Decreto Legislativo $\mathrm{N}^{\circ} 491$ el día 28 de marzo de $2020^{5}$, donde señaló en el artículo 16, que durante el periodo de aislamiento preventivo obligatorio las personas naturales vinculadas a las entidades públicas por medio de contratos de prestación de servicios profesionales y de apoyo a la gestión “continuarán desarrollando sus objetos y obligaciones contractuales mediante trabajo en casa y haciendo uso de las tecnologías de la información y las comunicaciones" (MinJusticia, Decreto 491 de 2020), y aunque la prestación del servicio deba realizarse de forma presencial "continuarán percibiendo el valor de los honorarios durante el periodo de aislamiento preventivo obligatorio, previa verificación por parte del supervisor de la cotización al Sistema General de Seguridad Social” (MinJusticia, Decreto 491 de 2020), con el compromiso de cumplir tanto el objeto como las obligaciones del contrato, una vez hayan sido superadas las causas que dieron origen al Estado de Emergencia Sanitaria (Roa, 2020).

Frente a lo anterior, se considera acertada la decisión adoptada por el Gobierno Nacional de no suspender los contratos de prestación de servicios estatales mientras permanezca incólume el periodo de aislamiento preventivo obligatorio en todo el territorio colombiano, con ocasión del Coronavirus, por cuanto esta medida de carácter 
excepcional, además de corresponder a una de tantas para conjurar esta crisis de fuerza mayor ${ }^{6}$ en materia de salud pública, también vela por la protección de derechos fundamentales, como la vida, la dignidad humana y el mínimo vital; y derechos económicos y sociales, como la salud y el trabajo, de aquellos individuos vinculados bajo dicha modalidad de contratación en las diferentes entidades, órganos y organismos estatales, y que en muchos eventos, los honorarios por concepto del servicio prestado representan la única fuente de ingreso tanto del contratista como del resto de los integrantes de su núcleo familiar para garantizar su subsistencia, lo cual justifica que el Estado asuma esa carga "en virtud del principio de solidaridad" (AIL, 2020), contenido en el artículo 957 de la Constitución Política de 1991.

\section{Referencias bibliográficas}

Agencia de Información Laboral (2020) TIPS para la defensa laboral personal en tiempos del Coronavirus. Recuperado de: http://ail.ens.org.co/informeespecial/tips-para-la-defensa-laboral-personal-en-tiempos-del-coronavirus/.

Cifuentes Muñoz, Eduardo. (2002). Los estados de excepción constitucional en Colombia. Ius et Praxis, 8(1), 117-146.https://dx.doi.org/10.4067/S071800122002000100009.

Congreso de la República de Colombia. (1994). Ley 137 de 1994-Por el cual se reglamentan los Estados de Excepción en Colombia. Recuperado de: http:// www.secretariasenado.gov.co/senado/basedoc/ley_0137_1994.html.

Colombia Compra Eficiente (2018) Concepto de suspensión de contrato de prestación de servicios profesionales. Recuperado de: https://sintesis.colombiacompra. gov.co/documento/4201814000004346-suspensi\%C3\%B3n-de-contratode-prestaci $\% \mathrm{C} 3 \% \mathrm{~B} 3 \mathrm{n}$-de-servicios-profesionales.

Consejo de Estado, Sala de lo Contencioso Administrativo-Sección Tercera-Subsección A. (2012). Sentencia 1996-07799-01 del 11 de abril de 2012. Exp. 17434. CP. Carlos Alberto Zambrano Barrera.

Consejo de Estado, Sala de Consulta y Servicio Civil (2016) Sentencia 2016-00001-00. Exp. 2278. CP. Germán Bula Escobar (E). 
Corte Constitucional, Sala Plena. (2016). Sentencia SU-449 del 22 de agosto de 2016. Exp. T- 5.380.986. MP. Jorge Ignacio Pretelt Chaljub.

El colombiano (07 de marzo de 2020) Llegó el Coronavirus a Colombia ¡Ahora qué? Disponible en: https://www.elcolombiano.com/coronavirus-en-colombiacontra-el-miedo/llego-el-coronavirus-a-colombia-ahora-que-JB12578742.

Ministerio de Justicia y del Derecho de la República de Colombia (2020) Decreto Legislativo 491 del 28 de marzo de 2020. Recuperado de: file://C:/Users/ Sergio\%20Mondragon/Downloads/Decreto-491-28-marzo-2020.pdf.

Ministerio de Salud y de la Protección Social de la República de Colombia (2020) Nuevo Coronavirus COVID-19. Recuperado de: https://www.minsalud.gov.co/ portada-covid-19.html.

Ministerio del Interior de la República de Colombia (2020) Decreto 457 del 22 de marzo de 2020. Recuperado de: https://dapre.presidencia.gov.co/normativa/ normativa/DECRETO\%20457\%20DEL\%2022\%20DE\%20MARZO\%20 DE\%202020.pdf.

Organización Panamericana de la Salud (2020) La OMS caracteriza a COVID-19 como una pandemia. Disponible en: https://www.paho.org/hq/index. php?option=com_content\&view $=$ article\&id $=15756$ :la-oms-caracteriza-acovid-19-como-una-pandemia\&catid=740\&lang=es\&Itemid=1926.

Presidencia de la República de Colombia (2020) Decreto 417 del 17 de marzo de 2020. Recuperado de: https://dapre.presidencia.gov.co/normativa/normativa/ DECRETO\%20417\%20DEL\%2017\%20DE\%20MARZO\%20DE\%20 2020.pdf.

Roa, D. (2020). Responsabilidad disciplinaria de los supervisores de contratos estatales en época de COVID-19 (Documento en línea). Disponible en: davidroasalguero.com/responsabilidad-disciplinaria-de-los-supervisoresde-contratos-estatales-en-epoca-de-covid-19/ 


\section{TENDENCIAS NEUROCOGNITIVAS EMERGENTES DE UN PROCESO DE TRANFORMACIÓN SOCIOECONÓMICA ANTE LA CRISIS DEL COVID-19}

\section{NEUROCOGNITIVE TRENDS EMERGING FROM A PROCESS OF SOCIOECONOMIC TRANSFORMATION IN THE FACE OF THE COVID-19 CRISIS}

\section{Efraín de Jesús Hernández Buelvas}

Magíster en biotecnología de la Universidad de Córdoba. Docente investigador vinculado al Departamento Curricullum Común Unisinú, Facultad de Ciencias Humanas, Arte y Diseño, Universidad del Sinú, Montería-Colombia. Correo electrónico: efrainhernandezb@unisinu.edu.co.

\section{Arney Alfonso Vega Martínez}

Magíster en estudios políticos de la Universidad de Caldas. Docente investigador vinculado al Departamento Curricullum Común Unisinú y al Programa de Comunicación Social de la Facultad de Ciencias Humanas, Arte y Diseño, Universidad del Sinú, Montería-Colombia. Correo electrónico: arneyvega@ unisinu.edu.co.

\section{Nataliya Barbera de Ramírez}

Doctora en Planificación y Gestión del desarrollo Regional de la Universidad del Zulia. Docente investigador vinculado al Departamento Curricullum Común Unisinú, Facultad de Ciencias Humanas, Arte y Diseño, Universidad del Sinú, Montería-Colombia. Correo electrónico: nataliaberbera@unisinu.edu.co.

\section{Objetivo}

Comprender la tendencia neurocognitiva emergente durante la crisis del COVID-19.

\section{Descripción del contexto}

En el mundo actual, los problemas han tenido una mayor exposición ante la influencia que ejercen los medios digitales, sumado a la inmediatez y velocidad intangible a la que viaja la información. Así mismo, Colombia se encuentra sumergida ante la crisis originada por el COVID-19, un problema de ámbito cultural y socioeconómico, que ha trascendido a los entornos educativos. Esta nueva realidad ha promovido cambios en los modelos pedagógicos tradicionales del docente, intentando optimizar el rendimiento 
académico a través de nuevas coyunturas comunicativas y tecnológicas. No obstante, García et al. (1995) afirmaron que existe una dominancia generalizada por el hemisferio cerebral izquierdo $(\mathrm{CI}+\mathrm{LI})$ especializado en el registro y archivo de material verbal; por tanto, nuestra tendencia neurocognitiva generalmente responde a un aprendizaje tradicional, teórico, sin conciencia crítica; alimentada por estrategias pedagógicas docentes que carecen de creatividad, innovación y que separan las tecnologías del aprendizaje y el conocimiento, de la enseñanza en las aulas.

\section{Metodología}

Para este análisis se empleó la hermenéutica como método de comprensión para reflexionar sobre la experiencia de vida a partir de la práctica cotidiana o modos de vida del ser (Gadamer, 2005). En este sentido, el abordaje metodológico se basó en una revisión documental que fundamenta y describe la utilidad que pueden brindar las tecnologías del aprendizaje y el conocimiento, al desarrollo de nuevas tendencias neurocognitivas en los estudiantes.

\section{Hallazgos}

A pesar de existir una hemisfericidad izquierda generalizada en los estudiantes de los países que emplean la enseñanza formal o tradicional, como lo es Colombia; López (2015) señala que la arquitectura neuronal puede ser modificada por estímulos externos mediante la plasticidad cerebral generando alteraciones en la organización cerebral, de modo que se puede aprender en tiempos diferentes a partir de la codificación de la información. En este sentido, los estudiantes colombianos como un mecanismo de supervivencia estudiantil ante el COVID-19 han producido videos, juegos, objetos virtuales y múltiples propuestas autodidácticas que han buscado mejorar su aprendizaje desde el reconocimiento de las ideas previas y el uso de progresiones en el aprendizaje. De esa misma manera, establecen un clima de confianza que favorece el entendimiento, la armonía en clase y sin saberlo, potencian su hemisferio cerebral derecho (CD +LD) como una tendencia cognitiva emergente. Del mismo modo la integración de los hemisferios (Derecho+ Izquierdo) permite la autorregulación del aprendizaje por medio de la integración de múltiples habilidades, dando origen a una tendencia neurocognitiva que responde a las necesidades del entorno. 


\section{Rerefencias bibliográficas}

García-Moreno, L. M., Portellano, J. A., Zahonero, M., Martínez, R., y Pascual, J. (1995). Memoria y lateralidad: Memoria verbal y espacial en sujetos diestros y zurdos. Archivos de Neurobiología, 58(4), 377-389

López, M.I. (2015). Enseñanza-aprendizaje musical: una visión de los docentes de instrumento en los conservatorios profesionales. Programa de doctorado en Psicodidáctica: psicología de la educación y didácticas específicas: Universidad del País Vasco. 


\title{
ANÁLISIS DE LA PLANEACIÓN DE PROSPECTIVA ESTRATÉGICA COMO HERRAMIENTA PARA VISUALIZAR EL FUTURO
}

\section{ANALYSIS OF STRATEGIC PROSPECTIVE PLANNING AS A TOOL TO VISUALIZE THE FUTURE}

\author{
María de Lourdes Tiburcio Sánchez \\ Doctora en Gestión Tecnológica e Innovación, Docente en la Universidad de \\ Guanajuato, México. Correo electrónico: mtiburcio@ugto.mx.
}

\section{Roberto Godínez López \\ Doctor en Administración, Docente investigador en la Universidad de Guanajuato, México. Correo electrónico: godinez.r@ugto.mx.}

\section{Objetivo}

Analizar la planeación prospectiva estratégica a partir de las comparaciones bibliográficas como una herramienta para el futuro en entornos de turbulencia como es el caso de la pandemia ocasionada por el virus SARS-CoV ${ }_{2}$ (COVID-19).

\section{Descripción del contexto}

La prospectiva estratégica, concepto que suele confundirse con la planeación estratégica, es un tema de reflexión para analizar los escenarios futuros, esa perspectiva ayuda a tomar las mejores decisiones sobre el o los escenarios a largo plazo, el conocer diferentes posibilidades que puede traer el futuro permite reflexionar sobre eventos descriptores, posibles tendencias y generar conjeturas para tener ese enfoque de adaptabilidad y flexibilidad ante estos cambios.

El hablar de este nuevo enfoque de la planeación, denominado prospectiva estratégica, permite a los líderes de los gobiernos y diferentes sectores conocer sobre la utilidad de esta poderosa herramienta, que implica un enfoque holístico de la realidad, donde se considera tanto lo cuantitativo, como lo cualitativo, así como entender que ante los escenarios que se presenten las actitudes a tomar deben ser activas, creativas y adaptativas. (Miklos, 2016; Baena, 2015). 
De acuerdo a la revisión de literatura, en México como en América Latina la planeación no es un tema de absoluta importancia, porque estos países han pasado por conflictos, revoluciones, pobreza, que difícilmente el futuro se convierte en algo no visualizable. (Baena Paz, 2015). En este sentido la planeación estratégica es lo más actual que se considera, pero hablar de la prospectiva estratégica, según (Godet, 2007), se considera como la forma de actuar ante la incertidumbre, la turbulencia y el riesgo para una visión a largo plazo.

\section{Metodología}

El método que se utilizó es un estudio cualitativo inductivo y diseño de investigación documental aplicando la hermenéutica analógica (Galetar Porter, 2013), utilizando como técnica la revisión documental y el empirismo de los autores a partir de la investigación bibliográfica de diferentes documentos prospectivos a nivel internacional y de la experiencia de más de 10 años en el área de planeación.

\section{Hallazgos}

Muchos de los países europeos y latinoamericanos cuentan con documentos estratégicos que incluyen tendencias globales e indicadores, pero entonces en qué medida se consideraron estos efectos sistémicos tanto de la salud como económicos.

El Instituto Español de Estudios Estratégicos (IEEE) en el documento Panorama de Tendencias Geopolíticas, 2040 se mencionaba la potencialidad de las pandemias, y se diagnosticaba una situación similar a las pandemias de 1918.

En otro documento del Centro De la Política Estratégica Europea (EPSC), “Tendencias Globales 2030” publicado en 2015, también se habla de agentes patógenos que dañan a las personas.

En otro documento de la comunidad de inteligencia norteamericana se señala, que resultado de ese tipo de virus, tendrá efectos dañinos en el cual sufrirían miles de personas. (Jordán, 2020). 
Por otro lado, en México en el libro "Los futuros de la salud en México 2050", realizado por el Dr. Enrique Barajas y el Dr. Antonio Alonso Cachero en el 2010, se comenta sobre la situación de la salud hablando del 2020 sobre la pandemia como un virus de alta letalidad.

Entonces, qué sucede con la prospectiva estratégica, porque si se tenía información cualitativa, cuantitativa, datos históricos, los gobiernos no utilizaron la planeación prospectiva estratégica como una disciplina para la toma de decisiones, porque no se hizo uso de toda la información, sobre todo estos efectos dan cuenta de lo vulnerable que se encuentran los países independientes de la situación económica, social y política que tenga un país.

\section{Referencias bibliográficas}

Baena Paz, G. (2015). Planeación prospectiva estratégica. México : Consultoría y Servicios de Comunicación S. C. .

Galetar Porter, L. (2013). La planeación situacional desde la hermenútica analógica. Diálogos sobre educación, 1-23.

Godet, M. (2007). Manuel de prsopective stratégique. París : Dunod.

Jordán, J. (28 de 03 de 2020). 'COVID-19' Y PROSPECTIVA EN SEGURIDAD Y DEFENSA. Obtenido de Agenda Pública_El país: http://agendapublica. elpais.com/covid-19-y-prospectiva-en-seguridad-y-defensa/

Miklos , T., y Baena Paz, G. (2016). Planeación prospectiva hacia el mejor de los futuros posibles. México: Cuadernos del Centro de Investigación en Economía Creativa(CIEC). 


\title{
LA RESPONSABILIDAD SOCIAL UNIVERSITARIA: UNA HERRAMIENTA DE GESTIÓN ORGANIZACIONAL CENTRADA EN EL SER HUMANO

\author{
UNIVERSITY SOCIAL RESPONSIBILITY: A HUMAN \\ CENTERED ORGANIZATIONAL MANAGEMENT TOOL
}

\section{Gustavo Adolfo Rubio-Rodríguez}

PhD Administración y Gestión de Proyectos. Corporación Universitaria Minuto de Dios, Colombia. Correpo electrónico: gustavo.rubio-r@uniminuto.edu.co.

\author{
Alexander Blandón López \\ PhD Development Studies. Universidad del Tolima, Colombia.
}

\section{Guillermo Meza Salcedo}

Magister en Filosofía Latinoamericana. Corporación Universitaria Minuto de Dios, Colombia.

\section{Objetivo}

Determinar las políticas de Responsabilidad Social Universitaria (RSU), que deben ser objeto de implementación, respecto las dinámicas de clima organizacional generadas en los profesores universitarios, con ocasión de las repercusiones que ha transferido el COVID-19.

\section{Descripción del contexto}

Si bien las universidades en su labor responsable de mirar hacia afuera con programas de impacto social, les ha llegado la hora de mirar hacia adentro. Esto es importante para el ejercicio académico, en vista del cambio estratégico que están asumiendo las instituciones de educación superior, representadas en acciones de RSU que propendan por mejorar, o en su defecto sostener, un buen ambiente laboral.

Se han adelantado por parte de este tipo de instituciones, disímiles estudios en materia de RSU, pero muy pocos han concentrado su atención en el comportamiento de sus agentes de interés (stakeholders) internos, dado que se han inquietado por conocer 
y analizar las acciones que dichas instituciones adelantan en función de la comunidad, inclusive, de las menos favorecidas.

Por tanto, esta nota científica concentrará su atención en los stakeholders representados por los profesores universitarios. Para ello, es necesario precisar, si las políticas de bienestar impulsadas en el contexto universitario, se materializan en acciones que optimizan la labor, fortalecen el vínculo y potencializan el compromiso de los profesores, en estos tiempos de distanciamiento social que nos ha obligado a orientar los procesos formativos a través de diferentes herramientas digitales.

\section{Metodología}

Para el cumplimiento del objetivo de este manuscrito, se acudió a una cuidadosa revisión bibliográfica, de aquellos escritos cuyos autores son considerados como referente en materia de RSU; sin embargo, no se encontró en las bases datos, la relación entre la RSU y las consecuencias que hasta la fecha ha provocado el COVID-19, como tampoco se halló esa relación soportada en el clima laboral. Por tanto, se ha recurrido axiológicamente a emitir algunos pensamientos que son propios de los autores, sin desconocer la critica que sobre éstos intenten promover. El análisis crítico aquí suministrado, obedece además a la experiencia de los autores, y lo asumen frente a cualquier otro argumento que se levante en contrario.

\section{Hallazgos}

Las medidas que, en materia sanitaria, se han tomado desde el orden gubernamental, generan en su población académica como en la sociedad, total desconcierto, al no conocerse a ciencia cierta, hasta cuando se volverá a los escenarios físicos, en el afán de interactuar con los educandos y con los homólogos en general.

El uso de diferentes herramientas tecnológicas, ha permitido adelantar el trabajo desde casa en forma regulada; no obstante, las universidades deben preocuparse por el estado comportamental del profesorado en este periodo de confinamiento en el que nos encontramos. Es imperante conocer esta realidad, en procura de intervenir con acciones que redunden en benéfico de la población afectada, ofreciendo, entre otros, ayuda psicológica si fuera necesaria. 
La distancia social tendrá que conservarse hasta que se encuentren respuestas médicas, por su parte, las instituciones educativas tendrán que idear estrategias que proporcionen protección personal a sus colaboradores, no únicamente referidas a la salud física, sino, a la salud mental, inclusive, aun cuando volvamos a nuestras prontitudes tradicionales. En ultimas, se trata de velar por el alcance de un buen clima organizacional.

Concluyendo, las políticas que estén o vayan a ser implementadas por las organizaciones educativas de orden superior, según Flórez et. al (2017), les incumbe estar en incesante cambio, y más cuando se observan tendencias globales que pueden transformar de una manera contundente el escenario universitario, enfrentando a estas instituciones a retos de adaptación a esos nuevos escenarios.

\section{Fuentes bibliográficas}

Flórez, M., Rubio-Rodríguez, G. A., Rodríguez, M., y Cúrvelo. J.(2017). Responsabilidad social universitaria "una aproximación desde la percepción de la colectividad académica”. Revista Cientifica Hermes, (17), 80-103. 


\section{IMPACTO DEL COVID-19 EN EL TURISMO DE LA CIUDAD DE PACHUCA DE SOTO, HIDALGO, MÉXICO IMPACT OF COVID-19 ON TOURISM IN THE CITY OF PACHUCA DE SOTO, HIDALGO, MEXICO}

\section{Carolina González}

Doctora en Planificación Territorial y Gestión ambiental, Docente investigadora de la Universidad Autónoma del Estado de Hidalgo. Correo electrónico: cgesp@ uaeh.edu.mx.

\section{Noemi Vega Lugo}

Maestra en Administración de Empresas, Docente investigadora de la Universidad Autónoma del Estado de Hidalgo. Correo electrónico: noemivl@ uaeh.edu.mx.

\section{Nancy Testón \\ Maestra en Tecnología Educativa, Docente investigadora de la Universidad Autónoma del Estado de Hidalgo. Correo electrónico: nteston@uaeh.edu.mx.}

\section{Objetivo}

Identificar el impacto del COVID-19 en el turismo de la Ciudad de Pachuca, Hidalgo y las medidas tomadas por el Gobierno para la recuperación de este sector en dicha comunidad receptora.

\section{Descripción del contexto}

El turismo aporta el 8.7 \% al PIB en México, actividad que se ha visto mermada por la cuarentena del COVID-19; el número de contagios asciende a más de 10544 y 970 muertos, según datos emitidos por la Secretaría de Salud hasta el día de redacción de la presente nota. En el estado de Hidalgo, hay 106 casos positivos y 16 defunciones, muy por debajo de la Ciudad de México, Estado de México y Puebla, estados circunvecinos.

A partir de la declaración de Fase 1 se determinó el aislamiento voluntario, en Fase 2 la suspensión de trabajos no esenciales y Fase 3, fase de ascenso rápido y solicitan las autoridades continuar con la Jornada Nacional de Sana Distancia. \#QuedateEnCasa. 
Tales medidas tuvieron consecuencias económicas debido al cierre parcial de empresas de servicio de alojamiento, alimentación y actividades turísticas.

\section{Metodología}

La información recabada corresponde a una investigación documental que desvela datos de fuentes oficiales como: la Secretaria de Salud de México, Secretaria de Turismo Estatal y Dirección Municipal de Turismo. Se solicitó información vía Whatsapp a servidores turísticos de Pachuca para conocer la situación real de la operatividad de las empresas. Se consultaron comunicados de autoridades gubernamentales para identificar acciones a favor del turismo.

\section{Hallazgos}

En México esta pandemia inicia en la Ciudad de México con una persona contagiada duante su viaje a Italia, identificado en marzo, de acuerdo con las cifras emitidas por el Gobierno Federal al 16 de marzo de 2020 existían 82 casos confirmados de COVID-19 por lo que, la Secretaría de Salud decide tomar medidas de salud más extremas, como: evitar eventos públicos, suspensión de clases, a la ciudadanía en general evitar salir de casa (Salud S. d., 2020). Al 12 de abril los casos confirmados sumaron 4661 y 296 defunciones; el gobierno decreta la Fase 2 y toma como medidas: cerrar restaurantes, bares, cines, lugares de esparcimiento y reforzar las medidas para no salir de casa (México, 2019).

Por su parte, el gobierno de Hidalo para evitar la propagación del virus, considerando la cercanía con el Estado de México y Ciudad de México, puntos de mayor número de contagios, determina: la suspensión de classes en todos los niveles, el cierre de parques, plazas, gimnasios, cines, bares, y parcialmente restaurantes y hoteles.

En Pachuca (capital del estado) con relación al turismo se han suspendido los recorridos turísticos, modúlos de información, cierre de museos y actividades culturales. En tanto, la Dirección de Turismo Municipal proporciona información vía telefónica y recorridos virtuales. Los hoteles operan al 50\% de ocupación, los restaurantes ofrecen servicio a la mesa al $50 \%$ con medidas sanitarias y comida para llevar; situación que 
deja un panorama económico desalentador ante la contingencia que se extiende hasta mayo. El apoyo del gobierno al sector turismo es: eximir en un $100 \%$ el impuesto por la prestación de servicios de hospedaje en el periodo marzo-abril, apoyo en créditos y $50 \%$ del pago del impuesto sobre nómina para pequeñas y medianas empresas (UNOTV, 2020).

\section{Fuentes bibliográficas}

México, G. d. (12 de abril de 2019). Subsecretaria de Prevención y Proimoción de la Salud. Obtenido de https:/www.gob.mx/cms/uploads/attachment/ file/546237/Comunicado_Tecnico_Diario_COVID-19_2020.04.12.pdf

Salud, S. d. (16 de abril de 2020). Gobierno de México. Obtenido de https://www.gob. $\mathrm{mx} / \mathrm{cms} /$ uploads/attachment/file/541582/Comunicado_Tecnico_Diario_ COVID-19_2020.03.16.pdf

UNOTV. (16 de abril de 2020). Hidalgo anuncia medidas para reactivar su economía por coronavirus. . Obtenido de https:/www.unotv.com/noticias/estados/ hidalgo/detalle/coronavirus-hidalgo-anuncia-medidas-para-reactivar-sueconomia-660356/ 


\title{
COMPETENCIAS TIC PARA IMPLEMENTAR LA \\ EDUCACIÓN VIRTUAL ANTE LA PANDEMIA DE LA \\ COVID-19
}

\section{ICT COMPETENCES TO IMPLEMENT VIRTUAL EDUCATION IN THE FACE OF THE COVID-19 PANDEMIC}

\author{
Josnel Martínez Garcés \\ Magister Scientiarium en Planificación y gerencia de ciencia y tecnología. \\ Coordinador de investigación en la Corporación Universitaria Autónoma de \\ Nariño. Santiago de Cali, Colombia. Correo electrónico: josnel.martinez@, \\ aunarcali.edu.co.

\section{Jacqueline Garcés Fuenmayor} \\ Especialista en Enseñanza de la lengua. Docente a tiempo completo en la \\ Corporación Universitaria Autónoma de Nariño. Santiago de Cali, Colombia. \\ Correo electrónico: jacqueline.garces@aunarcali.edu.co.
}

\section{Objetivo}

Determinar el nivel de competencias TIC en los docentes de la Corporación Universitaria Autónoma de Nariño para la implementación de la educación virtual ante la pandemia de la COVID-19.

\section{Descripción del contexto}

El 06 de marzo de 2020 el Ministerio de Salud de la República de Colombia (2020) anuncia el primer caso confirmado de COVID-19 en el país. Desde ese momento, se activan las alarmas de alerta en todo el territorio nacional donde de manera articulada el gabinete ministerial junto a las autoridades departamentales y municipales establecen estrategias de distanciamiento social que suponen la completa reorganización del sistema socioeconómico. En este marco, el presidente de la República Dr. Iván Duque Márquez solicita que desde el lunes 16 de marzo de 2020 hasta el viernes 20 de marzo de 2020 las instituciones de educación superior desarrollen estrategias de educación virtual como medida alternativa de distanciamiento social; exigencia que tras el decreto 457 
emitido por la Presidencia de la República (2020) se vuelve obligatoria hasta el 13 de abril de 2020 y posteriormente prorrogable, por lo menos, hasta el 27 de abril de 2020 (El Tiempo, 2020).

Esta situación representa facilidad de trabajo para algunos docentes, pero serias dificultades para otros que, tal como afirman Martínez, Burbano y Burbano (2019), consideran el uso de TIC como un obstáculo en su proceso de enseñanza. En este contexto, surge el presente trabajo donde se pretende determinar en qué nivel de competencias TIC se encuentran los docentes de la Corporación Universitaria Autónoma de Nariño (Colombia), a la cual se encuentran afiliados los autores.

\section{Metodología}

Se aplica una metodología de tipo descriptiva con un diseño de campo, no experimental y transversal (Hurtado, 2010) aplicando un cuestionario entre el 23 y el 27 de marzo de 2020 a cincuenta y dos (52) docentes de la institución (error muestral 6,5\%). Para la representación de los hallazgos de utilizó la estadística descriptiva, haciendo una adaptación del modelo de nivel de competencias TIC propuesto por el Ministerio de Educación Nacional (2013).

\section{Hallazgos}

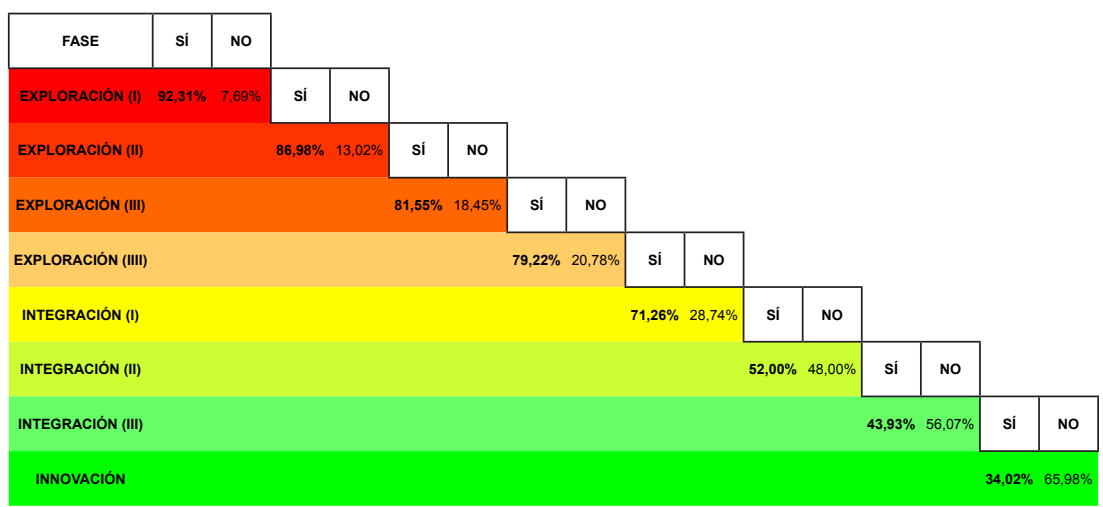

\section{Gráfico 1. Nivel de competencias TIC.}

Fuente: Elaboración propia (2020). 
Como muestra el gráfico 1, la mayor parte de los docentes encuestados $(52,00 \%)$ se encuentra en el nivel de Integración II, es decir: 1) usan las TIC por sí mismos, 2) las utilizan en sus labores cotidianas, 3) entienden las implicaciones éticas de su uso en los procesos educativos, 4) las integran de manera pertinente con el Proyecto educativo institucional, 5) combinan distintas herramientas para el diseño de ambientes de aprendizaje y 6) se consideran pioneros en adoptar nuevas ideas tecnológicas. Sólo un 34,02\% llega al nivel de Innovación donde, además de lo anterior, son capaces de 1) establecer criterios para argumentar como las TIC facilitan el aprendizaje y 2) comparte sus actividades aplicadas y las ajusta de acuerdo a la retroalimentación de sus compañeros. Estos resultados permiten orientar las estrategias futuras para el fortalecimiento de estas competencias, previendo que posiblemente el aislamiento preventivo obligatorio se extienda por un período de tiempo mayor.

\section{Rerefencias bibliográficas}

El Tiempo (2020). Siete datos claves que debe saber sobre la extensión del aislamiento, fecha 07/04/2020. Disponible en: https://www.eltiempo.com/politica/ gobierno/claves-de-ampliacion-de-cuarentena-hasta-el-29-de-abril-2020ordenada-por-ivan-duque-481782

Hurtado, J. (2010). El proyecto de investigación. Caracas: Ediciones Quirón.

Martínez, J.; Burbano, M. y Burbano, E. (2019). Obstáculos y perspectivas al emplear tecnologías de información para enseñar contabilidad. Educación y humanismo, 21(37), 104-119.

Ministerio de Educación Nacional (2013). Competencias TIC para el desarrollo profesional docente. Bogotá: Imprenta nacional.

Ministerio de Salud de la República de Colombia (2020). Colombia confirma su primer caso de COVID-19. Disponible en: https://www.minsalud.gov.co/Paginas/ Colombia-confirma-su-primer-caso-de-COVID-19.aspx

Presidencia de la República (2020). Decreto número 457. Disponible en https://dapre. presidencia.gov.co/normativa/normativa/DECRETO\%20457\%20DEL\%20 22\%20DE\%20MARZO\%20DE\%202020.pdf 


\title{
IMPACTO ENFERMEDAD COVID-19 EN LA ORGANIZACIÓN SOCIAL A PARTIR DE LA DINÁMICA Y FUNCIÓN FAMILIAR
}

\section{IMPACT OF CORONAVIRUS DISEASE 2019 (COVID-19) ON SOCIAL ORGANIZATION BASED ON FAMILY DYNAMICS AND FUNCTION}

\author{
Lesbia Rosa Tirado Amador \\ Odontóloga. Especialista en Estadística Aplicada. Profesor Escuela de \\ Odontología, Universidad del Sinú. Seccional Cartagena. Colombia. Correo \\ electrónico: lesbia.tirado@unisinu.edu.co.

\section{Carlos Arturo Leal Acosta} \\ Odontólogo. Magister en microbiología. Profesor Programa de Odontología, \\ Corporación Universitaria Rafael Núñez. Cartagena. Colombia. Correo \\ electrónico: carlos.leal@curnvirtual.edu.co.
}

\section{OBJETIVO}

Describir y analizar el impacto social de la pandemia de covid-19 a partir de la dinámica y función familiar.

\section{DESCRIPCIÓN DEL CONTEXTO}

El concepto clásico de la familia la concibe como una institución en la que se generan vínculos interpersonales que logran influir en la consolidación de la sociedad, pues impacta la formación, desarrollo e incluso la salud de los individuos mediante la transmisión de creencias, valores y pautas de comportamiento entre otros. Por ende, la estructura y función de la misma, será indispensable para actuar como factor protector de apoyo intrafamiliar.

Desde los primeros meses del año 2020, el mundo experimenta un proceso transformador a expensas de la enfermedad del coronavirus 2019 (COVID-19) que había iniciado en China y que de manera imprevista se fue extendiendo geográficamente, hasta consolidarse como pandemia tal como fue declarado por La Organización Mundial de la Salud (OMS) (El Tiempo, 2020). En respuesta a esta situación sanitaria, los gobiernos 
mundiales han optado por diversas medidas de contención y mitigación, incluyendo cierre de fronteras, distanciamiento, aislamiento social y cuarentena. En esta última, se ha propiciado la permanencia en los sitios de residencia de cada individuo, lo que implica la convivencia obligatoria con la familia inmediata. Por consiguiente, la crisis sanitaria por COVID-19 ha sometido a prueba la conformación, estructura organizacional y la funcionalidad familiar, debido a que compartir mayor cantidad de tiempo ha obligado a cada uno de sus miembros a descubrir y conocer mayor información alusiva a gustos, hábitos, vicios y manifestación de sentimientos, emociones y preocupaciones (Brooks et al., 2020). Con lo anterior, ha quedado expuesta la dimensión afectiva, emocional y mental del ser humano, misma que debido a la situación sanitaria de tensión e incertidumbre puede generar efectos negativos sobre la familia que en tiempos de pandemia puede ser un pilar para superación de los flagelos sociales derivados de la crisis mundial sanitaria.

\section{Metodología}

Mediante un método cualitativo se realiza una revisión documental hermenéutica, articulando la información de los textos consultados en concordancia con los propósitos de investigación para presentar una reflexión que permite ampliar o mostrar lo conocido y propone fundamentos de nuevo conocimiento alusivo al impacto del COVID-19 en la organización social con énfasis en los cambios experimentados en la dinámica y función familiar.

\section{Hallazgos}

La cuarentena como medida de salud pública contra COVID-19 provoca efectos a nivel sicosocial tales como síntomas depresivos, ansiedad, estrés y miedo. Estos, en un contexto de convivencia familiar obligatoria, potencian una percepción de tensión a nivel del hogar, con irritabilidad hacia las personas con las que se convive, afectando la interacción entre sus miembros y posiblemente distorsionando la misión social de la familia. Lo anterior, puede evidenciarse en los crecientes reportes de situaciones indeseables y desestabilizadoras en la organización social, incluyendo la violencia intrafamiliar, abuso sexual, aumento de consumo de drogas y alcohol entre otras. Estas prácticas finalmente degradan y fragmentan la funcionalidad familiar. 


\section{Fuentes bibliográficas}

Brooks, S. K., Webster, R. K., Smith, L. E., Woodland, L., Wessely, S., Greenberg, N., \& Rubin, G. J. (2020). The psychological impact of quarantine and how to reduce it: rapid review of the evidence. The Lancet.

Wang, C., Pan, R., Wan, X., Tan, Y., Xu, L., Ho, C. S., \& Ho, R. C. (2020). Immediate psychological responses and associated factors during the initial stage of the 2019 coronavirus disease (COVID-19) epidemic among the general population in china. International Journal of Environmental Research and Public Health, 17(5), 1729.

El Tiempo. (2020). Aislamiento por covid-19 podría aumentar violencia intrafamiliar: $O N G$. Recuperado de: https://www.eltiempo.com/justicia/servicios/ coronavirus-que-hacer-si-es-victima-de-violencia-de-genero-enaislamiento-475600 


\title{
COVID-19 Y LA EDUCACIÓN SUPERIOR EN AMÉRICA LATINA: UNA APROXIMACIÓN HACIA LOS EFECTOS SOBRE DOCENTES Y ALUMNOS Y POSIBLES RESPUESTAS
}

\author{
COVID-19 AND HIGHER EDUCATION IN LATIN \\ AMERICA: AN APPROACH TO EFFECTS ON \\ TEACHERS AND STUDENTS AND POSSIBLE \\ RESPONSES
}

Fernando Xavier Rosas Salas

Candidato a Doctor en Administración, Magister en Cs. Econ. y Adm., Master en Dirección Comercial y de Marketing, Docente de la Pontificia Universidad Católica del Ecuador (PUCE), Quito-Ecuador, Correo electrónico: fxrosass@ puce.edu.ec.

\author{
Myrian Patricia Rubio Díaz \\ Magister en Docencia Universitaria e Investigación Educativa, Docente de la \\ Pontificia Universidad Católica del Ecuador (PUCE), Quito-Ecuador, Correo \\ electrónico:mrubiod@puce.edu.ec.
}

\section{Objetivo}

Comprender los efectos del COVID-19 sobre docentes y alumnos de América Latina, desde la perspectiva de organismos internacionales vinculados con la educación superior.

\section{Descripción del contexto}

La pandemia de la COVID-19 ha generado una crisis educativa sin precedentes. Los gobiernos adoptaron medidas urgentes para asegurar el derecho de niños, jóvenes y adultos a una educación de calidad (Educación Internacional, 2020). La teleeducación ha propiciado la continuidad formativa. Algunos países de América Latina experimentaron una aminoración en la rapidez de banda ancha fija -p. ej. Ecuador (-19,6\%) y Chile (-3\%). En otros, la latencia ha aumentado. El $44,89 \%$ de la población posee un computador 
(Telecom Advisory Services LLC et al., 2020). La conectividad es el 45\% (IESALC, 2020a). Las iniciativas privadas en capacitación (p. ej. Google Clasrroom) y recursos educativos suplen la falta de plataformas tecnológicas (CAF et al., 2020).

\section{La interrupción educativa}

Desde la declaración de la pandemia el 11 de marzo por la Organización Mundial de la Salud (OMS), cerca de 1.579.634.506 alumnos, un 90,2\% del total global, han sido afectados (UNESCO, 2020). Los países de América Latina y el Caribe adoptaron el cese temporal de las actividades presenciales (IESALC, 2020), afectándose, en mayor o menor medida, su derecho a la educación superior, reflejado en el objetivo de desarrollo sostenible cuatro: "Garantizar una educación inclusiva, equitativa de calidad y promover oportunidades de aprendizaje durante toda la vida para todos" (General Assembly United Nations, 2015, p. 17).

\section{Efectos en la docencia y alumnos}

Los efectos sobre la docencia van desde la ansiedad y estrés; reticencias hacia el teleaprendizaje; problemas de adecuaciones virtuales de materias; privaciones de herramientas y recursos de apoyo tecnológio y pedagógico; carencias institucionales de servios de Internet, conectividad e infraestructuras apropiadas; dipares usos on line y accesos a la conectitividad; y, hasta despidos y mermas salariales (IESALC, 2020). La disrupción prolongada afecta a los alumnos -y aspirantes a la educación superioren condiciones vulnerables. Aflicciones sobre su cotidianidad y propio equilibrio, costes financieros, baja conectividad, desafectos y dudas acerca del modo virtual de aprendizaje y sus logros, surgen como probables impactos inmediatos y poscrisis que pueden provocar abandonos y no compleciones formativas; profundizándose la inequidad educativa.

\section{EI llamamiento a la acción sobre el profesorado y alumnos}

Los gobiernos, gestores educativos y prestamistas públicos y privados, deben involucrarse en la autentificación y sostenimiento del rol docente en la respuesta y recuperación poscrisis (Equipo Especial Internacional sobre Docentes para Educación 2030, 2020). Este "llamado a la acción" busca la protección del empleo, salarios y 
otros derechos laborales; soportes socioemocionales que aseguren la salud, seguridad y bienestar docente y estudiantil; implicación de profesores y sus instituciones en el diseño y replanteo de políticas educativas; apoyo profesional y entrenamiento tecnológico; equidad educativa a través de la disponibilidad de electricidad, conectividad, dispositivos y ambientes físicos para educadores y estudiantes, entre otras proclamas.

\section{Metodología}

El estudio fue cualitativo de revisión documental hermenéutica para, a partir de datos y documentos oficiales y fidedignos, comprender los efectos del fenómeno sobre la educación superior, desde la perspectiva de organismos internacionales vinculados con la educación superior. El análisis de discurso facilitó la interpretación y análisis de información (Hernández y Mendoza, 2018).

\section{Hallazgos}

La inexistencia de sucesos similares pasados dificulta predecir el futuro poscrisis. El corolario de la emergencia educativa es incierto: disminuciones de matrículas, deserciones, recortes públicos, cierres definitivos de universidades, entre otros. El debate puede nutrirse de los escenarios posibles, propuestos por Ehlers y Kellerman (2019): (1) el de habilidades futuras, (2) estudio multinstitucional en red, (3) "miuniversidad", (4) aprendizaje de toda la vida-. En esos contextos, la tecnología puede ser (y lo es) una respuesta temporal; no obstante, el aprendizaje y la interacción profesoralumno en el aula, serán difícilmente sustituibles. El objetivo de desarrollo sostenible sobre una educación inclusiva, equitativa, de calidad y proveedora de oportunidades de aprendizaje como un continuo, podría lograrse a través de acuerdos gobiernosuniversidades, rediseños de políticas públicas y normativas, reformulaciones de ofertas educativas y la investigación. De ahí, el apoyo por parte de la UNESCO hacia las acciones gubernamentales para ralentizar los efectos negativos inmediatos y futuros de la suspensión temporal de las actividades presenciales.

\section{Referencias bibliográficas}

CAF, CEPAL, LAW, D. P. A., \& Telecom Advisory Services Llc. (2020). Las oportunidades de digitalización en América Latina frente al COVID-19. 
1-33. https://www.un.org/en/development/desa/population/migration/ generalassembly/docs/globalcompact/A_RES_70_1_E.pdf

Educación Internacional. (2020). Principios rectores sobre la pandemia del COVID-19. 2-4. https://www.ei-ie.org/spa/detail/16701/principios-rectores-sobre-lapandemia-del-covid-19

Equipo Especial Internacional sobre Docentes para Educación 2030. (2020). Respuesta frente al brote del COVID-19. Llamado a la acción respecto a los y las docentes (pp. 1-3). http://www.teachersforefa.unesco.org/v2/index.php/en/ ressources/file/472-respuesta-frente-al-brote-del-covid-19-1lamado-a-laaccion-respecto-a-los-y-las-docentes

General Assembly United Nations. (2015). Transforming our world: the 2030 Agenda for Sustainable DEvelopment. International Organization. https://doi. org/10.1017/S0020818300007827

Hernández, R., \& Mendoza, C. (2018). Metodología de la investigación (McGraw-Hill Education (ed.); 1era.). Edamsa Impresiones, S.A. de C.V.

IESALC. (2020). COVID-19 y educación superior: De los efectos inmediatos al día después. Análisis de impactos, respuestas políticas y recomendaciones. http:/www.iesalc.unesco.org/wp-content/uploads/2020/04/COVID-19060420-ES-2.pdf

IESALC. (2020). COVID-19 y educación superior: políticas públicas nacionales.

Telecom Advisory Services LLC, Katz, R., Jung, J., \& Gallorda, F. (2020). El estado de la digitalización de América Latina frente a la pandemia del COVID-19. https://es.unesco.org/covid19/educationresponse 


\title{
MEDIDAS ECONÓMICAS PARA LOGRAR LA REACTIVACIÓN DE LA ECONOMÍA COLOMBIANA ANTE LA PANDEMIA DE LA COVID-19
}

\author{
ECONOMIC MEASURE TO ACHIEVE THE \\ REACTIVATION OF THE COLOMBIAN ECONOMY IN \\ THE FACE OF THE COVID-19 PANDEMIC
}

\author{
Walter Serna Borja \\ Magister en Economía. Docente medio tiempo en la Corporación Universitaria \\ Autónoma de Nariño y Docente de cátedra en la Fundación Universitaria \\ Católica Lumen Gentium. Santiago de Cali, Colombia. Correo electrónico: \\ wasebo76@gmail.com.
}

\section{César Alveiro Trujillo Solarte}

Especialista en Gerencia pública para el desarrollo social. Docente en la Universidad del Cauca y en la Universidad del Valle. Santiago de Cali, Colombia. Correo electrónico de contacto: cats_ingenieria@hotmail.com.

\section{Objetivo}

Proponer medidas que pueden ser usadas para reactivar la actividad económica en Colombia ante la pandemia actual de la COVID-19.

\section{Descripción del contexto}

Colombia hoy se enfrenta a uno de sus más grandes retos evitar la propagación de una pandemia que se inició en China a finales del 2019. Esta infección respiratoria pertenece a la familia del coronavirus el cual ha sido identificado con las siglas en inglés COVID-19, localizado en la provincia de Wuhan (Trilla, 2020). Debido a la consecuente declaratoria de pandemia por parte de la Organización Mundial de la Salud, en Colombia el presidente de la República Dr. Iván Duque Márquez junto al ministro Dr. Fernando Ruiz Gómez a través del Ministerio de Salud y Protección social (2020) informan que a partir del 23 de marzo de 2020 se inicia la medida de confinamiento preventivo nacional con el fin de combatir el contagio y propagación del COVID-19. 
Esta medida trae consigo implicaciones a la economía que impactan en el desempeño de todos los sectores económicos del país.

\section{Metodología}

Se aplica una metodología hermenéutica fundamentada en los informes emitidos por parte de organismos públicos con competencia en asuntos sanitarios, así como en artículos científicos y de opinión que han sido publicados a medida que esta situación adquiere relevancia en el interés de investigadores que intentan explicar su comportamiento y efectos en los distintos campos de la sociedad.

\section{Hallazgos}

La historia ha mostrado que los países que cuentan con un mejor sistema público de atención a sus ciudadanos y mejores instituciones son los que pueden salir mejor librados de todo tipo de crisis ya sean económicas o sociales. El Estado está concebido para intervenir en la economía cuando esta por sí sola no sea capaz de lograr su dinamismo; es aquí donde se requiere de este una fortaleza que sea capaz de movilizar los recursos hacia los sectores económicos que lo requieran.

En este caso se debe mostrar un interés especial hacia el sector de la salud, pero también se hace necesario diseñar una serie de estrategias que vayan encaminadas a lograr reactivar el dinamismo de la actividad económica. La crisis generada por esta pandemia nos puede llevar a una crisis financiera y económica que afectará a todo el sector empresarial del país donde sufrirán las grandes, pequeñas y medianas empresas. El impacto en cada una dependerá de su flujo de caja para enfrentarla y permanecer en funcionamiento.

Dentro de esta política se considera necesario implementar las siguientes estrategias para reactivar la actividad económica:

i) Crear un subsidio a las personas que trabajan en la economía informal ya que, en el país la proporción de las personas ocupados en la economía informal es del 46,7\% (Departamento Administrativo Nacional de Estadística, 2020). Con esta problemática 
sus ingresos tendrán una disminución considerable, situación que afectará de manera directa la demanda y el consumo de los hogares y la economía en general.

ii) Concientizar al sistema financiero que el país necesita de su ayuda, colocando créditos a todas las empresas que necesiten recursos a tasas que estén entre el $6 \%$ y $7 \%$ anual, esto permitiría que fueran fáciles de pagar y tendrían una alta probabilidad de cumplimiento.

iii) Disminución de algunos impuestos de manera temporal con el objetivo de brindar liquidez a las familias y empresas para así incentivar la demanda, el consumo y la producción.

iv) Intervención del Estado en el mercado con el fin de garantizar el suministro de alimentos y ejercer control sobre los precios de estos para que todas las personas tengan acceso a ellos.

\section{Referencias bibliográficas}

Departamento Administrativo Nacional de Estadística (2020). Mercado Laboral. Recuperado de: https://www.dane.gov.co/index.php/estadisticas-por-tema/ mercado-laboral/empleo-informal-y-seguridad-social

Ministerio de Salud y Protección social 2020). "Serán 19 días muy importantes para frenar la incidencia de la COVID-19". Recuperado de: https://www. minsalud.gov.co/Paginas/Seran-19-dias-muy-importantes-para-frenar-laincidencia-de-la-COVID-19.aspx

Trilla, A. (2020). Un mundo, una salud: la epidemia por el nuevo coronavirus COVID-19. Medicina Clínica, 154, 175-177. DOI:10.1016/j.medcli.2020.02.002 


\title{
INVERSIÓN EN CAPITAL HUMANO EN LA MANUFACTURA INTERMEDIA, DE LA INDUSTRIA AUTOMOTRIZ HONDUREÑA, Y EL EFECTO DEL COVID-19
}

\author{
INVESTMENT IN HUMAN CAPITAL IN \\ INTERMEDIATE MANUFACTURING, IN THE \\ HONDURAN AUTOMOTIVE INDUSTRY, AND THE \\ EFFECT OF COVID-19
}

\section{Mario Sosa-González}

Doctorando en Dirección Empresarial, Universidad Nacional Autónoma de Honduras. Académico Universidad Metropolitana de Honduras, Honduras. Correo electrónico: mario.sosa@umh.edu.hn.

\section{Ángel Acevedo-Duque}

Post-Doctor en Gerencia Pública y Gobierno, y Doctor en Ciencias Gerenciales, Universidad Dr. Rafael Belloso Chacín. Universidad Autónoma de Chile. Correo electrónico: angel.acevedo@uautonoma.cl, Pedro de Valdivia, 425 Providencia - Santiago, Chile.

\section{Objetivo}

Valorar el posible impacto que recibirá Honduras en el periodo de tiempo de esta Emergencia Nacional por SARS-CoV-2 (COVID-19) con respecto al clúster de manufactura intermedia y en industrias a fin, para que esta información pueda ser utilizada durante las estrategias de las distintas instituciones asignadas con el abordaje de esta problemática de salud pública, así como también sea de utilidad al público en general.

\section{Descripción del Contexto}

El 31 de diciembre de 2019 la Comisión Municipal de Salud y Sanidad de Wuhan (provincia de Hubei, China) reportó un clúster misterioso de casos de neumonía, todos aparentemente ligados a un mercado mayorista de mariscos en el sur de China OMS (2020). Posteriormente se denominó a esta enfermedad como SARS-CoV-2 o COVID-19; un coronavirus de alto grado de contagio. Este virus se esparció rápidamente por todo el 
mundo y ahora es considerado como una pandemia que afecta al planeta entero, aún sin vacuna y sin una cura oficial.

Sinager (2020) da a conocer el primer caso de este virus registrado en Honduras desde el 10 de marzo, el crecimiento de los casos ha continuado día con día hasta la fecha. Al día de hoy 22 de abril existen 510 casos registrados 46 fallecidos y 30 recuperados. Se mantiene decretado un Estado de Emergencia Nacional y con toque de excepción en la zona norte departamentos de Cortes que es el epicentro de la pandemia, Yoro y Colon han tomado toda una gama de medidas y estrategias por parte del Gobierno y la población para disminuir la propagación de la enfermedad.

\section{Metodología}

El aspecto metodológico abordado en este estudio será de carácter descriptivo y documental, ya que permitirá el Branding Responsable como aproximación estratégica a las acciones sociales de las organizaciones chilenas. Es por ello que, Danhke, (citado por Hernández et al., 2006), refiere que los estudios de tipo descriptivos buscan especificar las propiedades, las características y los perfiles de personas, grupos, comunidades, procesos, objetos o cualquier otro fenómeno que se someta a un análisis. Es decir, miden, evalúan o recolectan datos sobre diversos conceptos (variables), aspectos, dimensiones o componentes del fenómeno a investigar.

\section{Hallazgos}

La emergencia sanitaria ha obligado a cerrar temporalmente operaciones de las empresas tales como Novem de Honduras, Comtronic, Delphi y Empire Electronics Honduras (2020) esta última cerrando sus operaciones en el país ubicada en el departamento de Cortes en la ciudad de San Pedro Sula epicentro de la pandemia en Honduras con 365 casos confirmados.

Después de semanas de encierro obligatorio, nos preguntamos ahora, cuál es el plan para responder a la incertidumbre de más de 9 millones de hondureños debilitados por otro tipo de factores principalmente económicos. Según la CEPAL (2019) en Honduras alrededor de un $60 \%$ de la población vive en condiciones de pobreza, aliviada por 
las remesas familiares que representan un $41.4 \%$ del ingreso total de las divisas del país, superando por mucho, lo que se capta por exportaciones, servicios y clústeres maquiladores.

\section{Referencias bibliográficas}

Comisión Económica para América Latina y el Caribe, CEPAL. (2019). Informe Panorama Social de América Latina. Santiago de Chile: CEPAL.

Empire Electronics Honduras. (2020). Comunicado de Suspencion de Labores. Para Todos los Empleados Empire of Honduras, S.A (pág. 1). San Pedro Sula : Empire Electronics Honduras.

Hernández, Fernández y Baptista (2006) Principios de la Metodología de la Investigación. Editorial Limusa. México.

Paul, A. (2020). El Reinicio Corona. La Tempestad .

Ramírez, T. (2010), Como hacer un proyecto de Investigación”. Caracas - Venezuela. Editorial Panapo de Venezuela, C.A

Salud, Organizacion Mundial de la OMS . (2020). Prevención y control de infecciones en los centros de atención de larga estancia en el contexto de la COVID-19. Ginebra Suiza: CC BY-NC-SA 3.0 IGO.

SINAGER. (2020). covid19honduras.org. Recuperado el 7 de Abril de 2020, de copeco. gob: https://covid19honduras.org/?q=comunicados

Silva, J. (2006), Metodología de la Investigación. Elementos Básicos. CaracasVenezuela, Ediciones CO-BO 


\title{
LA EVOLUCIÓN EDUCATIVA MEXICANA, ANTES Y DESPUÉS DEL COVID-19: UNA TRANSFORMACIÓN EMERGENTE
}

\author{
THE MEXICAN EDUCATIONAL EVOLUTION, \\ BEFORE AND AFTER COVID-19: AN EMERGING \\ TRANSFORMATION
}

\section{Martín Cano Contreras}

Doctor en Ingeniería Eléctrica. Docente Investigador de la Universidad Tecnológica del Suroeste de Guanajuato, México. Correo electrónico: mcano_ cco@utsoe.edu.mx.

\section{María Susana Acosta Navarrete}

Doctora en Ingeniería Bioquímica. Docente Investigador de la Universidad Tecnológica del Suroeste de Guanajuato, México. Correo electrónico: msacosta@utsoe.edu.mx.

\section{Héctor Cuevas Vargas}

Doctor en Ciencias de la Gestión, Docente Investigador de la Universidad Tecnológica del Suroeste de Guanajuato, México. Correo electrónico: hcuevas@ utsoe.edu.mx

\section{Objetivo}

Mostrar los cambios en el paradigma de la educación tradicional para continuar y terminar el ciclo presente y esperar nuevo aviso para reanudar actividades regulares.

\section{Descripción}

En México, hasta el 30 de abril del 2020, se reporta un acumulado de 1,859 muertes y 19,224 infectados (Universal, 2020). Para el sector productivo, de servicios y los sistemas educativos este acontecimiento ha obligado a realizar cambios en todos sus procesos. Por instrucción de las autoridades a permanecer en casa el mayor tiempo posible para evitar el incremento de contagios entre la población. Entre otros puntos para lograrlo, de acuerdo con (Infobae, 2020) se consideró las reuniones públicas con menos de 100 participantes, resguardar a los adultos mayores y sobre proteger a enfermos. En el caso del sector educativo, la encomienda fue la suspensión de clases presenciales, 
dejando la tarea a las autoridades educativas buscar alternativas para continuar y terminar el ciclo presente y esperar nuevo aviso para reanudar actividades regulares. Se tiene la tarea ante una infra-estructura escasa o incluso inexistente en varios centros educativos, modificando los gastos familiares por uso de internet o "de datos personales".

\section{Metodología}

De acuerdo con el Instituto Federal de Telecomunicaciones (IFT 2, 2020), organismo público federal mexicano y los datos de la encuesta septiembre - diciembre 2019 en los gráficos 1 y 2 se muestran los patrones de consumo (IFT, 2020).

\section{Hallazgos}

En comunicado del 03 de enero del 2020, donde la Secretaría de Hacienda y Crédito Público (SHCP) notificaba las nuevas reglas de operación para las plataformas digitales en vigor para el año 2020, buscando la recaudación de impuestos por parte de las mismas (México, 2020). Se esperaba una disminución de los servicios digitales ofertados por tales operadoras (Belén, 2020).

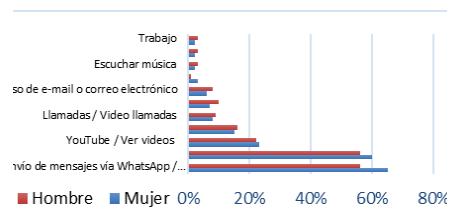

Gráfico 1. Usos principales del dispositivo móvil.

Fuente: Instituto Federal de

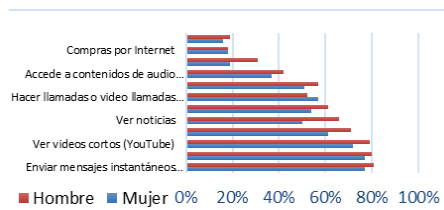

Gráfico 2. Usos principales del internet fijo.

Fuente: Instituto Federal de Telecomunicaciones (2020b).

Se preveía se tuviese una ligera disminución por parte de los proveedores. A partir del anuncio del 12 de marzo del 2020, donde todos los sectores deberán reducir o suspender operaciones, los patrones en el uso del internet aumentaron a más del $40 \%$ (Arias, 2020), considerando que la infraestructura de los proveedores no soportarían la demanda (Abarza, 2020), (Net, 2020), como se puede observar en los gráfico 3 y 4. 


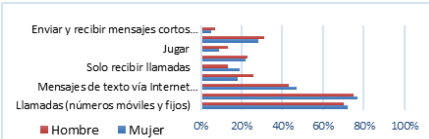

Gráfico 3. Usos principales del dispositivo móvil. Encuesta ene-abr 2020.

Fuente: (IFT 2, 2020).

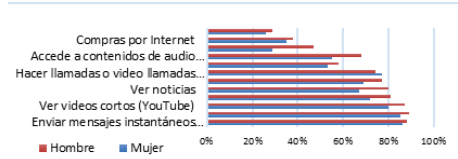

Gráfico 4. Usos principales del internet fijo por género de usuario. Encuesta ene-abr 2020.

Fuente: (IFT 2, 2020).

La demanda de internet se ha incrementado por las restricciones a la población por cuestiones de seguridad y se han visto forzadas a trabajar y estudiar desde los hogares y así evitar la propagación del Covid-19. El incremento no refleja una hora pico de consumo en los servicios; éstos son de manera continua.

\section{Referencias bibliográficas}

Abarza, F. (20 de 04 de 2020). Coronavirus Covid-19. (BeeTrack) Recuperado el 20 de 04 de 2020, de https://www.beetrack.com/es/blog/coronavirus-aumentodemanda-online-delivery

Arias, A. (20 de 04 de 2020). Crece 40\% demanda. (Heraldo de México) Recuperado el 20 de 04 de 2020, de https://heraldodemexico.com.mx/mer-k-2/cuarentenapandemia-coronavirus-saturacion-internet-covid-19/

Belén, S. (22 de 04 de 2020). El Economista. (El Economista) Recuperado el 22 de 04 de 2020, de https://www.eleconomista.com.mx/sectorfinanciero/Prevendisminucion-en-la-demanda-de-servicios-digitales-por-cambios-fiscalesen-2020-20191222-0040.html

IFT, 2. (21 de 04 de 2020). Trimestrales. Obtenido de http://www.ift.org.mx/usuarios-yaudiencias/encuestas-trimestrales

Infobae. (25 de 03 de 2020). México. Medidas adoptadas. Obtenido de https:// www.infobae.com/america/mexico/2020/03/25/estas-son-las-medidas- 
preventivas-adoptadas-por-el-gobierno-federal-ante-la-evolucion-delcovid-19-a-la-fase-2/

México, B. (21 de 04 de 2020). Boletín Fiscal: Enero 2020. (Global Network) Recuperado el 21 de 04 de 2020, de https://www.bdomexico.com/es-mx/ publicaciones/boletines-fiscales/1a-quincena-de-enero-2020

Net, S. D. (20 de 04 de 2020). Coronavirus sobrecarga de tráfico. (Sci Dev Net) Recuperado el 20 de 04 de 2020, de https://www.scidev.net/america-latina/ salud/noticias/coronavirus-sobrecarga-trafico-de-datos-en-america-latina. html

Universal, E. (30 de 04 de 2020). Los 10 municipios con más fallecimientos. Obtenido de https://www.eluniversal.com.mx/estados/coronavirus-1-de-mayo-los-10municipios-de-mexico-con-mas-muertes-por-covid-19 


\title{
IMPACTO DEL COVID-19 SOBRE LA INDUSTRIA DEL CAFÉ EN EL TOLIMA, COLOMBIA \\ IMPACT OF COVID-19 ON THE COFFE SECTOR IN THE TOLIMA STATE, COLOMBIAN REGION
}

\author{
Yeimy Mireya Cuellar Medina \\ Estudiante de Ingenieria de Sistemas, Corporación Universitaria Remington, \\ correo electrónico: yeimy.cuellar.4463@miremington.edu.co.
}

\section{Objetivo}

Analizar desde una perspectiva crítica el modelo económico que representa la producción del café en el departamento del Tolima y el efecto que está presentado por el COVID-19.

\section{Ddescripción del contexto}

El Tolima es uno de los 32 departamentos que tiene Colombia, y cuenta con 1427 984 de habitantes, las dinámicas económicas tradicionales están basadas principalmente en la agricultura y el comercio. Según la secretaría de salud, el Tolima posee un total de 40 casos infectados por el covid-19, de los cuales 36 son casos presentados en el municipio de Ibagué y 3 en Espinal, 1 en Melgar; el alcalde del municipio de Ibagué recalcó la importancia de quedarse en casa, de cumplir con la cuarentena para así mismo poder evitar el riesgo de contagio y propagación. El comercio esta desacelerado por el aislamiento preventivo decretado por el gobierno, ocasionando el cierre temporal de pequeñas y grandes empresas. En relación con la agricultura, la recolección del café también se ha visto afectada puesto que no hay recolectores suficientes y se podría perder la cosecha.

\section{Metodología}

La investigación se desarrolló bajo el enfoque cualitativo el cual trata de identificar la naturaleza profunda de las realidades, su estructura dinámica aquella que da razón plena de sus comportamientos y manifestaciones (Martínez 2012), se aplicó el análisis documental. 


\section{Hallazgos}

Según cifras del Comité Nacional de Cafeteros, el Tolima tiene 38 municipios cafeteros, 70516 fincas dedicadas a producir grano y unas 110169 hectáreas sembradas en café de las 377148 hectáreas disponibles para la agricultura. La actividad cafetera les brinda sustento a más de 61506 familias que realizan la caficultura en 1287 veredas. El Tolima reporta un área promedio de café por hectárea de 1,56; es decir una caficultura basada en pequeños y medianos productores, teniendo en cuenta que también es el tercer productor de café a nivel nacional. Debido a la pandemia, los productores se encuentran a la deriva al no conseguir los trabajadores suficientes para su recolección; Desde la Gobernación, se ha pedido un esfuerzo entre las comunidades para contratar las personas que recolecten el café y no producir pérdidas, una tarea bastante difícil debido a que los tiempos de maduración del café varían entre finca y finca y existen picos de producción donde se requiere más personal. Además, existe otro aliciente, la carga de café está a $\$ 1$ 222 000, siendo una motivación para los caficultores y para la economía en Colombia.

La Federación Nacional de Caficultures (FNC) público que el café es una de las excepciones, en las medidas que se toman en la cuarentena siempre y cuando se cumpla los reglamentos de higiene en los trabajadores y que conserven una respectiva distancia.

En algunos sectores como el municipio de Planadas, que es una de las regiones más productivas del grano, los caficultores toman sus respectivas medidas entre los trabajadores, cumpliendo con las normas reglamentarias, realizando protocolos de limpieza y desinfección de los trabajadores, El líder y representante de Dignidad Cafetera y Agropecuaria, Fredy Mosquera manifestó que los municipios más afectados por falta de mano de obra son: Dolores, Rovira, Palocabildo, Anzoátegui entre otras.

Según las cifras que muestra la FNC la producción de café en Colombia cae en un $12 \%$ y la exportación en un $21 \%$ en el mes de marzo. 
Tabla 1. Producción y exportación de café Colombia.

Producción de café - Mar 2020

(Sacos $60 \mathrm{~kg}$ )

\begin{tabular}{|l|r|}
\hline Marzo 2020 & $\mathbf{8 0 6 . 0 0 0}$ \\
\hline Marzo 2019 & 914.000 \\
\hline Variación & $\mathbf{- 1 2 \%}$ \\
\hline
\end{tabular}

Exportación de café - Mar 2020 (Sacos $60 \mathrm{~kg}$ )

\begin{tabular}{|c|r|}
\hline Marzo 2020 & 903.000 \\
\hline Marzo 2019 & 1.141 .000 \\
\hline Variación & $\mathbf{- 2 1 \%}$ \\
\hline
\end{tabular}

Exportación de café - Últimos 12 meses (Sacos $60 \mathrm{~kg}$ )
Producción de café - Año corrido (Sacos $60 \mathrm{~kg}$ )

\begin{tabular}{|l|r|}
\hline Ene-Mar 2020 & 2.857 .000 \\
\hline Ene-Mar 2019 & 3.316 .000 \\
\hline Variación & $\mathbf{- 1 4 \%}$ \\
\hline
\end{tabular}

Exportación de café - Año corrido (Sacos $60 \mathrm{~kg}$ )

\begin{tabular}{|l|r|}
\hline Ene-Mar 2020 & 3.046 .000 \\
\hline Ene-Mar 2019 & 3.553 .000 \\
\hline Variación & $\mathbf{- 1 4 \%}$ \\
\hline
\end{tabular}

Exportación de café - Año cafetero (Sacos $60 \mathrm{~kg}$ )

Fuente: Federación Nacional de Caficultures (2020).

En este escrito se expuso el tema del café y de la importancia en la economía que este presenta, el estudio fue basado en artículos, noticias, que involucran al tema del café en esta época del coronavirus, obteniendo como resultado, preocupación por falta de recolectores, pero también se plantea soluciones para no perder la cosecha, siguiendo las normas de higiene establecidas por la FNC, todo esto con el fin de que no afecte mucho la economía y a las familias campesinas que viven de ello.

\section{Referencias bibliográficas}

Caracol Radio, 13 de abril año 2020, "falta de recolectores del cafè se reporta en el Tolima" Caracol Radio. https://caracol.com.co/emisora/2020/04/14/ ibague/1586819530_712467.html

Comité Nacional de Cafeteros, 2020, "producción de cafè de colombia cae un 12\%", Comité Nacional de Cafeteros. https://federaciondecafeteros.org/wp/listadonoticias/produccion-de-cafe-de-colombia-cae-12-en-marzo/

Comité Nacional de Cafeteros, 2020," protocolo covid-19 para caficultores" Comité Nacional de Cafeteros. https://federaciondecafeteros.org/wp/blog/todos-loscaficultores-a-cuidarnos/ 
Germán Enrique Núñez, 2019, “cuerpo y acidez, café enorme que produce el Tolima grande", Diario la economia. https://diariolaeconomia.com/tomemos-cafe/ item/4632-aroma-cuerpo-y-acidez-cafe-enorme-que-produce-el-tolimagrande.html

Martínez, M. (2012). Nuevos fundamentos de la investigación cientifica. México. Trillas.

Samuel Barreto Bonilla, 25 de marzo 2020, “ en riesgo cosecha cafetera en el Tolima por el coronavirus", Alerta Tolima https:/www.alertatolima.com/noticias/ judicial/en-riesgo-la-cosecha-cafetera-en-el-tolima-por-el-coronavirus 


\section{IMPACTO DE LA RSE EN COLOMBIA ANTE LA PRESENCIA DEL CORONA VIRUS (COVID-19)}

\section{THE CSR IN COLOMBIA IMPACT, IN THE FACE OF THE COVID-19 PANDEMIC}

\section{Paula Andrea Jaramillo García}

Estudiante Administración de Empresas, Semillero SIEMCUR y Joven Investigadora Uniremington. Colombia correo electrónico: paula. jaramillo.0086@miremington.edu.com

\section{Feibert Alirio Guzmán Pérez}

Profesor investigador del Grupo de Investigación Mundo Organizacional, maestría en Ciencias de la Educación, Par académico de Colciencias. Colombia, correo electrónico: feibert.guzman@remingtonedu.onmicrosoft.com

\section{Leibniz Huxlay Flórez Guzmán}

Profesor investigador del Grupo de Investigación Miguelanense, MBA(e), Mgr(e) en Gestión de los Recursos Humanos. leibniz.florez@hotmail.com

\section{Objetivo}

Mostrar la tipología de responsabilidad social que están usando las empresas colombianas que apoyan al estado en la contingencia causada por el COVID-19.

\section{Descripción del contexto}

El COVID-19 generó en el mundo problemas de aumento en las brechas de pobreza, aumento de necesidades básicas y desespero a las comunidades menos favorecidas, mismas que cuentan con el dinero que ganan día a día y que se encuentran en el límite de la brecha de pobreza establecida por la ONU. A este panorama oscuro se presenta una luz, aquella ocasionada por las acciones de Responsabilidad Social que están haciendo las organizaciones colombianas y que buscan mitigar los impactos que sobre estas poblaciones está generando la pandemia, la cual asciende actualmente a más del $27 \%$ del total de la población (DANE, 2019). 


\section{Metodología}

La investigación es de corte descriptiva-explicativa, las fuentes de información fueron diarios, revistas especializadas, información recolectada en las páginas de los ministerios y en las páginas web de las empresas objeto de investigación. Como muestra se eligieron las 7 empresas colombianas que han aportado en mayor cuantía al país.

\section{Hallazgos}

En Colombia existen una cantidad de empresas y organizaciones acogidas a la Responsabilidad Social Empresarial, quienes, en su compromiso ético, se vincularon en su mayoría a las donaciones que benefician a personas de todo el país. Empresas como Asocaña, del sector agroindustrial entregó sus donaciones a los gobernantes de cerca de 9 departamentos, así mismo, Unilever Colombia, Grupo Familia, Grupo Nutresa, Colanta, Interrapidísmo, Unilever, Sony Corporation entre otras, con su gama de productos se unen a las donaciones para ser dispersas en todo el país. Por otra parte, Corona, Homecenter y Falabella, invierten en el sector salud y Fundación Santo Domingo los destina a salud, bienestar y alimentación.

Tabla 1. Caracterización de las empresas donantes en Colombia.

\begin{tabular}{|c|c|c|c|}
\hline EMPRESA & OBJETO SOCIAL & $\begin{array}{l}\text { ACTIVIDAD } \\
\text { ECONÓMICA }\end{array}$ & DONACIÓN \\
\hline Asocaña & Agroindustrial & Industria & 395.000 lts alcohol \\
\hline Unilever Colombia & Comercialización & Industria & 196 toneladas productos \\
\hline Grupo Nutresa & Comercialización & Industria & $\begin{array}{l}216.500 \text { mercados y dinero para } \\
\text { aumentar la capacidad de los } \\
\text { servicios de salud }\end{array}$ \\
\hline Grupo Familia & Comercialización & Industria & $\begin{array}{c}5^{\prime} 000.000 \text { toneladas toallas } \\
\text { higiénicas }\end{array}$ \\
\hline $\begin{array}{c}\text { Corona, Homecenter, } \\
\text { Falabella }\end{array}$ & Construcción & Industria & \$ 1'000 Millones \\
\hline Colanta & Agro & Industria & 215 toneladas \\
\hline Fundación Santo Domingo & Varios sectores & Industria & $\$ 100.000$ Millones \\
\hline Inter-rapidísimo & Mensajería & Servicios & 4.000 mercados a adultos mayores \\
\hline Unilever & Jabones & Industria & $\begin{array}{c}50.000 \mathrm{~kg} \text { de detergente a las } \\
\text { SS. SS }\end{array}$ \\
\hline Sony Corporation & Electrónica de consumo & Industria & U\$100 millones (fondo global) \\
\hline
\end{tabular}

\footnotetext{
Fuente: El Espectador, (2020).
} 
De esta manera, es evidente que la responsabilidad social empresarial evocada en tiempo de Coronavirus, es un tema más allá de la normatividad, en donde todos los sectores económicos están comprometidos voluntariamente con esta buena causa, desde la perspectiva filantrópica o discrecional tal como lo plantea Carroll (1999).

\section{Referencias bibliográficas}

Asocaña. (06 de Abril de 2020). Asocaña. Recuperado el 23 de Abril de 2020, de Ya son 9 departamentos y Fuerza pública del país los beneficiados por el alcohol donado por los ingenios azucareros de Colombia.: https://www.asocana.org/ Default.aspx

El Colombiano. (08 de Abril de 2020). El Colombiano. Recuperado el 23 de Abril de 2020, de Tres frentes de donación con el sello de Santo Domingo: https://www. elcolombiano.com/coronavirus-buenas-noticias-en-colombia-y-antioquia/ tres-frentes-de-donacion-con-el-sello-de-santo-domingo-AM12781364

El Espectador. (19 de abril de 2020). Más de 10 empresas se suman para brindar ayudas a afectados por coronavirus. Recuperado el abril de 2020, de Donación de mercados y millonarios recursos, entre las ayudas anunciadas: https://www. elespectador.com/coronavirus/mas-de-10-empresas-se-suman-para-brindarayudas-afectados-por-coronavirus-articulo-912833

Semana. (18 de Abril de 2020). Semana. Recuperado el 23 de Abril de 2020, de Solidaridad en tiempos de crisis: la donaciones empresariales: https://www. semana.com/economia/articulo/cuales-son-las-donaciones-empresarialesque-se-han-hecho-por-el-coronavirus/664345 


\title{
AGUDIZACIÓN DE LA VIOLENCIA INTRAFAMILIAR POR EL COVID-19. EL CASO DE LA CIUDAD DE MEDELLÍN, COLOMBIA
}

\author{
UNCOVER THE INCREASE IN INTRA- \\ FAMILY VIOLENCE FROM THE MANDATORY \\ CONFINEMENT ORIGINATED IN THE COVID-19 \\ PANDEMIC IN THE CITY OF MEDELLÍN, \\ COLOMBIA
}

\section{Elvigia Cardona Zuleta}

Magíster en Educación de la Universidad de Antioquia, Colombia, profesora de la Universidad Católica Luis Amigó, Colombia. Correo electrónico: elvigia. cardonazu@amigo.edu.co.

\section{María Isabel Uribe López}

Magíster en Educación de la Universidad de Antioquia, Colombia, profesora de la Universidad Católica Luis Amigó, Colombia. Correo electrónico: maria. uribeop@amigo.edu.co.

\section{Objetivo}

Develar el incremento de la violencia intrafamiliar a partir del confinamiento obligatorio originado en la pandemia Covid-19 en la ciudad de Medellín, Colombia.

\section{Descripción del contexto}

Medellín es la capital del departamento de Antioquia, Colombia, según cifras de 2019 el 53\% de sus habitantes son mujeres. Realizo especial hincapié en ello, debido a que las mujeres son quienes de manera desproporcionada se ven afectadas por la violencia intrafamiliar, derivado de prejuicios y estereotipos sobre los roles, preferencias sexuales y comportamientos socialmente creados al interior de la familia, que se traducen en diversas violencias, tales como: física, psicológica, verbal, sexual, económica, simbólica y estructural. En Colombia la cuarentena obligatoria inició el 20 de marzo de 2020.

En esta situación de pandemia derivada del Covid-19, UN Women realiza un llamado de atención puesto que la violencia intrafamiliar ha aumentado en el mundo la 
coexistencia forzada debido a cuarentenas, estrés económico, inseguridad alimentaria y temores sobre el virus, ponen en mayor desventaja a mujeres y niñas que asumen roles de cuidadoras informales y al mismo tiempo proveedoras. (UN Women, 2020).

\section{Metodología}

Se recurre a la investigación cualitativa, a partir de la estrategia de revisión documental de los informes nacionales provenientes de la Fiscalía General de la Nación, contrastada con lo informado por la Secretaría de las Mujeres en Medellín.

Tabla 1. Fiscalía General de la Nación - Denuncias Violencia intrafamiliar.

\begin{tabular}{cccccccccc} 
Mes & $2019-1$ & $2019-2$ & $2019-3$ & $2019-4$ & $2019-5$ & $2019-6$ & $2019-7$ & $2019-8$ & $2019-9$ \\
Denuncias & 6.020 & 5.926 & 6.498 & 5.809 & 6.986 & 6.461 & 8.786 & 8.829 & 9.252 \\
\hline Mes & $2019-10$ & $2019-11$ & $2019-12$ & $2020-1$ & $2020-2$ & $2020-3$ & & & \\
\hline Denuncias & 8.386 & 7.956 & 7.531 & 8.078 & 7.842 & 2.236 & & & \\
\hline
\end{tabular}

Fuente: Elaboración propia a partir de los datos disponibles enhttps://www.fiscalia.gov.co/colombia/gestion/estadisticas/delitos/ - 25 de abril de 2020.

\section{Hallazgos}

Los datos revisados permiten señalar lo siguiente: 1. Una aparente tendencia a la baja en las denuncias realizadas por el delito de Violencia Intrafamiliar, puesto que en 2019 se presentaron 88 440, con un promedio mensual de 7370 denuncias, mientras que para los meses de enero de 2020 se presentan 8.078, en febrero 7842 y en marzo 2236 , mostrando una reducción del $71.48 \%$ respecto al mes anterior. Se infieren dificultades de las mujeres para acceder a denunciar los casos al estar confinadas con su victimario, más que superación de esta situación por una política clara de prevención y atención del Estado. 2. Las dificultades para acceder a los datos desagregados por municipio, sexo, edad, no permiten establecer las cifras oficiales para el municipio de Medellín, sin embargo, al contrastarlos con lo informado por la Secretaría de las Mujeres, frente a la línea de atención 123 Mujer puede observarse un incremento, según lo reportado entre el 20/marzo y el 12/abril: "recibió 1177 llamadas en las que se reportaron 234 casos de agresiones físicas, 86 de violencia psicológica, 16 de abusos sexuales, 13 de violencia sociopolítica, 1 de violencia económica y 1 feminicidio ocurrido el 12 de abril 
en el barrio Santa Cruz. Los principales agresores son las parejas, con 156 casos; las exparejas, con 78; familiares, 45; hijos, 28; desconocidos, 13; conocidos sin trato, 8; amigos o amigas, 9; vecinos o vecinas, 8 y 7 de padre o madre." (Secretaría de las Mujeres) Así mismo, se incrementaron el número de líneas telefónicas y programas dirigidos a la atención de las mujeres víctimas de violencia, liderados por organizaciones de mujeres.

\section{Referencias bibliográficas}

Fiscalía General de la Nación (2020) [Página Web] https://www.fiscalia.gov.co/ colombia/gestion/estadisticas/delitos/

Municipio de Medellín. Secretaría de las Mujeres (2020) [Página Web] https://www. medellin.gov.co/portal_mujeres/\#

UN WOMEN (2020) The Impact of Covid-19 on Gender Equality in the Arab Region. https://www.unescwa.org/sites/www.unescwa.org/files/20-00131_gpid_pb_ eng_apr5.pdf 


\title{
EFECTOS VINCULANTES POST COVID-19: UNA MIRADA GLOBALIZANTE
}

\section{BINDING EFFECTS POST COVID-19: A GLOBALIZING LOOK}

\author{
Judeira Batista \\ Universidad de La Guajira, Colombia. Correo electrónico: jjbatista@uniguajira. \\ edu.co.

\section{Judith Batista} \\ Universidad del Zulia, Venezuela. Correo electrónico: jbatista80@gmail.com.

\section{Edison Perozo \\ Universidad de la Guajira, Colombia. Correo electrónico: eeperozom@ uniguajira.edu.co.}

\section{Objetivo}

Analizar, desde una perspectiva globalizante, los efectos sociales, económicos y tecnológicos producidos a nivel mundial post Covid-19, con base en el informe emitido por la Comisión Económica para América Latina y el Caribe (CEPAL) de abril 2020.

\section{Descripción del contexto}

A nivel mundial, la pandemia COVID-19 ha generado una red de múltiples efectos que ha impactado el escenario social, económico y tecnológico de manera significativa. Esta situación que tomó desprevenida a la Organización Mundial de la Salud (OMS), a los sistemas sanitarios y a las sociedades en general, conduce a la perentoria necesidad de determinar cuáles son las repercusiones especificas post pandemia a fin de generar estrategias paragua, es decir, que puedan ir alineadas a la pronta recuperación de los escenarios o sectores afectados, principalmente, en los países con menor potencial económico como los pertenecientes a la América Latina y el Caribe. El impacto y las repercusiones mencionadas se fundamentan en el informe emitido por la CEPAL (2020) el cual se presenta en la tabla 1 a continuación. 
Tabla 1. Resumen del informe emitido por la CEPAL.

\begin{tabular}{|c|c|c|}
\hline Sectores & Impacto Directo & Propuestas de la CEPAL (2020) \\
\hline Social & $\begin{array}{l}\text { Empleo } v s \\
\text { tecnología }\end{array}$ & $\begin{array}{l}\text { La crisis ha obligado a las empresas a adecuar su funcionamiento interno } \\
\text { a las medidas de distanciamiento social. A medida que la robótica, la } \\
\text { automatización y el uso masivo de plataformas de teletrabajo se vuelven } \\
\text { más eficientes, más baratas y fáciles de implementar, es probable que la } \\
\text { automatización de algunos sectores y procesos productivos se acelere, } \\
\text { con impactos sobre el empleo. }\end{array}$ \\
\hline Económico & Manufactura & $\begin{array}{l}\text { Desde la irrupción del COVID-19, las nuevas órdenes manufactureras } \\
\text { mundiales han tenido la caída más rápida de los últimos } 11 \text { años. El índice } \\
\text { global del sector manufacturero (índice de gestores de compras (PMI)) } \\
\text { del primer trimestre de } 2020 \text { confirma un deterioro de la producción } \\
\text { mundial: solo en febrero, la producción manufacturera mundial se } \\
\text { derrumbó } 7 \text { puntos (IHS Markit, 2020). }\end{array}$ \\
\hline Tecnológico & $\begin{array}{l}\text { Producción vs } \\
\text { tecnología }\end{array}$ & $\begin{array}{l}\text { La vulnerabilidad de las redes internacionales de producción ante } \\
\text { fenómenos imprevistos de gran magnitud, y la consecuente necesidad de } \\
\text { dotarlas de una mayor resiliencia. } \\
\text { Desde la óptica de las empresas multinacionales que lideran esas redes, } \\
\text { esto implica diversificar su red de proveedores en términos de países y } \\
\text { empresas, privilegiar ubicaciones más cercanas a los mercados finales } \\
\text { de consumo (nearshoring) y relocalizar procesos críticos cuando sea } \\
\text { económicamente factible, mediante el uso de tecnologías como la } \\
\text { manufactura aditiva. Hay señales de movimientos en este sentido en las } \\
\text { principales economías mundiales: } \\
\text { En Japón: Se ha destinado } 2.200 \text { millones para relocalizar la producción } \\
\text { fuera de china. } \\
\text { Estados Unidos: el índice de relocalización alcanzó su valor máximo } \\
\text { en } 2019 \\
\text { Unión Europea: más de } 200 \text { empresas relocalizaron su producción }\end{array}$ \\
\hline
\end{tabular}

Fuente: (CEPAL) abril 2020.

La tabla 1, reporta el impacto que sigue ocasionando el COVID-19 en los sectores social, económico y tecnológico que desde la globalización van a obligar a los países más 
industrializados a repensar y reestructurar sus estrategias. Por ejemplo, desde el empleo se pueden activar protocolos de mantenimiento del personal, considerando los efectos psicosocioemocionales y el uso excesivo de la robótica y la tecnología, generando una simbiosis humano y tecnología.

Así mismo desde la producción y manufactura mundial las caídas de los insumos afectan la oferta y la demanda, obligando a reactivar el aparato productivo de una manera agresiva, pero gradual, incorporando al hombre con el uso de la inteligencia artificial (IA) para monitorear y ejecutar procesos desde el distanciamiento. Esto tomando en cuenta el desconfinamiento parcial de la pandemia COVID-19. De la misma forma, activar las redes internacionales de producción concibiendo a un individuo resiliente y gestor del conocimiento para considerar la relocalización de la producción en espacios donde la tecnología permee la manufactura aditiva y su impacto sea menor.

Aun cuando este análisis generaliza el impacto mundial, la magnitud y la capacidad de reacción dependerán de: la vulnerabilidad de los sectores sociales de menor acceso al empleo y en gran medida de la estructura productiva de cada economía; de la participación de sus empresas en las cadenas de valor y de las capacidades productivas existentes.

\section{Metodología}

Para el análisis se empleó un enfoque cualitativo y un diseño de investigación documental que emplea la hermenéutica y el análisis del discurso (Hernández et al. 2011) se utiliza como técnica de recolección de datos el fichaje con el propósito de conseguir la información pertinente para el alcance del objetivo propuesto.

\section{Hallazgos}

Una vez realizado el análisis hermenéutico de los discursos emitidos por las diferentes fuentes de información consultadas, se evidenció cómo el efecto global del COVID-19 ha impactado la economía desde la producción y al aspecto social desde el empleo, mientras que, sobre el sector tecnológico también han repercutido los dos aspectos anteriores. De tal manera que las estrategias paragua citadas en la introducción de este trabajo habrán de tomar en cuenta dos evidencias centrales observadas: 
- La configuración de redes internacionales de producción con demostraciones de agotamiento visible en la paralización de muchas economías.

- La pérdida de dinamismo del comercio y la alta volatilidad desde la crisis financiera mundial que afecta de manera directa la salud económica, social y tecnológica de América Latina.

- La economía de la post pandemia nos enfrenta al desafío de repensar los antiguos esquemas o bases en que se cimentaba la rentabilidad. La salida de esta crisis, importará parámetros nuevos, gastos diferentes, seguridad, higiene, entre otros.

\section{Fuentes bibliográficas}

Comisión Económica para América latina y el Caribe (CEPAL) (2020). Dimensionar los efectos del COVID-19 para pensar en la reactivación.

Hernández, R.; Fernández, y Baptista, P. (2001) Metodología de la Investigación. $2^{a}$. ed. McGraw-Hill. México, D.F., 2001. Pág. 52 - 134.

(IHS Markit, 2020). IHS Markit (2020), "Manufacturing downturn deepens outside of China", 1 de abril [en línea] https:// ihsmarkit.com/research-analysis/ manufacturing-downturn-deepens-outside-of-china-April2020.html. 


\title{
PRODUCTO INTERNO BRUTO (PIB) DEL \\ DEPARTAMENTO DEL TOLIMA (COLOMBIA) \\ AFECTADO POR EL COVID-19
}

\section{GROSS DOMESTIC PRODUCT (GDP) OF TOLIMA DEPARTMENT (COLOMBIA) AFFECTED BY \\ COVID-19}

\author{
Juan José Quintero Rivera \\ Estudiante de Contaduría Pública, Corporación Universitaria Remington. \\ Correo electrónico: juan.quintero.5497@miremington.edu.co.

\section{Leydi Daniela Rodríguez Díaz} \\ Estudiante de Contaduría Pública, Corporación Universitaria Remington. \\ Correo electrónico: leydi.rodriguez.0581@miremington.edu.co.
}

\section{Objetivo}

Evidenciar los efectos del covid-19 en la economía del departamento del Tolima (Colombia), y las consecuencias en el PIB regional producto de la disminución de las actividades económicas de la región.

\section{Descripción del contexto}

Desde el 24 de marzo (2020) por efectos del Covid-19, aparte de los problemas de salud que conlleva la pandemia; la economía de Colombia y del departamento del Tolima se encuentra paralizada, también ha afectado la vida social y laboral de su gente, teniendo un impacto negativo en el crecimiento del PIB del departamento del Tolima, y del país.

Sectores económicos que son importantes en la contribución del PIB del departamento como son servicios, industrial, minería, agricultura, pecuaria, textil, etc., (figura 1) están siendo afectados por el problema sanitario que hoy se vive, provocando problemas socioeconómicos en la región. 


\section{Metodología}

Con un enfoque cualitativo se realizó la recolección y análisis de datos del Departamento Administrativo Nacional de Estadística (DANE) sobre el PIB regional y las actividades económicas del Tolima en el año 2018; obteniendo una referencia para comparar la información hallada en el 2020.

\section{Hallazgos}

El Producto Interno Bruto (PIB) de Colombia es del 3.3\% (2019) y del departamento del Tolima se ha crecido a un ritmo de $1,5 \%$ en el periodo $2015-2018$, mientras el promedio nacional de crecimiento del PIB fue de 2,2\%. Esta falta de competitividad con otras regiones del país se traduce en un índice de desempleo del $15.3 \%$ en el departamento (2019) y en la ciudad de Ibagué un 18.6\% (DANE, 2020). Durante el trimestre de noviembre-enero de 2020, las actividades de comercio y reparación de vehículos representaron el 23,8 \% del total de Ibagué, siendo el nicho que más empleabilidad aportó a la región. Con la llegada del Covid-19 al Tolima los pequeños negocios, las microempresas y las pymes, que son la médula de la economía regional entraron en crisis, lo que a la fecha tiene a la región con estimaciones de desempleo del $30 \%$; los restaurantes de la ciudad de Ibagué han disminuido sus ventas en estimativas de un $80 \%$, junto con la disminución del comercio automotriz en un $40 \%$. Es por ello, que la proyección que se tenía para el desarrollo de la región para el periodo 2020-2023 (Gobernación del Tolima, 2020), con una fuerte inversión en proyectos de infraestructura, lastimosamente ha quedado atrás, planteando a la fecha una revisión de las proyecciones financieras para priorizar la reconstrucción económica y social de la región.

Finalmente podemos concluir que producto del covid-19 los sectores productivos en el Tolima frenaron sus actividades debido a las medidas preventivas biosanitarias, ocasionando una recesión económica y una reducción de los bienes y servicios que irremediablemente ocasionara una reducción aún mayor del PIB en el Tolima. 


\section{Referencias bibliográficas}

Boletín Económico del Tolima. (2020). Instituto de desarrollo regional. Universidad de Ibagué. Disponible en: https://repositorio.unibague. edu.co/jspui/bitstream/20.500.12313/1825/1/Boleti\%CC\%81n\%20 econo $\%$ CC $\% 81$ mico $\% 20 \mathrm{del} \% 20$ tolima.pdf

Dane. Departamento Administrativo Nacional de Estadística. (2020). https://www.dane. gov.co/

Gobernación del Tolima. Plan de desarrollo 2020-2023. Disponible en: https://www. tolima.gov.co/publicaciones/21341/proyecto-plan-de-desarrollo-el-tolimanos-une-2020-2023/

Ministerio de Comercio (Colombia). Perfiles Económicos Departamentales. Oficina de Estudios Económicos marzo 2020. Disponible en: https://www.mincit.gov. co/getattachment/eda93571-34c2-48d8-956e-6cffb358d488/Tolima.aspx 


\section{EL TELETRABAJO CONTRA LA INTERRUPCIÓN DEL MERCADO LABORAL EN COLOMBIA DEBIDO A LA CRISIS DEL COVID-19}

\section{TELEWORK AGAINST THE INTERRUPTION OF THE LABOR MARKET IN COLOMBIA DUE TO THE COVID-19 CRISIS}

\section{Marino Valencia R}

Doctor en Gestión Tecnológica e Innovación y Doctor en Ciencias Técnicas, Docente Investigador de la Universidad de San Buenaventura, Cali, Colombia. Correo electrónico: mvalencia3@usbcali.edu.co.

\section{Verena González C}

Doctora (C) en Administración, Docente Investigador de la Universidad de San Buenaventura, Cali,Colombia. Correo electrónico: vgonzale@usbcali.edu.co.

\section{Luis Ferney Bonilla B}

Doctorando en Administración, Docente Investigador de la Universidad de San Buenaventura, Cali, Colombia. Correo electrónico: lfbonilla@usbcali.edu.co.

\section{Objetivo}

Evaluar, a partir de la revisión de la literatura especializada, la importancia del teletrabajo como factor resolutivo contra la interrupción del mercado laboral en Colombia, para aminorar los efectos de la pandemia Covid-19.

\section{Descripción del contexto}

La situación contingente actual en el mundo ha exigido un cambio inmediato en algunas empresas pasando del trabajo presencial a la virtualidad sin tener una preparación suficiente; sin embargo, "se requiere gestionar el cambio de mentalidad de supervisores y colaboradores hacia una cultura más flexible, basada en la confianza, la orientación a resultados y el uso de la tecnología, que hacen más competitiva a la organización en el mercado actual" (MinTIC, Mintrabajo, Colombia Digital, s.f., p. 16). De acuerdo con la Corporación Andina de Fomento (CAF, 2020) la Covid-19 "implica una disrupción adicional en el mercado laboral ocasionada por la proporción de la fuerza 
de trabajo que puede transicionar al teletrabajo" (p. 4), es así que muchas empresas acudieron a una de las modalidades de trabajo, como es el trabajo en casa, con el fin de garantizar la continuidad de las labores y la permanencia de sus trabajadores, claro está, aprovechando el uso de las TIC. Sierra (2011) afirma que: "El teletrabajo es una nueva forma de organización del trabajo cuya prestación de servicios se caracteriza por la realización del trabajo a distancia" (p. 4), además que involucra la flexibilidad como una de sus características principales, puesto que es un trabajo flexible que puede llevarse a cabo a través de horarios también flexibles; esta modalidad es vista como una práctica comúnmente adoptada por organizaciones que tienen dentro de sus estrategias de gestión buscar la atracción, motivación y retención de talentos clave dentro de la organización (Hill et al., 2008, como se citó en Bachion y De Souza Rocha, 2019). Sin embargo, esta modalidad de trabajo establece unos retos que deberán enfrentar tanto las empresas como sus colaboradores, de manera inmediata.

\section{Metodología}

La metodología se aborda desde un enfoque cualitativo, teniendo en cuenta la investigación documental en bases de datos, en organismos e instituciones nacionales e internacionales, a partir de unas categorías de análisis como: teletrabajo, organizaciones, mercado laboral, actividades productivas, Covid-19.

\section{Hallazgos}

Así como en Estados Unidos el teletrabajo se rige por el Telework Enhancement Act of 2010, en España por el Real Decreto-Ley 3 de 2012 y en diferentes países existe el Libro Blanco del Teletrabajo, en Colombia se encuentra definido en la Ley 1221 de 2008, que les da soporte a las organizaciones para enfrentar la pandemia con posibilidades de sostenimiento de su actividad productiva; en definitiva, esta modalidad laboral se convierte en una oportunidad para las empresas, ya que reduce costos de infraestructura y los empleados disminuyen sus gastos diarios y sus tiempos de desplazamiento (Julsrud, 2010, como se citó en Benjumea-Arias et al., 2016, p. 61), además, ofrece ventajas centradas en el aumento de la productividad, debido a situaciones como "utilizar momentos de desplazamiento y tiempos muertos durante la jornada laboral en actividades productivas que le generen más rentabilidad a la empresa y mayor satisfacción laboral a sus empleados" (Dinero.com, 2013). 
"No obstante, en las nuevas tendencias de trabajo, como el trabajo en red o teletrabajo, no se identifican marcos conceptuales establecidos sobre los procesos claves de la teoría y la práctica de gestión humana (...) Así, la incorporación de nuevas tecnologías trae consigo transformaciones en los estilos de vida de las personas, las prácticas de consumo, las relaciones interpersonales y por consiguiente cambios en las condiciones de supervivencia y competitividad de las empresas" (Benjumea-Arias et al., 2016, pp. 68-69). Aunado a lo anterior, el control es un desafío para teletrabajo, pues ya no está relacionado con un horario ni con un sitio concreto, no se encuentra asociado a la presencia del jefe y tampoco a la forma en que se ejecuta la labor, el énfasis en la tarea trasciende hacia el énfasis en el objetivo y los resultados (Ruiz, 2017). Así, la actividad de control mejora su función de apoyo en complemento a su condición de seguimiento porque exige una articulación entre dirigidos y líderes para el logro de los objetivos organizacionales. Como resultado complementario se debe incrementar el empoderamiento, la confianza, el compromiso y el sentido de pertenencia, para aprovechar de la mejor manera el escenario de trabajo remoto; sin embargo, estas mismas condiciones son la principal limitante para la consolidación de una cultura organizacional y el desarrollo de la identidad empresarial, ya que la interacción social es impersonal.

\section{Referencias bibliográficas}

Bachion, H. y De Souza Rocha, G. (2019). Uma análise da relação entre flexibilização do trabalho, exaustão emocional e engajamento dos trabalhadores. Rev. Ciênc. Admin., 25(1), 1-14. http://dx.doi.org/10.5020/2318-0722.2019.7420

Benjumea-Arias, M. L., Villa-Enciso, E. M. y Valencia-Arias, J. (2016). Beneficios e impactos del teletrabajo en el talento humano. Resultados desde una revisión de literatura. Revista CEA, 2(4), 59-73. https://tinyurl.com/y9ho8f5f

Corporación Andina de Fomento (CAF). (2020). El estado de la digitalización de América Latina frente a la pandemia del COVID-19. Observatorio CAF.

Dinero.com. (16 de oct. de 2013). Teletrabajo reduce costos. https://cutt.ly/cyaWTic 
MinTIC, Mintrabajo, Colombia Digital (s.f.). Libro blanco. El ABC del teletrabajo en Colombia. https://cutt.ly/nyaWbRJ

Ruiz, N. (Julio de 2017). Las empresas y sus políticas de conciliación de la vida laboral y personal: especial referencia al Teletrabajo. El caso de Grupo Repsol. Universidad de Valladolid.

Sierra, E. M. (2011). El teletrabajo ante los cambios económicos y sociales. Ponencia $X$ Congreso Europeo de Derecho del Trabajo y de la Seguridad Social, Sevilla, España, 21 al 23 de septiembre de 2011. 


\title{
DESAFÍOS DE ENSEÑAR Y APRENDER VIRTUALMENTE. LA ACADEMIA EN CUARENTENA \\ VIRTUAL TEACHING AND LEARNING CHALLENGES. THE ACADEMY IN QUARANTINE
}

\author{
Robinson Escobar Soto \\ Licenciado en Lengua extranjera inglés y psicopedagogía. Docente tiempo \\ completo en la Corporación Universitaria Autónoma de Nariño. Santiago de \\ Cali, Colombia. Correo electrónico: robinson.escobar@aunarcali.edu.co.
}

\section{Objetivo}

Plantear estrategias pedagógicas que faciliten el proceso de enseñanza-aprendizaje bajo virtualidad en el marco de las medidas adoptadas en Colombia ante la pandemia actual del COVID-19.

\section{Descripción del contexto}

Desde el pasado 16 de marzo de 2020 cuando desde la Presidencia de la República de Colombia (2020) se emite el Decreto 457 para el aislamiento obligatorio por causa de la pandemia del COVID-19 las escuelas, colegios, universidades y demás instituciones educativas se enfrentan a un gran desafío en sus procesos de enseñanza, aprendizaje y evaluación de los conocimientos y competencias propios de sus diferentes cursos, carreras y programas planeados en sus currículos respectivos. Pero el mayor reto empieza cuando lo planificado inicialmente estaba dispuesto y diseñado para ser desarrollado en una metodología presencial con contenidos y criterios previamente establecidos y acordados con los estudiantes.

\section{Metodología}

Se aplica una metodología hermenéutica fundamentada en información publicada por organismos del Estado con competencia en salud y educación, así como en artículos científicos y de opinión en el campo pedagógico que han sido divulgados a medida que la situación adquiere relevancia e interés de investigadores que intentan explicar 
la dinámica e impactos del nuevo desafío que enfrenta la comunidad académica en Colombia.

\section{Hallazgos}

Es evidente que el cambio de escenario debe generar transformación en las estrategias y metodologías empleadas a la hora de impartir y recibir clases en un modelo virtual buscando los mismos objetivos de aprendizaje y desarrollo de las competencias requeridas para cada área del conocimiento. Llegan aquí los desafíos para asumir por parte de profesores y estudiantes para establecer una comunicación mediada por computadora y tecnologías relacionadas como un medio para facilitar la interacción humana, en este caso con fines educativos y de formación, la cual es conocida en el mundo como Computer mediated communication - CMC, por sus siglas en inglés -. En este orden de ideas las universidades y su equipo de profesores necesitan y deben repensar la propuesta pedagógica para el proceso de enseñanza, aprendizaje y evaluación teniendo en cuenta los problemas que el país enfrenta en materia de conectividad y recursos tecnológicos por parte de estudiantes (Semana, 2020).

La reflexión por parte de los docentes en la coyuntura actual implica replantear varios comportamientos sobre la dinámica en las prácticas pedagógicas a la hora de proponer cambios en las estrategias y metodologías de enseñanza aprendizaje que faciliten el alcance de los objetivos y el desarrollo de las competencias requeridas para cada profesional en un ambiente virtual que asume la ausencia del aula física y las prácticas tradicionales que allí se ejecutaban. En la actualidad, la enseñanza en la virtualidad demanda orientar las actividades a interacción sincrónica y asincrónica para la construcción creativa del conocimiento a través de la indagación, la reflexión y el pensamiento crítico (Meza et al., 2016).

Ante esta nueva realidad, resulta necesario que el conocimiento se produzca a partir de interrogantes que construyan respuestas y no que esté supeditado al conocimiento del docente; más ahora cuando los estudiantes necesitan docentes con capacidades innovadoras frente a sus prácticas pedagógicas y didácticas. No se trata sólo de ver un video o subir un texto a la plataforma de aprendizaje, se debe llegar más bien a enseñanza y evaluación desde el planteamiento de interrogantes que lleven a la reflexión 
y al análisis para el desarrollo de competencias en el marco de una interacción sincrónica y asincrónica que motive e invite a la construcción de un conocimiento significativo.

\section{Referencias bibliográficas}

Meza, J.; Morales, M. y Flores, Rosa. (2016). Diseño e implementación de un taller en línea sobre entornos personales de aprendizaje. Pixel-Bit. Revista de medios y educación, 49, 75-90. Recuperado de: https://www.redalyc.org/ pdf/368/36846509006.pdf

Presidencia de la República. (2020). Decreto número 457. Disponible en https://dapre. presidencia.gov.co/normativa/normativa/DECRETO\%20457\%20DEL\%20 22\%20DE\%20MARZO\%20DE\%202020.pdf

Semana. (2020). El reto de estudiar desde la casa, fecha 21 de marzo de 2020. Disponible en: https://www.semana.com/educacion/articulo/el-reto-de-estudiar-desdela-casa-en-medio-del-aislamiento-por-coronavirus/658225 


\title{
INJERENCIA DEL COVID-19 EN LA CONTABILIDAD DE LAS EMPRESAS COLOMBIANAS
}

\author{
INTERFERENCE OF COVID-19 IN THE \\ ACCOUNTING OF COLOMBIAN COMPANIES
}

\begin{abstract}
Albano Alexander Rojas-Britto
Candidato a Magister en Administración de Empresas. Docente tiempo completo en la Corporación Universitaria Autónoma de Nariño. Santiago de Cali, Colombia. Correo electrónico: albanor@yahoo.com.
\end{abstract}

\section{Objetivo}

Proponer acciones que podrían usar los contadores y revisores fiscales para corregir y modificar sus informes de los estados financieros en Colombia ante la pandemia actual de la COVID-19.

\section{Descripción del contexto}

Desde el punto de vista financiero, la pandemia de la COVID-19 ha impactado de manera negativa en las bolsas de valores a nivel mundial, donde Colombia no ha sido la excepción según su presidente Juan Córdoba (La República, 2020). Fue el 6 de marzo de 2020 cuando el Ministerio de Salud (2020) confirma el primer caso de coronavirus en el país y el presidente de la República declara el estado de emergencia económica, social y ecológica generando traumatismo en las finanzas nacionales tras la total intervención y suspensión de operaciones en varias oportunidades de la Bolsa de valores de Colombia para evitar la pérdida de los activos financieros transados afectando a personas naturales y jurídicas de todos los sectores productivos que aún no disponen de medidas proteccionistas frente a esta trágica situación. En este ámbito empresarial, un hecho significativo es la necesidad de reflejar nuevos sucesos en los estados financieros. Esta directriz de emergencia afecta, por ejemplo, el artículo 422 del Código de Comercio (Senado de la República de Colombia, 1971) donde se dan lineamientos en relación con las reuniones ordinarias de asamblea general de accionistas para el ejercicio contable del año 2019 y que ahora podrán efectuarse hasta dentro del mes siguiente a la finalización de la emergencia sanitaria declarada en el territorio nacional. 


\section{Metodología}

Se aplica una metodología hermenéutica fundamentada en los informes emitidos por parte de organismos públicos con competencia en asuntos de salud pública, así como en artículos científicos y de opinión que han sido publicados a medida que esta situación se desarrolla y los investigadores intentan explicar su comportamiento y efectos en todos los sectores productivos de los países.

\section{Hallazgos}

No hay exactitud de fecha para llevar a cabo la reunión ordinaria de Asamblea general de accionistas. Algunos efectos puntuales de la COVID-19 en las actividades de las personas naturales y jurídicas son: a) suspensión de producción, b) corte en supply chain, c) reducción o nulidad en ventas, d) despidos de personal, e) reducción salarial y licencias no remuneradas, f) decrecimiento, g) inexistencia de financiación, h) extrema volatilidad de instrumentos financieros en la bolsa de valores de Colombia, i) reducción de viajes turísticos en todos los medios, j) liquidación y cierre de personas jurídicas y naturales, k) suspensión de contratos, 1) revisión de seguros y pólizas, entre otros (Comisión Económica para América Latina y el Caribe, 2020; Portafolio, 2020).

En las sociedades donde prestan servicios los profesionales de revisoría fiscal se debe evaluar de manera exhaustiva y sigilosa el nivel de riesgo financiero al cual se están enfrentado. Los revisores fiscales tendrán la tarea de reemitir el pronunciamiento sobre ellas para el periodo 2019. El dictamen de los estados financieros deberá ser corregido, incluir un componente muy fuerte y exacto referente a los hechos posteriores, dado que podría estar totalmente en desacuerdo con la realidad del negocio en marcha hoy día. Haciendo referencia a los análisis más incisivos, deberán revisar los beneficios a empleados, vacaciones y contratos, así como los contratos de seguros, proveedores y clientes. También será necesario hacer una evaluación de los inventarios en todos sus modelos y características y, junto a la administración de las sociedades, evaluar los seguros que se tengan comprados, contratados y permitan una cobertura en parte o total, en alusión a la fuerza mayor o caso fortuito. 


\section{Referencias bibliográficas}

Comisión Económica para América Latina y el Caribe. (2020). COVID-19 tendrá graves efectos sobre la economía mundial e impactará a los países de América Latina y el Caribe, fecha 19 de marzo de 2020. Disponible en: https://www. cepal.org/es/comunicados/covid-19-tendra-graves-efectos-la-economiamundial-impactara-paises-america-latina.

La República. (2020). Presidente de la Bolsa de valores de Colombia hace un llamado a la tranquilidad, fecha 16 de marzo de 2020. Disponible en: https://www. larepublica.co/finanzas/presidente-de-la-bolsa-de-valores-de-colombiahace-un-llamado-a-la-tranquilidad-2978867

Ministerio de Salud de la República de Colombia. (2020). Colombia confirma su primer caso de COVID-19. Disponible en: https://www.minsalud.gov.co/Paginas/ Colombia-confirma-su-primer-caso-de-COVID-19.aspx

Portafolio. (2020). Ecopetrol cierra planta por muerte de empleado contagiado de covid-19, fecha 12 de abril de 2020. Disponible en: https://www.portafolio. co/economia/coronavirus-noticias-ecopetrol-cierra-planta-por-muerte-deempleado-contagiado-de-covid-19-539817

Senado de la República de Colombia. (1971). Código de Comercio de Colombia. Disponible en: http:/www.secretariasenado.gov.co/senado/basedoc/ codigo_comercio.html 


\title{
UNA EDUCACIÓN QUE PERMITA LA ADAPTACIÓN AL CAMBIO, LA GRAN ENSEÑANZA DE LA PANDEMIA DEL SARS-COV-2
}

\author{
AN EDUCATION THAT ALLOWS ADAPTATION TO \\ CHANGE, THE GREAT TEACHING OF THE SARS- \\ COV-2 PANDEMIC
}

\section{José Obdulio Curvelo-Hassán}

Doctor en Contabilidad. Profesor de la Facultad de Contaduría Pública de la Universidad Cooperativa de Colombia. Líder del grupo de investigación contabilidad y entorno social. Correo electrónico: jose.curvelo@ucc.edu.co.

\section{Mario Heimer Flórez-Guzmán}

Doctorado en Ciencias de la Educación, director institucional del Centro de Investigaciones e Innovación de los Negocios CIIN, Director del grupo de investigación Mundo Organizacional e integrante del grupo de investigación SUMAR. Correo electrónico: mario.florez@uniremington.edu.co.

\section{Objetivo}

Analizar desde una perspectiva crítica la capacidad de adpatación al cambio de los estudiantes colombianos en el contexto generado por la pandemia SARS-CoV-2.

\section{Descripción del contexto}

Colombia cuenta con más de 480000 estudiantes universitarios, en 697 Instituciones de Educación Superior (IES) ${ }^{8}$; la mayoría con modalidad presencial. Con la declaratoria de emergencia sanitaria por la pandemia SARS-CoV-2, el Ministerio de Educación Nacional ordena transitar a la educación remota, por tecnología, a fin de mantener la normalidad académica hasta el 31 de mayo (Directiva Ministerios 04). Esta medida generó rechazos por grupos de estudiantes que convocaron a paro virtual y conductas grotescas hacia los profesores, aludiendo que esta forma de enseñanza adolece de calidad; lo que permite preguntarse: ¿los profesores y estudiantes están familiarizados con los recursos digitales en la educación presencial? ¿están preparados profesores y estudiantes para adaptarse y transformar realidades en escenarios de incertidumbre? 


\section{Metodología}

La investigación fue de corte cualitativa, descriptiva-explicativa, de carácter mixto, en donde se aplicó una encuesta a docentes universitarios, conriterios de: Encuesta estructurada con $\alpha=0.91$, muestra con $Z=1.96, e=0.1$ y población infinita, para un $n=97$, finalmente se trabajó con $n=154$.

\section{Hallazgos}

El 96,3\% de los encuestados han respondido positivamente al cambio; manteniendo una motivación igual (59,2\%), o ha mejorado (37,1\%), en contraste con $3,7 \%$ desmotivados; lo que contrasta significativamente con el 56,30\% de los profesores encuestados que indican que ha mejorado la calidad de los trabajos presentados por los estudiantes; el $42 \%$ en uso de la biblioteca digital; $55,11 \%$ en uso de bases de datos; $47,40 \%$ en habilidades de pensamiento crítico; $66 \%$ en uso adecuado de las tutorías y un $63,70 \%$ en autoaprendizaje.

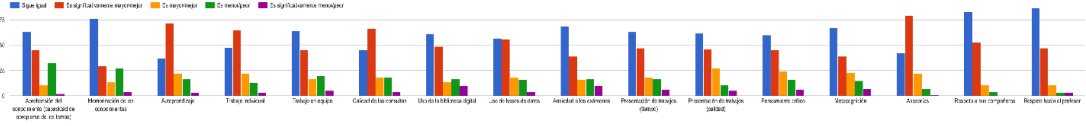

Figura 1. Percepción de docentes actitud/respuesta de estudiantes (1 mes después de confinamiento).

En concordancia con Valkanov et al. (2016), el test arroja que los estudiantes acuden mayoritariamente a las tutorías; por tanto, siguiendo a Sun y Chen (2016) sus formas de aprender en la educación remota privilegian el autoaprendizaje. Igualmente, de acuerdo con Deming et al. (2016), el momento coyuntural ha permitido mejorar la didáctica de los profesores y la indagación (pensamiento crítico) en los estudiantes. Así mismo, el estudio refleja que la mayoría de estudiantes aceptan educación remota, pero con un alto grado de incertidumbre: Si bien esta incertidumbre puede mejorar con el paso de los días, dado que el $61,40 \%$ de los encuestados manifiestan que sus estudiantes tienen una actitud proactiva y ha disminuido la resistencia al aprendizaje mediado por tecnologías, este escenario hace que las IES transiten a modalidades híbridas, puesto que, además 
de responder a las medidas de confinamiento, se muestran coherentes con las formas de aprender de los estudiantes contemporáneos y genera mayor confianza.

\section{Rerefencias bibliográficas}

Clark, J. T. (2020). Distance education. In Clinical Engineering Handbook (pp. 410415). Academic Press.

Valkanov, V., Stoyanov, S., y Valkanova, V. (2016). Virtual education space. Journal of Communication and Computer, 13(2), 64-76.

Deming, D. J., Lovenheim, M., y Patterson, R. W. (2016). The competitive effects of online education (No. w22749). National Bureau of Economic Research.

Sun, A., \& Chen, X. (2016). Online education and its effective practice: A research review. Journal of Information Technology Education, 15.

Datos.gov.co. 2020. INSTITUCIONES DE EDUCACIÓN SUPERIOR. [online] Available at: $<$ https://www.datos.gov.co/Educaci-n/INSTITUCIONES-DEEDUCACI-N-SUPERIOR/iwb2-skc4> [Accessed 26 April 2020]. 


\title{
LA RESPONSABILIDAD SOCIAL EMPRESARIAL EN ÉPOCA DE PANDEMIA
}

\section{CORPORATE SOCIAL RESPONSIBILITY IN TIMES OF PANDEMIC}

\author{
Mónica Alexandra Zarta Campos \\ Magister en logística Integral y comercio internacional, Docente Investigadora \\ de la Corporación Universitaria Minuto de Dios, Colombia. Correo electrónico: \\ monica.zarta@uniminuto.edu
}

\begin{abstract}
Alexander Beltrán Echeverry
Magister en administración de organizaciones, Docente Investigador de la Corporación Universitaria Minuto de Dios, Colombia. Correo electrónico: alebeltran@uniminuto.edu.

\section{Jesús David Vera Galicia \\ Estudiante noveno semestre de Administración de Empresas, Corporación Universitaria Minuto de Dios, Colombia. Correo electrónico: jveragalici@ uniminuto.edu.co.}

\section{Objetivo}

Realizar una descripción de la responsabilidad social empresarial como estrategia para superar crisis luego de la pandemia (COVID-19).

\section{Descripción del contexto}

La responsabilidad social empresarial es un tema crucial dentro de la contingencia que se está viviendo ya que las empresas juegan un papel importante teniendo en cuenta que la economía de la cual son agentes activos está viéndose directamente perjudicada debido a las medidas de aislamiento preventivo que han decretado los entes gubernamentales; sin embargo la RSE no es un tema nuevo en el contexto nacional e internacional, y es que en las últimas décadas ha ganado cada vez mayor peso dentro de la gestión empresarial, al hablarse que las empresas deben contribuir de alguna manera a la sociedad y/o comunidad ya que no solo se trata de que las empresas generen utilidades 
monetarias, sino que además deben ser capaces de generar beneficios cuantificables y no cuantificables a todos los actores de la comunidad en la que se encuentran impactando a través de diferentes programas.

\section{Metodología}

La metodología utilizada es de tipo cualitativa aplicándose una metodología de revisión y análisis documental (RAD) teniendo en cuenta que no se pueden utilizar fuentes primarias de información debido al aislamiento social obligatorio.

\section{Hallazgos}

A través de diferentes estudios se ha logrado demostrar cómo la aplicación de estrategias de RSE han generado mayores índices de rentabilidad, así por ejemplo (Obando Changúan, 2020) realizó un análisis cualitativo en 10 empresas ecuatorianas evidenciando una relación positiva entre la aplicación de estrategias de responsabilidad social y la rentabilidad de las empresas objeto de estudio.

En el caso Colombiano la revista portafolio (Portafolio, 2020) enfatiza el papel de más de 30 empresas Colombianas y con presencia en Colombia que han dado algún tipo de alivio en este tiempo de crisis, entre esos gestos de solidaridad se destacan algunos ingenios azucareros que han donado miles de litros de etanol para producir alcohol farmacéutico, otras como Bavaria han decidido entregar 100000 botellas de gel antibacterial, mientras que algunas se han solidarizado con donaciones de mercado y han enviado a sus colaboradores a casa sin descontar un peso de su sueldo. A nivel mundial también se han destacado muchas empresas que han mostrado un papel positivo y como es el caso de Indetex propietario de Zara y Massimo Dutti, realizando la donación de batas de laboratorio, gafas protectoras y guantes para distribuir de forma gratuita a los hospitales en España, uno de los países más afectados por el COVID-19 (Galicia, 2020); También es el caso de LVMH, empresa dueña de marcas de artículos de lujo como Moët \& Chandon, Tiffany \& Co. y Louis Vuitton, entre otros, también se ha unido a la lucha contra el coronavirus; tres fábricas del grupo, que normalmente producen perfumes y cosméticos, están produciendo alcohol en gel y tapabocas a Francia (Axotla, 2020). Para concluir se puede evidenciar que se pueden encontrar muchos ejemplos de buenas 
prácticas de responsabilidad empresarial en épocas de Pandemia en el mundo y que en un futuro se pueden convertir en resultados de buena reputación para las empresas que desembocará en mayores índices de rentabilidad cuando logremos superar el enemigo mundial: Covid -19 .

\section{Referencias bibliográficas}

Axotla, B. (2020). LVMH donará a Francia millones de cubrebocas. GRAZIA. Obtenido de https://grazia.mx/lvmh-donara-a-francia-millones-de-cubrebocas/

Galicia, A. (2020). El material sanitario donado por Inditex ya está en España. ABC GALICIA. Obtenido de https://www.abc.es/ espana/galicia/abci-material-sanitario-donado-inditex-estaespana-202003231711_noticia.html?ref=https\%3A\%2F\%2Frockcontent. com $\% 2 \mathrm{Fes} \% 2 \mathrm{Fblog} \% 2 \mathrm{~F}$ coronavirus $\% 2 \mathrm{~F}$

Obando Changúan, M. S. (2020). Responsabilidad social corporativa en la rentabilidad empresarial. Pro Sciences: Revista De Producción, Ciencias E Investigación,. 4(30), 48-54.

PORTAFOLIO. (2020). El muro de la solidaridad de las empresas colombianas. PORTAFOLIO. Obtenido de https://www.portafolio.co/negocios/ empresas/coronavirus-colombia-el-muro-de-la-solidaridad-empresarial-encolombia-539313 


\title{
IMPACTO ECONÓMICO EN LA REGIÓN DEL TOLIMA, COLOMBIA DEBIDO AL COVID-19
}

\section{ECONOMICAL IMPACT IN THE TOLIMA STATE, REGION BY COVID-19}

\author{
Kimberly Cortes Buitrago \\ Estudiante X Semestre, Administración de Negocios Internacionales, \\ Corporación Universitaria Remington. Correo electrónico: kimberly. \\ cortes.2008@miremington.edu.co.

\section{Alejandro Sánchez Quiñones \\ Maestro en Ciencias, Profesor Corporación Universitaria Remington, correo electrónico: alejandro.sanchez@uniremington.edu.co.}

\section{Objetivo}

Evidenciar los impactos económicos en el Tolima debido al covid-19 y las medidas implementadas para su mitigación.

\section{Descripción del contexto}

La situación actual causada por la crisis sanitara debido al virus Covid-19, ha obligado a los diferentes mandatarios de los países del mundo a tomar posición frente a un tema atípico para este siglo. Países del primer mundo como lo son Francia, España e Italia, se han visto fuertemente afectados en sus ámbitos, sociales, culturales y por supuesto económico; teniendo que tomar decisiones radicales como son: el cierre de fronteras, las suspensiones de vuelos comerciales, entre otras decisiones que llevaron a los sistemas capitalistas a trabajar a media máquina.

Desde luego, esta situación se extendió hacia todos los continentes del mundo, para el caso colombiano, el gobierno actuó decretando la resolución 470 de 2020, donde estipula una cuarentena y aislamiento obligatorio desde el 23 de marzo hasta el 11 de mayo de 2020. Esta medida se complementa con diferentes decretos generados por los 
diferentes gobiernos departamentales y municipales. Para el caso del Tolima el gobierno departamental por medio del decreto 322 del 23 de marzo de 2020 implemento toque de queda en la zona urbana y rural de sus municipios tal como lo indica el artículo "Las medidas por COVID-19 son para proteger la vida de los ciudadanos". En el ámbito macroeconómico de la región lo más preocupante es el aumento en la tasa de desempleo, (Orozco, 2020), aunque se nota los esfuerzos del gobierno nacional de mantener la tasa de desempleo de un solo dígito; estos esfuerzos no serán eficaces sino se actúa sobre el plan de desarrollo nacional y municipal generando estrategias enfocadas a actividades a distancia principalmente el teletrabajo.

\section{Metodología}

El estudio fue cualitativo de revisión documental hermenéutica para, a partir de datos y documentos oficiales, comprender los efectos del fenómeno sobre el impacto económico de la región de Tolima.

\section{Hallazgos}

En el ámbito microeconómico muchos sectores se han visto afectados por las medidas de mitigación, un claro ejemplo es el sector belleza donde muchos propietarios de diferentes salones, indican no tener ningún tipo de ayuda gubernamental teniendo que asumir gastos mensuales como proveedores, alimentos y diferentes créditos a entidades bancarias, llevándolos a reducir su nómina cancelando contratos al personal tal como lo indica caracol radio (Ecos del Combeima, 2020). Otro de los sectores afectados es el transporte público (Ecos del Combeima, 2020) las empresas han llegado a un límite donde no existen ingresos para pagar salario debido a que no se presta el servicio de transporte desde el 20 de marzo en la ciudad de Ibagué llevando a la decisión de suspender contrato a 300 colaboradores con el fin de salvar la empresa y esperando a que sea una medida transitoria.

Sin embargo, no todo el contexto es negativo pues algunos sectores productivos locales han adaptado su misión para generar productos y servicios necesarios en la crisis y que aporten a la mitigación de la misma, como son los sectores de industria textil; donde empresas como Roott + co, ha confeccionado tapabocas, overoles, batas, trajes 
de seguridad, 150 termos y 12000 trajes quirúrgicos (Morales, 2020), generando con esto un impacto social positivo para la región, otra compañía, el Grupo Carolina abrió convocatoria de empleo dirigido a personas que tengan acceso a maquinas planas y folder para la fabricación de 6 millones de tapabocas para todo el país (Morales, 2020). Estas acciones tomadas por las empresas generan no solo un impacto económico positivo que ayuda a enfrentar la crisis a personas independientes del sector, sino también un impacto social y cultural que da un aliciente de esperanza a la población tolimense.

Para finalizar, la crisis sanitaria que estamos viviendo en el mundo, conlleva a que los sectores económicos de las diferentes regiones tomen acciones, generando nuevas misiones y visiones en sus planes estratégicos, teniendo en cuenta que la economía como la conocemos hoy, no será igual al final de la crisis, pues algunos sectores que anteriormente no se conocían como grandes aportadores del PIB nacional, como el sector de alimentos, implementos de aseo y salud, se convertirán en sectores priorizados ganándole participación a otros sectores fuertes como el sector minero y de hidrocarburos.

\section{Referencias bibliográficas}

Orozco, R. (2020). Las medidas por CONVID-19 son para proteger la vida de los ciudadanos. Recuperado de: https://www.alertatolima.com/noticias/tolima/ las-medidas-por-covid-19-son-para-proteger-la-vida-de-los-ciudadanosricardo-orozco.

Ecos del Combeima. (2020). Como afecta el convid-19 la ocupación laboral en Ibagué. Recuperado de: https://ecosdelcombeima.com/ibague/nota-154292-comoafectara-el-covid-19-la-ocupacion-laboral-en-ibague.

Ecos del Combeima. (2020). Expresos Ibagué suspenden contratos más de 300 trabajadores. Recuerado de: http://ecosdelcombeima.com/economia/nota153919-expreso-ibague-suspende-contratos-mas-de-300-trabajadores 
Morales, E. (2020). Tapabocas y otros elementos hospitalarios fueron donados por Roott+co Recuperado de: https://www.alertatolima.com/noticias/tolima/ ibague/mas-de-2000-tapabocas-y-otros-elementos-hospitalarios-fuerondonados-por

Morales, E. (2020). empresas ibaguerena realiza convocatoria de empleo para la fabricación de cubrebocas. Recuperado de https://www.alertatolima. com/noticias/tolima/ibague/empresa-ibaguerena-realiza-convocatoria-deempleo-para-la-fabricacion-de 


\title{
IMPACTO PSICOLÓGICO DE LA PANDEMIA DE COVID-19 EN LOS PROFESIONALES Y LA FAMILIA \\ PSYCHOLOGICAL IMPACT OF THE COVID-19 PANDEMIC ON PROFESSIONALS AND THE FAMILY
}

\section{Gilberto Lázaro Galloso Cueto}

Doctor en Ciencias Médicas, jefe de carrera de Medicina en la Universidad Aquinino de Bolivia (UDABOL). Correo electrónico: ggalloso@udabol.edu.bo.

\author{
Alejandro Leoner Galloso Machín \\ Doctor en Medicina. Docente en la Universidad Aquinino de Bolivia (UDABOL). \\ Correo electrónico: agalloso@udabol.edu.bo.
}

\section{Objetivo}

Analizar el impacto que produce el COVID-19 en los profesionales y las familias.

\section{Descripción del contexto}

En el mundo a través de la historia, se han identificado diferentes tipos de pandemias, destacándose las siguientes: Peste de Justiniano (años 541-543, cobró la vida de 4 millones de personas); Peste Negra (1346 y 1353, perdieron la vida entre el 60 y $65 \%$ de la población en la región Ibérica y en la región italiana de la Toscana entre el 50 y el 60\%); Viruela (Siglo XVIII, alcanzó una tasa de mortalidad del 30\%); Gripe Española (1918, causada por el virus de la Influenza A del subtipo H1N1, la tasa de mortalidad consiguió un rango entre 20-50 millones de personas); Gripe A (H2N2, en China, registró un millón de muertos en el planeta); Gripe de Hong Kong (variación de la gripe A-H3N2, murió un millón de personas aproximadamente); Virus de Inmunodeficiencia Adquirida (VIH, se estima la muerte de al menos 25 millones de personas; y, Coronavirus de 2019-2020 (COVID-19), calificada como pandemia por el Dr. Tedros Adhanom Ghebreyesus, Director de la Organización Mundial de la Salud (OMS, 2019), donde el número de casos contagiados se multiplicó por 13 fuera de China, epicentro del brote del coronavirus, registrándose más de 118000 casos en 114 países y 4291 personas muertas. 


\section{Metodología}

El estudio es descriptivo-explicativo, a partir de un enfoque cualitativo y un diseño de investigación documental que emplea la hermenéutica y el análisis del discurso según Hernández et al. (2011).

\section{Hallazgos}

En el siglo XXI, desde el surgimiento del Síndrome Respiratorio Agudo Severo (SARS); Gripe Aviar (H5N1); Gripe Porcina (H1N1), hasta la actual del COVID-19, se ha corroborado, que todas tienen como origen común: un virus exclusivo de poblaciones animales que muta e invade al humano. En este sentido, hasta el 25 de abril de 2020, se han contagiado más de 2,92 millones de personas en más de 210 países y territorios en el mundo, siendo los más afectados: Estados Unidos, España, Italia, Francia y Alemania; obligándose a la humanidad al estado de cuarentena, para limitar el contagio entre personas potencialmente en contacto con el virus. Considerándose, un aislamiento y un distanciamiento social, que produce ruptura de las rutinas habituales de la vida social en profesionales y familias, generándose, una elevada carga psicológica desatendida por los gobiernos en la atención de la salud mental en los pacientes.

En tal sentido, se perciben efectos psicológicos negativos, relacionados a: síntomas de estrés postraumático, incertidumbre, aburrimiento, enojo, agotamiento, insomnio y depresión, dado el temor, de: infección, frustración, suministros insuficientes, información inadecuada, pérdidas financieras, estigma social; y, sobrecarga y extensión de la jornada laboral desde la casa. Esta situación, según Manes, conduce a una pandemia de miedo y ansiedad, de la cual, no se habla por los especialistas, siendo necesario enfrentarla, mediante: comunicación efectiva, contar suministros generales y médicos; y, considerar un período corto de expansión, que, solo debe de modificarse en situaciones excepcionales.

Asimismo, los profesionales son afectados psíquicamente por el distanciamiento social, al cambiarse su rutina, en cuanto a: cómo, cuándo y dónde desarrollan sus actividades. En ese sentido, a no pocos de los profesionales, les ha tocado aprender y actualizarse en las nuevas tecnologías, para cumplir con sus responsabilidades, 
generándose una cuota adicional de estrés y ansiedad. De manera particular, los profesionales de la salud, además de lo mencionado, corren el peligro de infectarse por la atención a los pacientes, estresándose con el miedo que experimentan a contagiar a sus amigos y familiares. En relación a la familia, el escenario cambia sustancialmente, pues el temor se centra en la pérdida del trabajo, cierre de las escuelas, pérdidas de ingresos, lo cual, les mantiene en un estrés constante, generándose nuevas enfermedades colaterales por la depresión del sistema inmunológico. A su vez, el compartir el mismo espacio las 24 horas del día, genera: conflictos, aburrimiento y aumento de la violencia familiar, mayor riesgo de inestabilidad en la pareja, debido el aumento de las tensiones y al cambio de ritmo de vida, sin considerar la edad de los que conviven. Con lo cual, es necesario para estabilizar los lazos de los componentes de la familia, lo siguiente:

- Organiza y practica las nuevas rutinas diarias, relacionadas a: horarios de comidas; ejercicios físicos, de respiración y meditación; y, actividades educativas, laborales y recreativas, desarrollándolas con tiempo o pausas.

- Limita el flujo de noticias y selecciona lo que vayas a leer. Se debe de enfocar la atención en la información de expertos. Asimismo, alejarse por períodos de tiempo, de las redes sociales (WhatsApp; Facebook), evitándose así, ansiedad y angustia en las personas, dada las noticias abrumadoras que fluyen diariamente.

- Mantente conectado con las personas, sin violar las medidas de bioseguridad. Asimismo, promueve y exige la higiene personal de todos en la casa y de los espacios físicos que comparten.

\section{Referencias bibliográficas}

Coronavirus: por qué la mayoría de las epidemias se originan en Asia y África. Suresh V. KuchipudiThe Conversation*. https:/www.bbc.com/mundo/ noticias-51806481.

Del SARS al coronavirus: las cuatro pandemias de origen animal que llegaron con el nuevo milenio. https://www.lavanguardia.com/vida/20200401/48246562156/sarscoronavirus-pandemias-origen-animal-milenio.html 
Hernández, R.; Fernández, y Baptista, P. (2001). Metodología de la Investigación. $2^{\mathrm{a}}$. ed. McGraw-Hill. México.

Manes Facundo. Coronavirus y la pandemia de miedo y ansiedad. https://elpais.com/ ciencia/2020-03-22/coronavirus-y-la-pandemia-de-miedo-y-ansiedad.html

Oficina Regional para las Américas de la Organización Mundial de la Salud 525 Twenty-third Street, N.W., Washington, D.C. 20037, United States of America (declaración de pandemia). https://www.redaccionmedica.com/ secciones/sanidad-hoy/coronavirus-pandemia-brote-de-covid-19-nivelmundial-segun-oms-1895

Recomendaciones actualizadas de la OMS para el tráfico internacional en rrelación con el brote de COVID-19?' https://www.who.int/ith/2019-nCoV_advice_for_ international_traffic-rev/es/ 


\section{LA ECONOMÍA Y LA PANDEMIA DEL VIRUS SARS- COV2 (COVID-19) PERSPECTICA MEXICANA}

\section{THE ECONOMY AND THE PANDEMIC OF THE SARS- COV2 VIRUS (COVID-19) MEXICAN PERSPECTIVE}

\section{David Rincón Ávila}

Doctorante en Administración, Universidad de Celaya; Universidad de Guanajuato (UG); Profesor - Investigador. Correo electrónico: davidtak@ hotmail.com, rincond@ugto.mx.

\section{Irsa Daniela Botello Arredondo}

Doctorante en Artes, Universidad de Guanajuato; Universidad de Guanajuato (UG); Profesor - Investigador. Correo electrónico: botello.irsa@gmail.com.

\section{Dolores Guadalupe Álvarez Orozco}

Doctora en Administración, Universidad de Celaya, Dir. de Vinculación de la Universidad Politécnica de Guanajuato. Correo electrónico: dalvarez@upgto. edu.mx.

\section{Objetivo}

Identificar el impacto económico que ha tenido en México de la pandemia ocasionada por el virus SARS-CoV2 (COVID-19).

\section{Descripción del contexto}

Esta investigación documental se realiza en México, país en vías de desarrollo, ubicado en el continente americano y está caracterizado por sus altos flujos humanos, en febrero del 2020 México recibió 7.6 millones de turistas internacionales (Secretaria de Turismo, 2020), esto llevó como consecuencia el ingreso del virus hacia la población mexicana, reportando al 26 de abril 14677 casos confirmados (Secretaría de Salud, 2020).

\section{Metodología}

Esta investigación implementó un enfoque cualitativo y un diseño de investigación documental hermenéutico con una delimitación temporal del 1 al 26 abril del 2020, donde se ubicaron los reportes que hacen referencia al país de México, 


\section{Hallazgos}

La pandemia generada por el virus coronavirus (COVID-19), al 19 abril, ha reportado 2.4 millones de casos infectados y 165000 muertos a nivel mundial (Foro Económico Mundial, 2020), esta situación ha creado una crisis sanitaria, además el efecto secundario es la inestabilidad económica, este último aspecto ha paralizado gran parte de las tareas productivas y a la sociedad en general (CEPAL, 2020).

Menciona Cárdenas (2020), la crisis económica que está viviendo el mundo, América Latina y en particular en México permanecerá un largo tiempo y tendrá efectos económicos importantes, Soto (2020), refiere que el Covid-19 se ha salido de control y pone de manifiesto cómo la globalización incluye a países con más y con menos desarrollo, además ha afectado y trastocado todos los sistemas (sociales, políticos y económicos) donde interactúa el hombre, modificando el entorno de manera significativa. Para Cárdenas (2020), México el gobierno federal, está en una posición de reducir la demanda, comprimir los ingresos y no apoyar a las empresas privadas que son las que deberían de estar generando empleos y garantizando su permanencia en el sistema económico.

El informe de la Comisión Económica para América Latina (CEPAL) generado en abril del 2020, menciona que América Latina y el Caribe enfrentan la pandemia con una perspectiva económica endeble a la del resto del mundo; ya que los pronósticos de los indicadores para la región mostraban que esta crecería un máximo del 1,3\% en el presente año. Sin embargo, tomando en cuenta la pandemia que se está viviendo a nivel mundial ha afectado el desarrollo de la zona con resultados PIB de al menos un 1,8\%, así como contracciones de entre un 3\% y un 4\% en la región.

De acuerdo a los análisis económicos que se han ejecutado coinciden en que la crisis económica que se está empezando a presentar en América Latina, y en específico México, durará algunos años, por ello se requiere un modelo económico que fomente flujos de comercio y evite las consecuencias de falta de economía a las próximas generaciones. En un enfoque globalizado, se puede identificar que los impactos del virus en la economía se catalogan de tres formas: 1. Demanda de bienes y servicios (consumo e inversión para reactivar la economía), 2. El aislamiento social obligado en cada uno de 
nuestros países con la intención de producir el menos número de contagios y con esto afectar de menor manera las actividades económicas y sociales y 3 . Oferta (afectaciones en las cadenas de suministros a nivel mundial, lo que afecta de manera importante la generación de bienes y servicios (Martínez, 2020).

Finalmente, y por desgracia en el país México se observa en la práctica que el diseño de distribución de la riqueza es sumamente injusta e inequitativo. Por qué en un país con un alto porcentaje de habitantes en pobreza y pobreza extrema, y que tiene un contraste tan ofensivo en las clases sociales, y trasladado este problema a la salud, se observa, por lo tanto, una gran carencia y déficit en la salud de un pueblo. México podría tardar hasta una década en estabilizar su economía a causa de la pandemia del virus sars-COV2 (COVID-19) (CEPAL, 2020).

\section{Referencias bibliográficas}

Banco Mundial. (2020). Respuesta del Banco Mundial a la Covid-19 (Coronavirus) en América Latina y el Caribe. Recuperado de: https://www.bancomundial. org/es/news/factsheet/2020/04/02/world-bank-response-to-covid-19coronavirus-latin-america-and-caribbean

Cárdenas, E. (2020, 23 de abril). El Financiero. Nos espera una larga crisis. Disponible en: https://www.elfinanciero.com.mx/opinion/enrique-cardenas/nos-esperauna-larga-crisis

CEPAL. (2020). Comisión Económica para América Latina y el Caribe. La única opción estratégica en el mediano plazo para mitigar los efectos del COVID-19 en la región es avanzar hacia un nuevo modelo de desarrollo a través de una mayor integración.Recuperado de: https:/www.cepal.org/es/comunicados/ la-unica-opcion-estrategica-mediano-plazo-mitigar-efectos-covid-19-laregion-es-avanzar.

Foro Económico Mundial. (2020). Here are the drugs, vaccines and therapies in development to tackle COVID-19. Recuperado de : https://www.weforum. org/agenda/2020/04/drugs-vaccines-therapies-covid19-health/?utm 
source $=$ sfmc\&utm_medium $=$ email\&utm_campaign $=2717243 \_$Agenda weekly-24April2020\&utm_term=\&emailType=Newsletter

Huitrín, A. y González, K. (2020, 26 de marzo). Nexos. Los efectos macroeconómicos del COVID-19 en México. Recuperado de: https://economia.nexos.com. $\mathrm{mx} / \mathrm{p}=2967$

Martínez, J. (2020). Contexto económico del COVID-19. EGADE IDEAS Thougth Leadership in Action. Recuperado en: https://egade.tec.mx/es/egade-ideas/ investigacion/contexto-economico-del-covid-19

Morales, Y. (2020, 12 de abril). El Economista. El Banco Mundial prevé contracción de $6 \%$ para México por efecto de medidas contra el Covid-19. Disponible en: https://www.eleconomista.com.mx/economia/El-Banco-Mundialpreve-contraccion-de-6-para-Mexico-por-efecto-de-medidas-contra-elCovid-19-20200412-0018.html

Soto, F. (2020, 23 de abril). El Independiente. La pandemia del siglo y la tecnología e innovación. Disponible en: https://www.elindependientedehidalgo.com.mx/ la-pandemia-del-siglo-y-la-tecnologia-e-innovacion/

Secretaria de Turismo. (2020). Reporte de actividad turística febrero 2020. Recuperado de: https://datatur.sectur.gob.mx/SitePages/versionesRAT.aspx

Secretaria de Salud. (2020). Mapa de casos acumulados. Recuperado de: https:// covid19.sinave.gob.mx/ 


\title{
ANÁLISIS DEL TECNOESTRÉS Y DIFERENCIAS DE PERCEPCIONES ENTRE LOS MODELOS EDUCATIVOS PRESENCIAL Y EN LÍNEA DURANTE EL AISLAMIENTO DEL CORONAVIRUS
}

\author{
ANALYSIS OF TECHNOSTRESS CONDITIONS \\ AND DIFFERENCES OF PERCEPTIONS BETWEEN \\ FACE TO FACE LEARNING MODEL WITH REGARD \\ ONLINE MODEL DURING CORONAVIRUS SOCIAL \\ DISTANCING
}

\author{
Carlos Alberto Moncada Sierra \\ Ingeniero en Mecatrónica, Adjunto de Investigación, Tecnológico Nacional de \\ México. Correo electrónico: m2003027@itcelaya.edu.mx. \\ Julián Ferrer Guerra \\ Maestro en Ciencias con Especialidad en Sistemas de Información, Profesor \\ Investigador, Tecnológico Nacional de México. Correo electrónico: julian. \\ ferrer@itcelaya.edu.mx.
}

\section{Objetivo}

Evaluar las condiciones de tecnoestrés en estudiantes que han enfrentado el distanciamiento social obligatorio, modificando su modelo educativo tradicional, a un modelo mediado en línea.

\section{Descripción del contexto}

Esta es una etapa sin precedentes, los estudiantes tradicionales, en modelos caracterizados por la interacción presencial han tenido que cambiar a un modelo en línea para el cual no necesariamente están preparados. En México 5.3 millones de personas en el sector de educación superior se han visto en la necesidad de suspender o modificar el modelo educativo que utilizan (ANUIES, 2020). La tendencia indica que siguen prefiriendo una educación presencial por todas las ventajas que esta representa (Ebner \& Gegenfurtner, 2019; Bejerano, 2008). El tecnoestrés es un padecimiento psicosocial negativo específico de los usuarios de tecnología derivado de la tecnoadición y tecnofobia con una sintomatología muy parecida a la del estrés convencional (Ventura et al., 2005). 


\section{Metodología}

Este es un estudio descriptivo, transeccional y con enfoque cuantitativo, se diseñó y validó un instrumento que fue aplicado a una muestra de 282 estudiantes, compuesto por cinco dimensiones, las tres primeras corresponden a la propuesta realizada por Salanova et al. (2007), que considera el tecnoestrés como daño psicosocial, se mide con tres tipos de dimensiones: 1) Afectiva, 2) Actitudinal y 3) Cognitiva. Se consideró medir la tecnoadicción (Gil Ibáñez, 2015), generada por el incremento sustancial en el uso de los medios digitales. Finalmente se incluye una dimensión conformada por un análisis comparativo entre los modelos presencial y en línea.

\section{Hallazgos}

Los sujetos en estudio presentan lo que se podría considerar un nivel alto de adicción a la tecnología, a la par que no presentan sentimiento de ineficacia al trabajar con tecnología lo cual resulta consistente con su perfil. Se pudo observar ansiedad, por revisar notificaciones constantemente, insomnio y un uso excesivo como distractor al aburrimiento. Se observa que presentan bajos niveles de fatiga. En su conjunto se observan síntomas de tecnoestrés en los participantes, pero su nivel puede ser considerado entre moderado y alto. No se encontró evidencia en el sentido que las variables de género, edad y carrera de estudio tuviesen diferencias significativas en los grupos que las conforman.

La percepción del modelo presencial resulta ser superior al virtual, generando condiciones de insatisfacción sobre el cambio obligado de modelo de aprendizaje, se observó que en el modelo presencial la única variable que resulta significativa es la percepción de los estudiantes sobre el interés del profesor en su aprendizaje. Mientras que en el modelo en línea se encontraron como significativas cuatro variables: interés del profesor en el aprendizaje, el ritmo de trabajo durante el curso, la estimulación del profesor y la forma en que el profesor facilita el aprendizaje. En un entorno virtual, los estudiantes confían en mayor medida en el facilitador para su proceso de aprendizaje, siendo tal vez consecuencia de su falta de experiencia. La conclusión general más importante permite establecer la complejidad que representa para los estudiantes acostumbrados al modelo presencial un cambio repentino y no deseado al modelo en línea. 


\section{Referencias bibliográficas}

Anuies. (2020). Respuestas de las Instituciones de Educación Superior Publica en México para enfrentar la crisis del Covid, Asociación Nacional de Universidades e Instituciones de Educación Superior, consultado en línea el 17 de abril, disponible en http://www.anuies.mx/media/docs/avisos/

Ebner, C., \& Gegenfurtner, A. (2019). Learning and Satisfaction in Webinar, Online, and Face-to-Face Instruction: A Meta-Analysis. Frontiers in Education, 4. https://doi.org/10.3389/feduc.2019.00092

Gil Ibáñez, A. (2015). Tecnoadicción: Una revisión teórica desde la psicología. http:// repositori.uji.es/xmlui/handle/10234/137398

Salanova, M., Llorens, S., \& Cifre, E. (2007). El tecnoestrés concepto, medida e intervención... - Google Académico. https://scholar.google. $\mathrm{com} / \mathrm{sch}$ olar? oi $=$ gsb20\&q=E1\%20tecnoestr\%C3\%A 9s\%20\%20 concepto $\% 2 \mathrm{C} \% 20$ medida\%20e\%20intervenci $\%$ C 3\%B 3 n $\% 20$ psicosocial\&lookup $=0 \& \mathrm{hl}=\mathrm{es}$

Ventura, M., Llorens Gumbau, S., \& Salanova, M. (2005). El tecnoestrés: Un estudio del desarrollo de diferentes instrumentos de medida. 


\title{
UNA APROXIMACIÓN AL COVID-19 COMO ACTOR- RED Y LAS MUTACIONES DEL CONSUMO
}

\author{
AN APPROACH TO COVID-19 AS AN ACTOR- \\ NETWORK AND CONSUMPTION MUTATIONS
}

\section{Jorge Sánchez-Maldonado}

Mg. Sc. En ecología humana y saberes ambientales. Jefe del Centro de Investigación Jorge Eliécer Gaitán de la Escuela de Derecho y Ciencias Sociales - Corporación Universitaria del Meta. Villavicencio, Colombia. Correo electrónico: jorge.sanchez@unimeta.edu.co.

\section{Yully Rodríguez Garzón}

Psicóloga. Investigadora independiente, miembro del Semillero de investigación interdisciplinario en Ecologías humanas y estudios biopolíticos. Correo electrónico: yullymallerly@gmail.com.

\section{Objetivo}

Analizar las formas en que un agente patógeno como el Covid-19, influye en la transformación los modos de vida de poblaciones humanas, afectando las esferas económicas, culturales, políticas y epistemológicas.

\section{Descripción del contexto}

Desde la antropología de las emociones y la psicología cultural, se puede abordar un amplio espectro de problemáticas de la vida individual y social. La pandemia declarada oficialmente por la Organización Mundial de la Salud - OMS el 11 de marzo del presente año (OMS, 2020), es una evidencia de la forma en que el Covid-19 ha afectado las esferas de la vida social, cultural, afectiva, emocional, económica y política de las sociedades humanas. Más allá de discutir las medidas tomadas por gobiernos para enfrentar a un agente patógeno que en otras circunstancias hubiera estado relegado a estudiarse únicamente en laboratorios por ciencias relacionadas con la medicina y la biología entre otras, desde una perspectiva interdisciplinaria vale la pena explorar cómo su fuerza letal nos inclina a reconocerle un nivel de agencia sobre lo humano, que se muestra como un punto de análisis para repensar lo social, las distinciones entre un 
mundo natural y un mundo social como entidades independientes y, además, a rastrear las formas en que el Covid-19 actúa modificando tradiciones, hábitos e incluso las formas en que comprendemos aquello que entendemos como "realidad". Así, nos preguntamos ¿cómo es posible que un agente compuesto de ARN y envuelto en proteínas que no podemos ver a simple esfuerzo ocular, se inmiscuya en los rincones más sacros de lo que históricamente hemos entendido como esferas exclusivamente humanas?

\section{Metodología}

Se parte de un enfoque cualitativo en tanto se busca comprender los fenómenos que se abordan. La etnografía, entendida como ejercicio de observación de las cotidianidades de los grupos sociales, es una herramienta que permite develar el sentido de sus prácticas y de lo que los actores dicen acerca de ellas (Restrepo, 2016). Considerar al Covid-19 como un actor-red (Latour, 2008), implica rastrear las relaciones que elementos heterogéneos (humanos y no humanos) establecen entre sí para crear mundos y realidades como la pandemia. Por ello, se realizan descripciones lo más objetivas posibles donde "objetivo" implica describir los entramados humano-naturales que dan sentido a lo que entendemos en otro espacio como el objeto de una "etnografía inter-especies" (SánchezMaldonado, 2018). Además, la revisión documental y el seguimiento de noticias a través de redes y las tecnologías de la información masiva, han sido fundamentales para hacer frente a limitaciones de un tradicional trabajo de campo marcado por el inevitable y siempre deseable contacto con la gente propio de las ciencias sociales.

\section{Hallazgos}

La investigación ha permitido comprender cómo el Covid-19 se convierte en vehículo de emociones tan básicas como el miedo y ver cómo éste es determinante, en el cambio de las formas de movilidad de la población. Además, el miedo lleva a que los patrones de consumo se modifiquen progresivamente, al punto que la gente prefiere gastar sus recursos en elementos de primera necesidad, no obstante que en algunos sectores sociales aumenta el de los llamados lujos (Scitovsky, 1986), particularmente plataformas de entretenimiento como el streaming. Esto lleva a una comprensión del consumo como aquello que da cuenta -a nosotros mismos- sobre lo que devenimos al ser vivos y sociales (Cortina, 2002). 


\section{Referencias bibliográficas}

Cortina, A. (2002). Por una ética del consumo. La ciudadanía del consumidor en un mundo global. Taurus - Pensamiento. Santillana Ediciones Generales. Santa Fe de Bogotá, Colombia. Impreso en España.

Latour, B. (2008). Reensamblar lo social. Una introducción a la teoría del actor-red. Manantial. Buenos Aires, Argentina.

Organización Mundial de la Salud. (2020). Covid-19: Cronología de la actuación de la OMS. En: https://www.who.int/es/news-room/detail/08-04-2020-whotimeline---covid-19

Restrepo, E. (2016). Etnografía. Alcances, técnicas y éticas. Envion Editores. Departamento de Estudios Culturales - Pontificia Universidad Javeriana. Bogotá, Colombia.

Sánchez-Maldonado, J. (2018). Familias-más-que-humanas. Sobre las relaciones humanos/no-humanos y las posibilidades de una etnografía inter-especies en Colombia. Desenvolvimento e meio ambiente. Vol. 49. Dezembro 2018. pp. 305 - 317. Universidad Federal de Paraná - UFPR. Brasil.

Scitovsky, T. (2014). Necesidades y lujos. En: Revista de Economía crítica. Núm. 17. ISNN 2013-5254. Pp. 174 - 190 http://revistaeconomiacritica.org/sites/ default/files/12_TiborScitovsky_NecesidadesComodidades_0.pdf 


\title{
NIÑEZ Y MUJER DURANTE LA PANDEMIA \\ DEL COVID-19. UNA MIRADA AL CASO \\ LATINOAMÉRICANO
}

\section{CHILDHOOD AND WOMAN IN COVID-19 TIMES. A LOOK AT THE LATIN AMERICAN CASE}

\author{
Jairo Alberto Olarte Cabana \\ Magister en contabilidad, docente investigador de UNIPANAMERICANA, \\ Fundación Universitaria Panamericana Valle.Correo electrónico:jalbertoolarte@ \\ unipanamericana.edu.co.
}

\section{Objetivo}

Analizar desde una perspectiva crítica la situación que enfrenta la niñez y la mujer durante la pandemia del COVID-19 en Latinoamérica.

\section{Descripción del contexto}

Latinoamérica desde su génesis y aun en las pautas diarias del siglo XXI, ha sido un territorio asaltado por flagelos sociales como el hurto y la corrupción, aunado a ello, el COVID-19 ha impacto en la latitud sur a través de diversos frentes, por ejemplo, la economía (desempleo, mayor endeudamiento del Estado, aumento de la pobreza), las organizaciones (cierre, costos emergentes, incremento de precios, endeudamiento), la niñez (impactos menormente visibles), la mujer (impactos ignorados), entre otros. De manera especial, esta nota busca disertar sobre la criticidad que representa para la niñez y las mujeres afrontar la pandemia en América Latina, especialmente, por la desprotección y el olvido de sus especificidades durante este momento histórico. Frente a lo anterior, el abordaje propuesto pudiera representar el punto de reflexión e inflexión que permita volver la mirada hacia dicha comunidad y aportar, desde los gobiernos y otras instancias, mayores oportunidades de prevención y estabilidad en medio de la crisis sanitaria.

\section{Metodología}

Desde las premisas planteadas por Méndez (2011), esta nota se suscribe a las bases de la investigación cualitativa y utiliza recursos documentales expedidos por 
organizaciones como la Comisión Económica para América Latina y el Caribe (CEPAL), United Nations Children's Fund (UNICEF por sus siglas en inglés), entre otros, como fuentes primarias de información. Para el análisis de las categorías "Niñez" y "Mujer" (ver tabla 1), se partió de un sistema fundamentado en la revisión de literatura, luego se operacionalizó bajo el enfoque de Reguant y Martínez-Olmo (2014) y se determinaron subcategorías e indicadores que permitieran el análisis de contenidos (Bardin, 2000), su interpretación y la generación de inferencias soportadas en los datos estudiados y tratados (codificación) a través del software Atlas. Ti.

Tabla1. Operacionalización de categorías.

\begin{tabular}{lll} 
Categoría & Subcategoría & Indicadores \\
\cline { 2 - 2 } & Educación & Acceso \\
\cline { 2 - 3 } Niñez & Alimentación & Cuidado \\
\cline { 2 - 3 } & Estabilidad emocional & Programas de alimentación escolar \\
\cline { 3 - 3 } & Educación & Primera infancia \\
\hline & Trabajo & Afecto \\
\cline { 2 - 3 } & Familia & Acceso \\
\cline { 2 - 3 } Mujer & Tiempo \\
\hline
\end{tabular}

Fuente: elaboración propia, basada en la recolección de los datos (2020).

\section{Hallazgos}

Con respecto a la categoría "Niñez", se identificó que los tres indicadores son altamente críticos y se interrelacionan directamente, es decir, si no hay acceso a la educación se afecta el desarrollo sociocognitivo, el disfrute de los servicios alimentarios que miles de niños reciben en la escuela y se niega la oportunidad de sinergias y didácticas fundamentadas en la virtualidad pues las minorías no siempre acceden al servicio de banda ancha. Sobre la categoría "Mujer", resulta significativo el impacto que la pandemia ha ejercido en las subcategorías propuestas, esto último, obtiene fundamento si se reconoce que en Suramérica la mujer articula simultáneamente y con mayores exigencias de tiempo, las actividades de formación de capital humano, 
el trabajo y la familia (cuidado, especialmente de los niños), excediendo las jornadas habituales, representando así altos niveles de estrés y agotamiento. Finalmente, a través de la política pública se pudieran favorecer condiciones que privilegien los dos actuantes de referencia; no obstante, solo será una posibilidad bajo las premisas de una ética del bien común y la erosión a la desigualdad exacerbada.

\section{Referencias bibliográficas}

Comisión Económica para América Latina y el Caribe (CEPAL). (2020). América Latina y el Caribe ante la pandemia del COVID-19. Efectos económicos y sociales. En: https://www.cepal.org/es/publicaciones/45337-america-latinacaribe-la-pandemia-covid-19-efectos-economicos-sociales 


\section{CAPACIDAD DE RESPUESTA DEL SISTEMA DE SALUD COLOMBIANO PARA AFRONTAR EL COVID-19}

\section{RESPONSE CAPACITY OF THE COLOMBIAN HEALTH SYSTEM TO FACE THE COVID-19}

\section{Mario Samuel Rodríguez Barrero}

Doctorando en Administración Gerencial, Magíster en Dirección de Marketing. Profesor Investigador Universidad Cooperativa de Colombia. Correo electrónico: mario.rodriguezb@campusucc.edu.co.

\section{Aracelly Buitrago Mejía}

$\mathrm{PhD}$ Ciencias económicas y administrativas. Docente Universidad del Tolima. Correo electrónico: abuitragom@ut.edu.co.

\section{Gustavo Adolfo Rubio Rodríguez}

$\mathrm{PhD}$ en Ciencias Gerenciales. Docente Investigador Universidad Minuto de Dios. Correo electrónico: gustavoadolforubio@gmail.com.

\section{Objetivo}

Analizar la capacidad de respuesta del Sistema de Salud colombiano para afrontar el Covid-19 desde una perspectiva crítica.

\section{Descripción del contexto}

Colombia es un país cerca de 50 millones de habitantes y obtuvo un PIB superior a mil billones de pesos en 2019 con un crecimiento del 3.3\%, posicionándose como la cuarta economía de la región después de Brasil, México y Argentina (Ministerio de Industria Comercio y Turismo, 2020). Según el Departamento Nacional de Estadísticas DANE, la inflación para 2019 fue de 3.8\%, el desempleo ascendió a 10.5\%, la pobreza monetaria fue $27 \%$ y pobreza la extrema fue $7,2 \%$ en 2018 , estadísticas que representan un coeficiente de GINI de 0,517 cuando en 2017 fue 0.508, evidenciando un aumento en la desigualdad. La salud en Colombia está regulada por la Ley 100 de 1993 y se gestiona mediante un sistema descentralizado que facilita la cobertura universal, caracterizado por la competencia controlada entre las Entidades Promotoras de Salud 
EPS. Los ciudadanos pueden escoger la EPS de su preferencia para afiliarse bajo las modalidades de régimen contributivo, subsidiado o especial, según su condición; por su parte, las EPS contratan a las Instituciones Prestadoras de Servicios IPS como clínicas, hospitales y centros de diagnóstico, mientras las entidades territoriales cumplen el papel de inspección y vigilancia. Este modelo ha sido evaluado favorablemente por organizaciones internacionales como la OMS y la OPS, sin embargo, en la práctica son frecuentes las dificultades que se representan. Una de las debilidades de este sistema de salud es que, aunque aumentó la cobertura disminuyó el acceso a los servicios, pues según Ayala-García (2014) el acceso a los servicios médicos en Colombia se redujo de $79.1 \%$ a $75.5 \%$, dificultad que se evidencia en el número de quejas que, en 2019, correspondió a 694068 PQRD ante la Superintendencia de Salud (2019), 83\% de las cuales hacen referencia al acceso a los servicios y un $12 \%$, a procesos administrativos y falta de efectividad en el servicio. Paralelamente en 2018 se presentaron 207734 tutelas, que representan el 5.2\% del total y un incremento del 5\% (Defensoría del pueblo, 2019). Esta situación permite identificar cómo debilidades del Sistema de Salud la insatisfacción de los usuarios, la prevalencia de enfermedades y eventos adversos, el traumatismo administrativo, aumento de enfermedades de alto costo por la falta de prevención e intervención oportuna y altos costos por indemnizaciones, aunado a la desfinanciación del sistema, la subcontratación de servicios y personal de salud y la corrupción que tienen en crisis al Sistema.

\section{Metodología}

Este análisis se hace a partir de un enfoque cualitativo y un diseño de investigación documental siguiendo a Hernández y Mendoza (2018), la técnica de recolección de datos es sistematización de información con el objeto de ser interpretada y analizada, teniendo como fuentes de información entidades como el Instituto Nacional de Salud, el Ministerio de salud y la Superintendencia de Salud. Una vez recolectada esta información, se hace su respectivo análisis teniendo en cuenta las estadísticas de la pandemia, para determinar la capacidad del Sistema.

\section{Hallazgos}

El 6 de marzo se reportó en Colombia el primer caso de Covid-19 y debido a la falta de control en aeropuertos, terminales y puertos, se expandió rápidamente por el país, sin 
embargo, gracias a las medidas de confinamiento se desaceleró su expansión. Bogotá presenta más del $40 \%$ de los casos y ha preparado el Centro de Corferias para coadyuvar la atención en salud ampliando la capacidad del Sistema, así como lo han hecho otras ciudades. Colombia reporta a 6 de mayo 8613 casos. Los principales aciertos del Gobierno han sido el confinamiento que ha disminuido el contagio del 25\% al 8.1\% (La República, 2020), así como la atención social durante la crisis.

Las principales dificultades que enfrenta el Sistema son de tipo financiero, los casos de corrupción con recursos destinados a atender la pandemia, deficiencias en el manejo de muestras y la falta de pruebas que está en 821 por millón de habitantes, por debajo de Chile, Panamá, Perú y Costa Rica, además, la falta de elementos de protección para los funcionarios de la salud que ha facilitado el contagio a cerca de 200 empleados (Semana, 2020). El 27 de abril se aprobó la reactivación de la construcción y manufactura bajo los protocolos de bioseguridad definidos en la Resolución 666 de 2020 del Ministerio de Salud, para tener un estricto control y evitar que los contagios sobrepasen la capacidad del sistema, sin embargo, la Organización Mundial de la Salud, ha instado a los gobiernos a mantener el aislamiento mientras no existan garantías suficientes, pero la pobreza, informalidad y el hambre que no dan espera, y las ayudas para atender la crisis social no han sido suficientes ni oportunas, por lo que esta pandemia se ha convertido en un desafío para que el Estado escuche a los más pobres, atienda las problemáticas del sector salud. Se concluye que, aunque el Sistema no ha colapsado, su capacidad de respuesta para enfrentar la pandemia es baja y se debe ampliar el número de muestras, así como de camas para un eventual incremento de infectados, una vez se retomen las actividades económicas, como sucederá a partir del 11 de mayo.

\section{Referencias bibliográficas}

Ayala-García J. (2014). La salud en Colombia: más cobertura, pero menos acceso. Serie Documentos de Trabajo Sobre Economía Regional. Banco de la República Sucursal Cartagena. (204), 1-39.

Congreso de la República de Colombia. (1993). Ley 100 de 1993. Por medio de la cual se crea el sistema de seguridad social integral y se dictan otras disposiciones. Diario Oficial No. 41.148 de 23 de diciembre de 1993. Bogotá: Colombia. 
Defensoría del Pueblo. (2018). La tutela y los derechos a la salud y a la seguridad social. Recuperado el 19 de diciembre de 2019 de https://www.defensoria. gov.co/public/pdf/Tutela-los-derechos-de-la-salud-2018.pdf

Departamento Nacional de Estadísticas DANE. (2019). Boletín Técnico Pobreza Monetaria en Colombia 2018. Consultado en https://www.dane.gov.co/files/ investigaciones/condiciones_vida/pobreza/2018/bt_pobreza_monetaria_18. pdf

Hernández, R. y Mendoza, C. (2018). Metodología de la investigación: las rutas cuantitativa, cualitativa y mixta. McGraw Hill México.

Leal-Acosta, A. C. (24 de abril de 2020). Evolución de diagnósticos de Covid-19 en Colombia. La República. Consultado en https://www.larepublica.co/ economia/desde-el-primer-caso-los-contagios-por-covid-19-han-crecido25-diariamente-2996935

Ministerio de Industria Comercio y Turismo. (2020). Noticia de Industria. Consultado el 14 de febrero de 2020 en https://www.mincit.gov.co/prensa/noticias/ industria/comercio-y-turismo-motores-crecimiento-economico

Semana. (25 de abril de 2020). Así va la curva del coronavirus. Sección salud. Consultado el 26 de abril de 2020 en https://www.semana.com/economia/ articulo/asi-va-la-curva-del-coronavirus/665964

Superintendencia de Salud. (2019). Comportamiento de peticiones, quejas, reclamos o denuncias (PQRD) y solicitudes de información formuladas por los usuarios del Sistema Nacional de Salud ante la Superintendencia de salud en el período comprendido entre enero y noviembre de 2019. Bogotá: Colombia. 


\section{ACCIÓN DE LOS GOBIERNOS LOCALES EN LA ATENCIÓN A LA PANDEMIA COMO EXPRESIÓN DE LA TENSIÓN ENTRE REPRESENTACIONES SOCIALES CONTRADICTORIAS}

\section{ACTION OF LOCAL GOVERNMENTS IN ATTENTION TO THE PANDEMIC AS AN EXPRESSION OF THE TENSION BETWEEN CONTRADICTORY SOCIAL REPRESENTATIONS}

Federico José Jiménez Varón

Magíster en Paz, Desarrollo y Ciudadanía. Profesor Investigador de la Universidad Minuto de Dios, Colombia.Correo electrónico: federico.jimenez@, uniminuto.edu.

\section{Objetivo}

Analizar la tensión entre los órdenes locales y centrales en el manejo de la emergencia de salud pública ocasionada por la covid-19 en Colombia durante los 15 días después de su arribo al país.

\section{Descripción del contexto}

Oficialmente la llegada de la covid-19 a Colombia tuvo lugar el 6 de marzo de 2020 cuando una ciudadana de 19 años procedente de Milán, Italia, acudió a los servicios de salud con los síntomas asociados al virus. Una vez confirmado el diagnóstico, el Ministerio de Salud nacional activó la etapa de contención y los respectivos planes de contingencia con las entidades del sector. Por su parte, los cursos de acción tomados por los y las diferentes jefas del poder ejecutivo de los ordenamientos territoriales y departamentales contrastaron con las medidas iniciales del gobierno central en al menos dos aspectos: i) el tiempo de reacción ante la presencia del virus en el país; y ii) el tenor de las medidas tomadas por las diferentes jefaturas locales. 


\section{Metodología}

Se utilizó como estrategia metodológica el análisis de representaciones sociales dentro de un enfoque cualitativo-interpretativo y que permite estudiar las creencias que motivan los cursos de acción de los individuos o sujetos de estudio (Araya, 2002), que para el caso son los decretos 418 de marzo de 2020 y 531 de abril de 2020, alocuciones presidenciales, notas y boletines de prensa emitidos en medios oficiales y privados (ver referencias bibliográficas).

\section{Hallazgos}

Según los datos del Ministerio de salud (Boletín de Prensa No. 050) para el 6 de marzo de 2020, 96 países reportaban la llegada de la pandemia a sus territorios de modo que existía un acervo significativo de experiencia mundial acumulada en el manejo y la gestión del riesgo de acuerdo con los protocolos de la Organización Mundial de la Salud. Esta experiencia indicaba que dentro de los cursos de acción más efectivos y recomendables para un país se encontraban, entre otros, el decretar la cuarentena en los territorios y el cierre total de los aeropuertos internacionales. Justamente, este fue el espíritu de las primeras medidas tomadas por parte de los y las gobernantes locales, quienes emitieron decretos que ordenaban simulacros de toques de queda y cuarentenas a todos los y las habitantes de sus ciudades, pueblos y departamentos, así como el cierre de sus vías de acceso y la suspensión del transporte local.

Ante estas iniciativas, la primera reacción del gobierno central consistió en emitir el decreto 418 del 18 de marzo de 2020 "Por el cual se dictan medidas transitorias para expedir normas en materia de orden público" y que dejaba sin efecto a las medidas tomadas por los alcaldes, alcaldesas y gobernadores con el argumento de que: La dirección del manejo del orden público con el objeto de prevenir y controlar la propagación del COVID-19 en el territorio nacional y mitigar sus efectos, en el marco de la emergencia sanitaria por causa del coronavirus COVID-19, estará en cabeza del presidente de la República" (Decreto 418 de 2020, cursivas añadidas).

El 20 de marzo de 2020, en alocución presidencial, Iván Duque anunció las medidas de contención por parte de su gobierno entre las que se encuentra el aislamiento 
preventivo obligatorio y un paquete de medidas económicas. Sólo hasta el 8 de abril el gobierno nacional expidió el decreto 531 "Por el cual se imparten instrucciones en virtud de la emergencia sanitaria generada por la pandemia del Coronavirus COVID-19, y el mantenimiento del orden público" en el que se ordena el aislamiento preventivo obligatorio en todo el territorio colombiano con excepción de 35 actividades consideradas condición de posibilidad de garantizar el orden público y el derecho a la vida. Únicamente los vuelos nacionales comerciales fueron restringidos en su totalidad.

Esta tensión entre los gobiernos locales y el gobierno central puede ser interpretada como la expresión manifiesta de una sensación presente desde hace tiempo en la sociedad colombiana -que empezó a materializarse en las movilizaciones sociales de noviembre de 2019- y que consiste en el clamor colectivo por formas de gobierno más orientadas al cuidado de la vida y la dignidad que a la conservación de las condiciones de posibilidad del actual modelo económico. En efecto, las redes sociales, los cacerolazos y las demás manifestaciones de apoyo a las decisiones de los gobernantes locales por parte de amplios sectores de la población, indican que hay unas nuevas ciudadanías gestándose y que la pandemia puede hacer surgir o renacer una conciencia colectiva resistente a las urgencias de la lógica del mercado.

\section{Referencias bibliográficas}

Araya, S. (2002). Las representaciones sociales. Ejes teóricos para su discusión. En: Cuadernos de Ciencias Sociales, 127. Flacso Ed. Costa Rica.

Alocución presidencial de Iván Duque Márquez del 20 de marzo de 2020. Recuperada de: https://www.youtube.com/watch?v=18RWEvBSbHI

Ministerio de Salud de Colombia, Boletín de Prensa No. 050 del 6 de marzo de 2020. Recuperado de: https://www.minsalud.gov.co/Paginas/Colombia-confirmasu-primer-caso-de-COVID-19.aspx

Ministerio del Interior de Colombia. Decreto 418 de 2020. Recuperado de: https://dapre. presidencia.gov.co/normativa/normativa/DECRETO\%20418\%20DEL\%20 18\%20DE\%20MARZO\%20DE\%202020.pdf 


\title{
IMPACTO ECÓNOMICO EN EL TRANSPORTE PÚBLICO DEL TOLIMA ANTE LA PRESENCIA DEL CORONA VIRUS (COVID-19)
}

\section{ECONOMICAL IMPACT TO PUBLIC TRANSPORT IN THE TOLIMA STATE (REGION) BY COVID-19}

\author{
Ingrid Eliana Gómez \\ Estudiante IX Semestre, Contaduría Pública, Corporación Universitaria \\ Remington. Correo electrónico: gómez_248@hotmail.com.
}

\section{Objetivo}

Analizar desde una perspectiva crítica el Impacto Económico en el Departamento del Tolima, ante la presencia del (COVID-19); enfatizando el impacto en las Empresas de Transporte Público de pasajeros en la ciudad de Ibagué.

\section{Descripción del contexto}

La crisis del Coronavirus, ha afectado gravemente la economía colombiana; los efectos de la cuarentena, los están sintiendo, la gran mayoría de las familias colombianas, sobre todo esas que dependen del trabajo informal e independiente, cuyos ingresos se desplomaron a cero, las economías ligadas al turismo y al comercio minorista han sido las más afectadas en regiones como el Tolima, para este trabajo en particular, analizaremos el caso de las empresas que prestan el servicio de transporte público colectivo en la ciudad de Ibagué.

El Tolima es un departamento que cuenta con 1,4 millones de habitantes, y su producto interno bruto representa el 2,1\% del PIB Nacional (DANE, 2020), siendo equivalente a 19453 miles de millones. Para Abril del 2020, en el Tolima se han identificado 40 casos de infectados con el covid-19 según la cifra del INS, sin embargo y a pesar que el número de contagios a la fecha no es significativo, este sigue incrementándose con el paso de los días; debido a las medidas adoptadas por el gobierno nacional, el 95\% de la población Tolimense se encuentra en aislamiento preventivo obligatorio en sus viviendas, lo cual genera una parálisis en la economía departamental, afectando a varios 
sectores, principalmente al sector turístico, y el comercio Minorista, y en caso particular para la ciudad de Ibagué, el servicio de transporte público en la modalidad, colectivo urbano de pasajeros.

\section{Metodología}

El presente escrito tiene un enfoque cualitativo y un diseño de investigación documental que emplea la hermenéutica y análisis de fuentes reales como artículos y entrevistas, se utiliza como técnica de recolección de datos la tabulación de datos referentes a estrategias adoptadas por diferentes empresas del sector transporte público, colectivo de pasajeros, para enfrentar el impacto de COVID-19 en sus economías. El formato utilizado para dicha sistematización se presenta en la tabla 1.

Tabla1 Tabulación de Estrategias.

\begin{tabular}{ll}
\hline Empresa & Estrategia \\
\hline Cooperativa Expreso Ibagué & Suspensión de contratos a 250 Conductores \\
\hline Expreso Galarza & Suspensión de Contratos 186 Conductores \\
\hline Cotrautol & Suspensión de Contratos 350 Conductores \\
\hline
\end{tabular}

Fuente: Diario El cronista - Diario el Nuevo Día - Diario El Olfato.

\section{Hllazgos}

Según la información recolectada, podemos verificar las acciones que han tomado las empresas que prestan el servicio de transporte público de pasajeros en la ciudad de Ibagué, en consecuencia, a las medidas tomadas por la pandemia, suman un número representativo de trabajadores que quedaron desempleados ascendiendo la cifra a 786 personas, lo cual impacta el índice de desempleo de Ibagué y del Tolima que de por sí ya se ubica en el 18,3\% según Dane (2020). Es común encontrar que las empresas analizadas adoptan esta determinación para evitar un descalabro en sus finanzas teniendo en cuenta tanto la pandemia declarada por causa del coronavirus COVID-19, como las órdenes y medidas decretadas de manera temporal por el Gobierno Nacional y la Administración Municipal, han afectado gravemente la actividad económica del sector, debido a la suspensión temporal y total de actividades y labores. 
- La economía nacional y departamental se ha visto afectada exponencialmente por la cuarentena declarada como medida ante COVID-19.

- Particularmente el sector del transporte público colectivo de pasajeros en la ciudad de Ibagué ha sufrido tal impacto que se vio obligado a suspender el contrato de sus trabajadores con el fin de evitar el cierre total de actividades, por falta de liquidez.

- Las empresas del transporte público, debido a esta crisis sanitaria, social y económica que se presenta, tienen que llegar a reinventar varios de sus procesos para no quedarse rezagadas ante la posibilidad real de más cuarentenas en el país para mantener la curva de infección lo más aplanada posible.

\section{Referencias bibligráficas}

Diario El cronista.co https://www.elcronista.co/aldea/flota-andres-lopez-de-galarzasuspende-contratos-a-mas-180-conductores

Diario El Olfato https://www.elolfato.com/expreso-ibague-suspende-contratos-a-masde-270-conductores-de-transporte-publico-en-medio-de-la

Cooperativa Expreso Ibagué LTDA - Resolución 001 del 7 de abril 2020.

DANE www.dane.gov.co. 


\title{
INCIDENCIA DEL COVID-19 EN EL CONTEXTO ECONÓMICO LATINOAMERICANO
}

\section{IMPACT OF COVID19 IN THE LATIN AMERICAN ECONOMIC CONTEXT}

\author{
Sandra Milena Malavera Pineda \\ Magister en Dirección de Marketing. Universidad Católica Luis Amigó. Correo \\ electrónico: sandra.malaverapi@amigo.edu.co.
}

\section{Objetivo}

Establecer de manera general la incidencia del Covid-19 en el panorama actual a nivel Latinoamericano.

\section{Descripción del contexto}

Todo lo que ha generado la crisis por la expansión del COVID-19 permanecerá en la historia como una de las peores catástrofes económicas que se hayan vivido en la era actual "esta enfermedad que afecta el sistema respiratorio y es de rápido contagio masivo hace que ponga en la economía mundial que ya de por sí ha sido muy golpeada por las decisiones de los gobernantes de los países desarrollados; además su afectación será tanto por el lado de la oferta como de la demanda que traerá consigo un golpe severo al comercio internacional y ello se traducirá en la generación de menores ingresos para las compañías y la pérdida de un considerable número de empleos y por ende la reducción de las mayores debido a las amplias dificultades de los empresarios de pagar sus obligaciones con el sistema financiero.

\section{Metodología}

Esta investigación es de tipo descriptiva, ya que se desea analizar y determinar las diferentes situaciones, costumbres, características que se presentan incidencia del COVID-19, con la finalidad de dar un diagnóstico acerca de los resultados que se recopilarán durante los hallazgos de la investigación. El proyecto es realizado con base en la investigación no experimental; ya que no se manipularán variables, sino que se observarán fenómenos y situaciones dentro de su contexto real para posteriormente ser analizados. 


\section{Hallazgos}

El COVID-19 ha afectado notoriamente a la disminución de la actividad económica de los principales socios comerciales en las exportaciones de bienes y servicios de los países industrializados y que propenden por el sostenimiento comercial a nivel mundial. Un ejemplo de ello es China, quien es un promotor importante para las exportaciones de las economías Latinoamericanas, como Chile, Perú y Brasil, por ello las fuentes de la CEPAL indican que las exportaciones de la región a ese destino podrían caer hasta $10,7 \%$ en el año 2020 .

Un frente que se afectará, además, es la consecuente caída en la demanda de servicios de turismo, que ha impactado severamente a los países del Caribe. Se calcula que si las restricciones de viajes por la propagación del COVID-19 se prolonga por uno, dos, o tres meses, la actividad turística en el Caribe, por ejemplo, en 2020 se contraería respectivamente en $8 \%, 17 \%$ y $25 \%$.

Un tercer frente de transmisión se daría a través del colapso de las cadenas globales de valor. Esto tendrá un efecto directo en las economías principalmente a México y Brasil, países que importan partes y bienes intermedios desde China para su industria manufacturera (sobre todo en la venta de repuestos para automóviles, electrodomésticos, productos electrónicos y farmacéuticos).

Un cuarto frente que tiene una connotación directa en la región de América Latina y el Caribe está en el derrumbe de los precios de los productos básicos (commodities), sobre todo para los países que exportan materias primas en Suramérica. Y, un quinto frente de afectación se da por el incremento de los indicadores de riesgo que tienen los inversionistas y el decremento de las condiciones financieras globales, y estos efectos se pueden apreciar en la fuerte reducción de los índices bursátiles en la región.

El COVID-19 tiene un potencial relevante de reorganizar la globalización geopolítica, y a su vez, es también una oportunidad para tener presente los beneficios de la acción multilateral. Por ello, las Naciones Unidas están esforzándose en ver cómo la coordinación de políticas puede apoyar a los países en desarrollo, debido a que las 
asimetrías entre las naciones desarrolladas y en desarrollo se vislumbran cada vez con mayor claridad. Ningún país podrá combatir esta pandemia sin la cooperación a nivel regional. Finalmente, lo que realmente se requiere es más la integración. Es fundamental moverse hacia una mayor coordinación y la prioridad de las políticas debe ser cómo abordar la actual crisis social y de salud en Latinoamérica.

\section{Referencias bibliográficas}

Gopinath, G. (2020). Limiting the Economic Fallout of the Coronavirus with Large Targeted Policies. Disponible en: https://blogs.imf.org/2020/03/09/limitingtheeconomic-fallout-of-the-coronavirus-with-largetargeted-policies/

López-Calva, L., (2020). ¿Cómo podría afectar el coronavirus la economía de América Latina?, Post opinión, The Washington Post, 4 de marzo de 2020.

Spence, M., (2020). Can China's economy withstand the coronavirus? Disponible en: https://www.projectsyndicate.org /commentary/china-economycoronavirusresilience-by-michael-spence-2020-02

WEF (2020). Global uncertainty. The economic fallout from coronavirus. Disponible en: https://www.weforum.org/agenda/2020/02/containing-the-coronaviruswhat-s-the-risk-to-the-globaleconomy/ 


\title{
EFECTOS DEL COVID-19 EN LOS SISTEMAS CONTABLES Y ADMINISTRATIVOS EN COLOMBIA \\ EFFECTS OF COVID19 ON THE ACCOUNTING AND ADMINISTRATIVE SYSTEMS IN COLOMBIA
}

\author{
Paula Andrea Malavera Pineda \\ Magister en Tributación y Política Fiscal. Institución Universitaria Remington. \\ Colombia. Correo electrónico: paula.malavera@uniremington.edu.co.
}

\section{Objetivo}

Analizar los efectos del Covid-19 en los sistemas contables y administrativos de las organizaciones productivas en Colombia.

\section{DESCRIPCIÓN DEL CONTEXTO}

El COVID-19 ha transformado las condiciones organizacionales como inversionista en el entorno local, (Spence, 2020). Si usted hubiera invertido en una compañía, o si hubiera prestado dinero a una compañía, ¿cuál sería su interés financiero principal en la compañía? Estaría interesado probablemente en dos cosas, las cuales conforman las perspectivas de flujo de efectivo de la compañía. Usted estaría interesado en la devolución, en alguna fecha futura, de la cantidad que haya invertido o prestado. Nos referimos a esto como el retorno de su inversión. Adicionalmente, usted esperaría que la compañía le pagara algo por el uso de sus fondos, bien sea como propietario o como acreedor. Lo que se conoce como el retorno sobre su inversión. La información que le es útil al efectuar juicios sobre la capacidad que tiene la compañía para proporcionarle lo que usted espera en términos del retorno de sus fondos en el futuro y el retorno sobre sus fondos mientras que usted no los está utilizando en lo que entendemos por información acerca de las perspectivas de flujo de efectivo. Pero la propagación del COVID-19 ha tenido grandes repercusiones para los inversionistas porque las empresas no generan flujos de efectivo para el retorno de su inversión; afectando directamente su nivel de riesgo para la generación de dividendos. 


\section{Metodología}

Esta investigación es de tipo descriptiva, ya que se desea analizar y determinar las diferentes situaciones, costumbres, características que se presentan para determinar los efectos del COVID-19, en los sistemas contables y administrativos en Colombia con la finalidad de dar un diagnóstico acerca de los resultados que se recopilarán durante los hallazgos de la investigación.

\section{Hallazgos}

Los tipos de información contable que debe desarrollar una compañía varían con factores tales como el tamaño de las organizaciones, si son de propiedad pública, y la filosofía de la gerencia. La necesidad de algunos tipos de información contable puede ser dictaminada por la ley. Por ejemplo, las regulaciones del impuesto sobre la renta exigen que cada negocio tenga un sistema contable que pueda medir el ingreso gravable de la compañía y explicar la naturaleza y fuente y fuente de cada renglón en la declaración de impuestos sobre la renta de la compañía. Las leyes federales sobre Valores exigen que las compañías de propiedad del público preparen estados financieros de conformidad con los principios de contabilidad generalmente aceptados. Dichos estados se deben presentar a la Comisión de Valores y Cambios, distribuidos a los accionistas y puestos a disposición del público. Otro tipo de información contable es requerida como asunto de necesidad práctica. Por ejemplo, cada negocio necesita conocer las cantidades por cobrar de cada cliente y las cantidades debidas a cada acreedor.

La gente que participa en el mundo de los negocios: propietarios, gerentes, banqueros, corredores de bolsa, inversionistas utilizan los términos y los conceptos contables para describir los recursos y las actividades de todo negocio, sea grande o pequeño. Aunque la contabilidad ha logrado su progreso más notable en el campo de los negocios, la función contable es vital en todas las unidades de nuestra sociedad.

La reciente crisis por la epidemia mundial de coronavirus ocasionará efectos importantes en la economía global durante los primeros trimestres de 2020, (Barcená, 2020). Aunque todavía es muy pronto para evaluar los alcances de la enfermedad y sus efectos en la economía, en la presente nota se muestran algunas de las posibles 
implicaciones y medidas de política que diversos especialistas e instituciones financieras han vertido sobre el tema. La expansión la epidemia de coronavirus está afectando de forma importante la actividad económica global. Sectores como el turismo, el comercio y las cadenas de producción y abastecimiento se encuentran entre los principales afectados.

Respecto al área contable se reducirá de forma considerable el Registro de la actividad financiera, ya que en un sistema contable se debe llevar un registro sistemático de la actividad comercial diaria en términos económicos (López-Calva, 2020). En una empresa se llevan a cabo todo tipo de transacciones que se pueden expresar en términos monetarios y que se deben registrar en los libros de contabilidad. Una transacción se refiere a una acción terminada más que a una posible acción a futuro. Ciertamente, no todos los eventos comerciales se pueden medir y describir objetivamente en términos monetarios y debido a la reducción de la cadena productiva y al cierre de operaciones; las organizaciones no tendrán muchos movimientos respecto a los hechos económicos que afectan su crecimiento económico.

\section{Referencias bibliográficas}

Barcená A. (2020). COVID-19 tendrá graves efectos sobre la economía mundial e impactará a los países de América Latina y el Caribe. Cepal (19 de marzo de 2020). Tomado de: https://www.cepal.org/es/comunicados/covid-19-tendragraves-efectos-la-economia-mundial-impactara-paises-america-latina

López-Calva, L., (2020), ¿Cómo podría afectar el coronavirus la economía de América Latina?, Post opinión, The Washington Post, 4 de marzo de 2020.

Spence, M., (2020), Can China's economy withstand the coronavirus? Disponible en: https://www.projectsyndicate.org /commentary/china-economycoronavirusresilience-by-michael-spence-2020-02 


\section{RELACIÓN ENTRE LA CONTAMINACIÓN AMBIENTAL Y EL COVID-19 EN MEDELLÍN Y SU IMPACTO ECONÓMICO}

\section{RELATION BETWEEN ENVIRONMENTAL POLLUTION AND COVID 19 IN MEDELLÍN AND ITS ECONOMIC IMPACT}

\section{Valentina Colorado Bedoya}

Estudiante de la Facultad de Ciencias Empresariales de la Fundación Universitaria María Cano en el programa de Administración de empresas. Correo electrónico: valentinacoloradobedoya@fumc.edu.co.

\section{María José Osorio Villa}

Estudiante de la Facultad de Ciencias Empresariales de la Fundación Universitaria María Cano en el programa de Administración de empresas. Correo electrónico: mariajoseosoriovilla@fumc.edu.co.

\section{Objetivo}

Realizar un análisis comparativo entre el fenómeno de contaminación ambiental y el Covid-19 en la ciudad de Medellín y los impactos que genera en las dinámicas de la economía local.

\section{Descripción del contexto}

Medellín ha estado sufriendo, durante aproximadamente cuatro (4) años, una situación en la que la calidad del aire es nociva para la salud de personas mayores de setenta (70) años, mujeres embarazadas, niños y personas con enfermedades pulmonares, debido a la contaminación que generan las fábricas, automóviles e incendios, además de la ubicación geográfica de la ciudad, al ser un valle dificulta la salida de agentes contaminantes y los deja en la atmosfera, formando un cumulo de gases contaminantes, situación que junto con la contingencia ambiental del Covid-19 puede poner en riesgo la salud de los pacientes de la ciudad, pero al mismo tiempo ha generado restricciones al desarrollo de las actividades económicas, poniendo en riesgo la dinámica productiva y de empleo en la ciudad. 


\section{Metodología}

Se realiza una revisión documental y teórica sobre el fenómeno de la contaminación ambiental y el comportamiento del Covid-19 en la ciudad de Medellín, haciendo énfasis en el impacto generado en las dinámicas económicas de la ciudad.

\section{Hallazgos}

Según la Organización Panamericana de la Salud, la contaminación del aire puede aumentar el riesgo de infecciones respiratorias, enfermedades cardíacas, accidentes cerebrovasculares y cáncer de pulmón (Oficina Regional para las Américas de la Organización Mundial de la Salud, 2018).

El Comité Ambiental del Foro de Sociedades Respiratorias Internacionales publicó un artículo titulado "Beneficios para la salud de la reducción de la contaminación del aire" en el cual citó "Un estudio (...) Determinó que una mejora de $10 \mu \mathrm{g} / \mathrm{m} 3$ en la exposición promedio de PM 2.5 resultó en un alargamiento medio de la esperanza de vida de más de 7 meses (Papa CA III , Ezzati M , Dockery DW., 2009), que representan el $15 \%$ del aumento general en la esperanza de vida (...) lo que implica que todas las poblaciones se benefician de una mejor calidad del aire.” (Schraufnagel et al., 2019).

Los registros de la calidad del aire, según el Área Metropolitana del Valle de Aburra, apuntan que, en promedio los registros para el mes de marzo de las partículas de PM 2.5 fueron de $132 \mu \mathrm{g} / \mathrm{m} 3$, este fue un mes dañino para los grupos sensitivos y para los pacientes de COVID-19; se estima que el mes de abril no supere los $100 \mu \mathrm{g} / \mathrm{m} 3$ y sea inferior a los $50 \mu \mathrm{g} / \mathrm{m} 3$ para que no afecte la evolución de los contagiados por la epidemia. En los registros suministrados por el INS, no se encuentra relación de afectación por la calidad del aire, sin embargo, se debe considerar que todos los contagiados y, parte de la población general, se encuentra en aislamiento obligatorio para evitar la expansión del virus y posibles complicaciones por la calidad del aire.

La situación de emergencia ambiental, con las restricciones de pico y placa que generó, y las afectaciones al sector comercial, se vieron agravadas con las medidas de confinamiento obligatorio y de pico y cédula que se decretaron desde los gobiernos 
nacional y local respectivamente para hacer freno a la expansión del Covid-19 en el territorio. Proyecciones de Fedesarrollo en los últimos días de marzo hablan de una reducción del PIB a niveles cercanos a cero; las proyecciones más recientes del FMI prevén crecimientos entre el $-2 \%$ y $-3 \%$ para el país, sin tener aún estimativos a nivel regional.

\section{Referencias bibliográficas}

Oficina Regional para las Américas de la Organización Mundial de la Salud. (2018). OPS/OMS. Obtenido de https://www.paho.org/hq/index.php?option=com content\&view=article\&id=14454:ambient-and-household-air-pollutionand-health-frequently-asked-questions\&Itemid=72243\&lang=es

Papa CA III , Ezzati M , Dockery DW . (2009). Contaminación del aire por partículas finas y esperanza de vida en los Estados Unidos. Nueva Inglaterra: New England Journal of Medicine.

Portafolio. (26 de Marzo de 2020). Fedesarrollo rebaja su proyección de crecimeinto para el país. Obtenido de https:/www.portafolio.co/economia/fedesarrollorebaja-su-proyeccion-de-crecimiento-para-colombia-539427

Portafolio. (17 de Abril de 2020). Si situación de salud se estabiliza, Colombia lideraría la región: FMI. Obtenido de https:/www.eltiempo.com/economia/ sectores/coronavirus-hoy-en-vivo-asi-ve-el-fmi-a-colombia-en-medio-depandemia-485494

Schraufnagel, D., Balmes, J., De Matteis, S., Hoffman, B., Kim, W., Perez Padilla, R., . . Wuebbles, D. (16 de Julio de 2019). ATS Journal. Obtenido de https:// www.atsjournals.org/doi/10.1513/AnnalsATS.201907-538CME\#_i21 


\title{
TEMPESTADE PERFEITA? INSTITUIÇÕES DE ENSINO SUPERIOR PRESENCIAIS EM TRANSIÇÃO PARA O ENSINO A DISTÂNCIA EM TEMPOS DE COVID-19. UM ESTUDO PRELIMINAR
}

\author{
¿TORMENTA PERFECTA? INSTITUCIONES \\ DE EDUCACIÓN SUPERIOR PRESENCIAL EN \\ TRANSICIÓN A LA ENSEÑANZA A DISTANCIA EN \\ TIEMPOS COVID-19. UN ESTUDIO PRELIMINAR
}

\section{Luísa Cagica Carvalho}

Doutora em Gestão, Docente Investigadora da ESCE - Instituto Politénico de Setúbal e CEFAGE - Universidade de Évora, Portugal. Correio eletrónico: luisa.c.carvalho@esce.ips.pt.

\section{Rui Dias}

Doutor em Gestão, Docente Investigador da ESCE - Instituto Politénico de Setúbal e CEFAGE - Universidade de Évora, Portugal. Correio eletrónico: rui. dias@esce.ips.pt.

\section{João Pereira}

Doutor em Gestão, Docente Investigador ISCAL - Instituto Politécnico de Lisboa, Portugal. Correio eletrónico: jmfpereira@iscal.ipl.pt.

\section{Adriana Backx}

Doutora em Engenharia, Docente Investigadora na Universidade de São Paulo, Brasil. Correio eletrónico: backx@usp.br.

\section{Objetivo}

Analisar a transição das instituições de ensino superior presenciais para um modelo de educação a distância devido ao COVID-19 na perspetiva dos estudantes.

\section{Descrição do contexto}

A Pandemia COVID-19 está a provocar impactos em vários contextos da atividade económica e social a nível mundial. Neste contexto, as Instituições de Ensino Superior 
(IES) também se tiveram de adaptar e de transitar rapidamente para o ensino a distância. Esta transição rápida e na maioria dos casos sem preparação de professores, alunos e da própria estrutura destas organizações trouxe um conjunto de desafios à comunidade educativa e aos estudantes em particular (Carvalho 2015; Carvalho et al, 2019). Este estudo exploratório tem por objetivo estudar a perceção dos estudantes de Instituições de Ensino Superior de Portugal e do Brasil, relativamente a esta transição para ensino a distância.

\section{Metodología}

A partir de um estudo quantitativo que usou como instrumento de recolha de dados um questionário online disponibilizado através da plataforma Lime Survey, recolheramse 1079 em abril de 2020 em IES de Portugal e do Brasil. A análise estatística envolveu medidas de estatística descritiva (frequências absolutas e relativas, médias e respetivos desvios-padrão) e estatística inferencial. O nível de significância para rejeitar a hipótese nula foi fixado em $\alpha \leq .05$. Utilizou-se o teste do Qui-quadrado para analisar a relação entre variáveis qualitativas. O pressuposto do Qui-quadrado de que não deve haver mais do que $20 \%$ das células com frequências esperadas inferiores a 5 foi analisado. Nas situações em que este pressuposto não estava satisfeito usou-se o teste do Qui-quadrado por simulação de Monte Carlo. As diferenças foram analisadas com o apoio dos resíduos ajustados estandardizados. A análise estatística foi efetuada com o SPSS (Statistical Package for the Social Sciences) versão 25.0 para Windows. A amostra era constituída por 1079 alunos. A maioria era do género feminino (71.1\%), com idade compreendida entre os10-25 anos (74\%), tinha nacionalidade portuguesa (95.9\%), estudante (71.8\%), frequentando uma licenciatura (89\%) em Instituto Politécnico (97.5\%). Os cursos mais frequentados eram Contabilidade (22.3\%) e Gestão (16.1\%). A tabela 1 mostra essa descrição. 
Tabela 1 - Caraterização $(\mathrm{N}=1079)$.

\begin{tabular}{lll} 
& N & $\%$ \\
\hline Género & & \\
$\quad$ Feminino & 767 & 71,1 \\
$\quad$ Masculino & 312 & 28,9 \\
\hline Idade & & \\
10 - 25 anos & 798 & 74,0 \\
26 - 40 & 192 & 17,8 \\
41 - 55 & 76 & 7,0 \\
$\quad>55$ anos & 13 & 1,2 \\
\hline Estatuto & & \\
Estudante & 775 & 71,8 \\
Estudante -trabalhador & 304 & 28,2 \\
\hline Tipo curso frequentado & & \\
Licenciatura & 960 & 89,0 \\
Mestrado & 109 & 10,1 \\
Outro (qual) & 10 &, 9 \\
\hline Instituição frequentada & 12 & 1,1 \\
Faculdade & 152 & 97,5 \\
Instituto Politécnico & & \\
Universidade & & \\
\hline
\end{tabular}

Fonte: self made (2020).

\section{Resultados}

Os resultados obtidos são extremamente interessantes e mostram que: a maioria dos estudantes inquiridos usa o computador para aceder às aulas virtuais, geralmente não partilha esse dispositivo com outras pessoas e assistem em maioria às aulas na sua residência, sendo o espaço mais comum o quarto. Também é interessante constatar que a esmagadora maioria não tinha tido alguma experiência anterior de ensino a distância e que consideram que a utilização de tecnologias digitais e o emprego de ambientes 
virtuais colaborativos era uma prática pouco incentivada antes pelos seus professores, referindo que o maior desafio que enfrentam é a falta de aulas presenciais. Indicam também que o ensino online e o contacto online não se adequa às suas necessidade e estilo de aprendizagem. Para além disso, para cerca de quase metade dos alunos a orientação dos seus professores em relação às tecnologias digitais e ambientes colaborativos virtuais está centrada essencialmente no papel do professor e do aluno. Os resultados mostram ainda que os estudantes que têm uma atividade profissional conjugada com os estudos, revelam maior aceitação em geral do ensino a distância do que os que apenas estudantam. Esse grupo de estudantes geralmente pertencente ao um escalão etário mais elevado, também manisfesta mais vontade em que nos período pós pandemia continue a haver aulas deste tipo. De seguida mostram-se os principais resultados do estudo.

\section{Os resultados gerais mostram o seguinte:}

- Um pouco mais de metade da amostra usava o Computador Portátil (Notebook) para assistir às aulas a distância e 39.2\% usava Computador pessoal (PC). Uma percentagem muito elevada indica que não partilha o dispositivo com outras pessoas (81.8\%). Cerca de $3 / 4$ indicou que assistia às aulas num espaço individual da residência $(75,4 \%)$, sendo que os espaços mais referidos eram o quarto $(48 \%)$ ou a sala $(29.9 \%)$. Na sua maioria, este espaço era de utilização exclusiva do próprio aluno (55.2\%).

- Uma proporção muito elevada não tinha tido alguma experiência anterior de ensino a distância (91.7\%). A utilização de tecnologias digitais e o emprego de ambientes virtuais colaborativos, como o caso da videoconferência, e-mails e plataformas colaborativas de partilha de conhecimento, constituem ou uma prática pouco frequente, incentivada pontualmente por alguns professores $(30.8 \%)$ ou uma prática frequente na minha instituição de ensino, incentivada pela maioria dos meus professores $(28.5 \%)$, para a maioria dos inquiridos. Sendo que a intencionalidade na utilização, ou não, destas tecnologias e dos ambientes virtuais colaborativos antes da situação do COVID-19 nas minhas unidades curriculares deve-se sobretudo à pouca utilidade/necessidade que os meus professores atribuem (28.7\%) ou à iniciativa dos meus professores, incentivada igualmente pela minha instituição de ensino (27.4\%) para a maioria dos alunos. 
- $\quad$ Revelam ainda que para $34 \%$ dos alunos as tecnologias ou ambientes virtuais colaborativos mais utilizados pelos seus professores eram a combinação dos três meios (plataforma de e-learning, correio eletrónico e videoconferência). No entanto quando têm um meio preferido, as suas preferências são justificadas pelo acesso e utilização facilitada (24.7\%). Para quase metade dos alunos a orientação dos seus professores em relação às tecnologias digitais e ambientes colaborativos virtuais está centrada essencialmente no papel do professor e do aluno, mediante o desenvolvimento de dinâmicas de grupo e na criação de um ambiente de aprendizagem colaborativo (24.7\%).

- Em termos pedagógicos e no concerne aos ambientes colaborativos a maioria dos estudantes considera que a importância do papel do professor e do aluno, mediante o desenvolvimento de dinâmicas de grupo e na criação de um ambiente de aprendizagem colaborativo.

- Com a passagem para ensino a distância, verificam-se alguns resultados interessantes. Mais de metade dos alunos (60.3\%) considera que o principal desafio com que se depara enquanto estudante é "a falta de aulas presenciais e o facto das alternativas disponíveis, nomeadamente, o ensino online ou outros meios de contacto online não serem ajustados e adequado às minhas necessidades e estilo de aprendizagem".

- É interessante denotar que quase metade da amostra (44.4\%) pensa que no futuro os meios de ensino colaborativo como a plataforma de e-learning devem ter da parte dos meus professores um nível de utilização "mais intensa como complemento das aulas presenciais, explorando outras potencialidades no âmbito da aprendizagem colaborativa, partilha de conhecimento".

\section{Considerações finais}

A maioria dos alunos (60.3\%) considera que o principal desafio com que se depara enquanto estudante é " a falta de aulas presenciais e o facto das alternativas disponiveis, nomeadamente, o ensino online ou outros meios de contacto online não serem 
ajustados e adequado às minhas necessidades e estilo de aprendizagem". Esta opinião é relativamente semelhante independentemente do género $\left(\chi^{2}(2)=3.479, p=.176\right)$, idade $\left(\chi^{2}(6)=10.993, p=.086\right)$ e estatuto dos alunos $\left(\chi^{2}(2)=1.980, p=.372\right)$. A maioria dos alunos (55.4\%) não experienciava dificuldades ou constrangimentos na utilização destas tecnologias e ambientes virtuais colaborativos. Esta opinião é relativamente semelhante independentemente do género $\left(\chi^{2}(3)=1.353, p=.717\right)$, idade $\left(\chi^{2}(9)=12.048, p=.211\right)$ e estatuto dos alunos $\left(\chi^{2}(3)=1.433, p=.698\right)$.

A opinião genérica dos alunos é a de no futuro as aulas virtuais devem ser realizadas apenas em situações excecionais, devendo-se privilegiar sempre as aulas presenciais (54.6\%). Esta opinião é partilhada de forma relativamente semelhante por ambos os géneros $\left(\chi^{2}(3)=5.233, p=.156\right)$.

No entanto quando se analisa em função da idade $\left(\chi^{2}(9)=27.789, p=.001\right)$ e do estatuto $\left(\chi^{2}(3)=24.744, p=.001\right)$ encontramos diferenças estatisticamente significativas.

Assim, nos alunos com idade 10-25 anos a opinião de que "as aulas devem ser realizadas apenas em situações excecionais, devendo-se privilegiar sempre as aulas presenciais" é significativamente mais elevada, enquanto nos alunos do escalão 2640 anos é mais elevada a opinião de que as aulas devem ser realizadas "com maior frequência e sempre que possivel em alternativa às aulas presenciais" . (Figura 6).

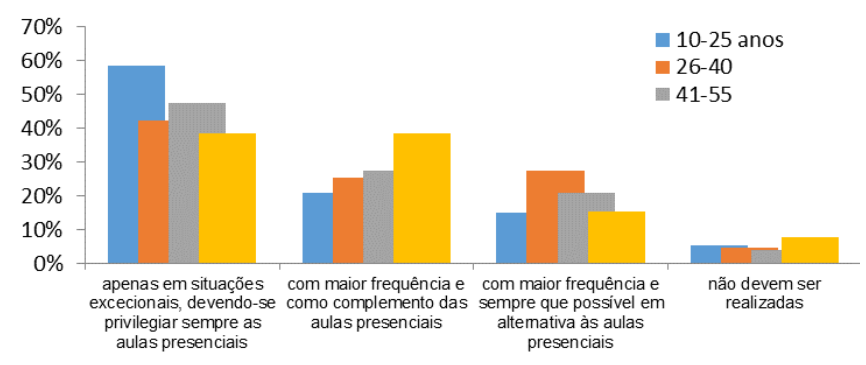

Figura 6. Perceção sobre o ensino a distância por idades.

Nos alunos inscritos como estudantes há uma proporção significativamente mais elevada com opinião de que "as aulas devem ser realizadas apenas em situações 
excecionais, devendo-se privilegiar sempre as aulas presenciais" enquanto nos estudantes trabalhadores há uma proporção significativamente mais elevada de alunos que defendem que as aulas devem ser realizadas "com maior frequência e sempre que possível em alternativa às aulas presenciais".

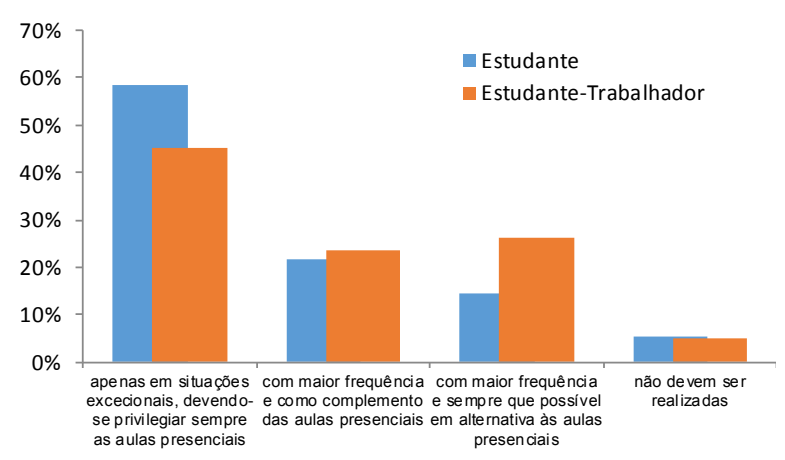

Figura 7. Comparação ente perfil de estudantes a tempo inteiro versus trabalhadores

\section{Referências bibliográficas}

Carvalho; L. (2015) "Challenges and opportunities for virtual universities in XXI century" Patricia Ordóñez, Robert D. Tennyson, Miltiadis D. Lytras (Eds) Assessing the Role of Mobile Technologies and Distance Learning in Higher Education, IGI Global, pp 131-153, DOI: 10.4018/978-1-4666-7316-8

Carvalho, L.; Cândido, R.; Ribeiro, D.; Viana, A. (2019). Estilos de aprendizagem de estudantes universitários portugueses: uma proposta para visualização dos estilos predominantes. Revista Pensamento \& Realidade, v. 34, n 3, 03-20. 


\section{RESPONSABILIDAD SOCIAL EMPRESARIAL VS SITUACIÓN EXCEPCIONAL POR EL COVID-19 EN LOS PAÍSES LATINOAMERICANOS}

\section{CORPORATE SOCIAL RESPONSIBILITY VS EXCEPTIONAL SITUATION BY COVID-19 IN LATIN AMERICAN COUNTRIES}

\section{Osmany Pérez Barral}

Doctor en Ciencias Económicas, docente de la Pontificia Universidad Católica del Ecuador Sede Ambato. Correo electrónico: operez@pucesa.edu.ec.

\section{Jorge Vladimir Núñez Grijalva}

Doctor en Ciencias Jurídicas, docente de la Pontificia Universidad Católica del Ecuador Sede Ambato. Correo electrónico: jnunez@pucesa.edu.ec.

\section{Mónica del Rocío Alarcón Quinapanta}

Doctora en Ciencias Técnicas, docente de la Universidad Regional Autónoma de Los Andes.

\section{Objetivo}

Analizar la Responsabilidad Social Empresarial en situación excepcional por el COVID-19 en los países latinoamericanos.

\section{Descripción del Contexto}

El contexto que vive Latinoamérica a partir del COVID-19, ha puesto en jaque a las empresas productivas y del sector de los servicios a partir de febrero hasta la actualidad. En este sentido, las organizaciones se han dado cuenta que no estaban preparadas para asumir un reto de vida no presencial ni de gestión a partir del teletrabajo, sobre todo, en las Micro, Medianas y Pequeñas Empresas (MIPYME's) y en el sector de la salud. De la misma manera, la afectación económica que han tenido en todo este tiempo las organizaciones por el COVID-19, ha conllevado, a que los gerentes comiencen a utilizar sus fondos de reservas para otorgar vacaciones masivas a sus trabajadores como una medida paliativa a la situación existente o comenzar con los despidos de sus trabajadores. Asimismo, se coincide con Rey (2020), que la pandemia alcanza una nueva 
etapa crítica donde los sistemas de salud pública, donde sus instituciones han colapsado por el incremento de contagios en la sociedad, exponiéndose la falta de Responsabilidad Social Empresarial (RSE), en cuanto a no garantizar habitaciones en los hospitales y clínicas, incremento en el desabastecimiento de insumos médicos (equipos protectores para médicos y enfermeras y medicamentos para pacientes), posibilidad de pruebas rápidas y de laboratorios, suficientes respiradores artificiales y un elevado nivel de contagios de los médicos y personal de enfermería, lo cual, demuestra una debilidad de la responsabilidad social interna y externa en el sector de la salud por ejemplo.

En tal sentido, la base económica de los países latinoamericanos es muy débil, acrecentándose aún más, por la baja del petróleo que ahora les golpea. Asimismo, los niveles de endeudamiento con el Fondo Monetario Internacional y el Banco Mundial, provoca que los gobiernos y empresarios latinoamericanos se encuentren atados de poder ayudar responsablemente a la subsistencia de las empresas para que estas logren sostenerse sin despedir a sus trabajadores ni obligarles a la quiebra, no garantizándose el bienestar mínimo de las familias de sus empleados, pues la RSE de una empresa, va más allá de la atención únicamente a los trabajadores, pues la familia, depende del sustento de éstos para garantizar salud, alimentación y educación como un derecho que tiene todo ser humano. Asimismo, esta percepción planteada en situación excepcional, deja claro, que existen otras aristas o dimensiones que normalmente se analizan y relacionan con la RSE.

\section{Metodología}

La metodología se sustenta en una investigación descriptiva-explicativa, con un enfoque cualitativo partir del empleo del método del análisis documental, producto de los acontecimientos del COVID-19 en Latinoamérica y su impacto en la RSE, tomándose como ejemplo, las Mipymes. Lo cual permite plantear, que la RSE tiene un carácter más amplio y profundo a las dimensiones que normalmente se plantean en el desarrollo de la ciencia, destacándose según Fernández (2020):

- Dimensión interna, que afecta a sus trabajadores, a su impacto medioambiental, a la gestión de las materias primas, a sus condiciones de trabajo o la peligrosidad de sus productos. 
- Dimensión externa frente a la sociedad en su conjunto, proveedores, consumidores, clientes externos y contratistas, con los cuales, la empresa se relaciona y a los que debe generar algún valor si se autodefine como socialmente responsable.

\section{Hallazgos}

La situación del COVID-19 en Latinoamérica y la baja del petróleo a nivel mundial, ha empeorado el escenario económico en la región y la interpretación de la RSE en los gobiernos y las empresas, por ende, el impacto ha sido mayor en el eslabón más vulnerable, los empleados y sus familias. En este sentido, se percibe que la RSE, no puede impedir un crecimiento de la desigualdad entre las clases sociales de cualquiera de los países de la región, en cuanto a: permanencia en los puestos de trabajo, disminución de los salarios de los empleados, posibilidad de continuar estudios en los diferentes niveles, acceso a la salud, posibilidades económicas para las necesidades básicas, entre otras. Por ejemplo, aun cuando existe un sector de la salud público en todos los países de Latinoamérica, las condiciones de sus instalaciones no dan abasto para atender todos los casos que se presentan y, si a ello se suma, que las empresas se encuentran en situaciones económicas deplorables por el paro obligatorio de su funcionamiento dada las medidas sanitarias, entonces, los empleados y sus familias, no podrán contar con un sustento que garantice que puedan ser atendidos en clínicas privadas, incrementándose así, los muertos en las familias de los empleados que laboran en estos tipos de organizaciones.

Otro ejemplo, muy bien tratado por González (2020), expone que, el confinamiento en el que vive actualmente casi una tercera parte de la población mundial hace más evidente la desigualdad habitacional. Estar confinado en una chabola con la nevera vacía no es lo mismo que estarlo en una casa con jardín y piscina, o en un piso de 110 metros cuadrados. Por supuesto, que esto se acrecienta en los países de la región objeto de estudio, donde los niveles de pobreza son superiores a los países desarrollados, marcado esto, porque las empresas no pagan realmente por el rendimiento de sus trabajadores, violándose de esta manera la RSE en cuanto al salario y atención de sus empleados por la labor que realizan, lo cual, se refleja después en las condiciones de vida y bienestar de la población más vulnerable. 
En tal sentido, aunque las constituciones de los países latinoamericanos garantizan un sistema de salud público, la realidad es que los recursos destinados para atender a las personas contagiadas por COVID es insuficiente, lo cual obliga o destina, a que los empleados y sus familias de bajos ingresos no puedan ser atendidos en otras clínicas, condenándoseles en la generalidad de los casos, a la muerte. Asimismo, la situación de desespero económico de las empresas, están acelerando el proceso de entrada de los empleados al trabajo, lo cual, pone en riesgo la salud de estos y sus familiares sin importar las consecuencias. Tal pareciera, que la RSE es la economía y no la vida de las personas, pues la desigualdad comienza como expone González (2020), por el mercado de trabajo, siendo el comienzo del no interés por la RSE por parte de los empresarios. En este sentido, y de acuerdo con lo analizado por éste mismo autor, la disminución en los ingresos en Latinoamérica repercutirá en un aumento de hasta el 10\% en el desempleo siéndose algo conservador en esta cifra. La pobreza en la región podría crecer hasta alcanzar a 210 millones de personas frente a los 185 millones actuales. Es decir, la crisis del coronavirus convertirá en pobres a 25 millones de personas más en Latinoamérica, lo que, sin duda, incidirá en un aumento de la desigualdad en esta región, donde la desigualdad es ya de por sí un problema estructural y es responsabilidad social de las empresas y los gobiernos.

\section{Referencias bibliográficas}

Fernández, R. (2010). Dimensiones de la responsabilidad social empresarial. Sus actores. Papel de las políticas públicas. Diario Responsable https:// diarioresponsable.com/opinion/11467-dimensiones-de-la-responsabilidadsocial-empresarial-sus-actores-papel-de-las-politicas-publicas

González, I. (2020). La COVID-19 acentuará la desigualdad en Latinoaméricahttps:// theconversation.com/la-covid-19-acentuará-la-desigualdad-enlatinoamerica-135673. 15 de abril. The conversation.

Rey, J. (2020). Resiliencia y RSE en Tiempos de COVID-19. https://hoy.com.do/ resiliencia-y-rse-en-tiempos-de-covid-19/ 


\title{
CORONA VIRUS (COVID-19): REFLEJOS SOCIOECONÓMICOS EN BRASIL
}

\section{CORONAVIRUS (COVID-19): SOCIOECONOMICAL REFLEXS IN BRAZIL}

\author{
Francieli Iung Izolani \\ Estudiante Maestra en Derechos Emergentes de la Sociedad Global de la \\ Universidad Federal de Santa Maria, Brasil. Correo electrónico: franizolani@ \\ hotmail.com.
}

\section{Objetivo}

Analizar desde una perspectiva complejo-sistémica los reflejos socioeconómicos en Brasil ante la presencia del COVID-19.

\section{Descripción del contexto}

La pandemia, designación utilizada para así referir a una molestia que se ha difundido por diversas partes del mundo simultáneamente, puede ser comprendida como un reflejo socioambiental de la sociedad globalizada, de riesgo, y ha afectado de modo sencillo socioeconómicamente a los países, incluyo Brasil. Ocurre que, así como otras consecuencias de esa sociedad de riesgo, afecta de forma desigual a las personas, de acuerdo con su potencial económico, estando entre los más impactados los menos favorecidos, revelando problemas en sectores de la salud y de la economía, principalmente. En Brasil, aunque haya sido destinado el montante de R\$1128780300 como crédito extraordinario el 10 de febrero, el cierre de escuelas y universidades, iglesias y templos, por si mismo no ha sido capaz de contornar los problemas socioeconómicos del Covid-19. Hubo el cierre del comercio, quedando abierto solamente las pequeñas actividades consideradas esenciales, como farmacias, mercados y gasolineras, los hospitales si han mantenido llenos, con la sumisión de trabajadores escogidos a hacer el sacrificio. Mas allá, en salud, si cumplió la necesidad de políticas públicas a la mejora 
del Sistema Único de Salud y el desempleo fue aumentado, juntos con el agravo de la situación socioeconómica de millones de brasileños.

\section{Metodología}

A partir de una visión transdisciplinar de la pesquisa cualitativa, como una manera de comprender y expresar los hechos de la actualidad, el método utilizado es el hermenéutico fenomenológico de Heidegger (1998), con la superación de la reducción, de la destrucción para entonces hacer la construcción para si orientar en el mundo a través de un horizonte abierto. El formato que se propone permite que se traigan los hallazgos delante de la tabla 1.

Tabla 1. Taja de desempleo en Febrero de 2020.

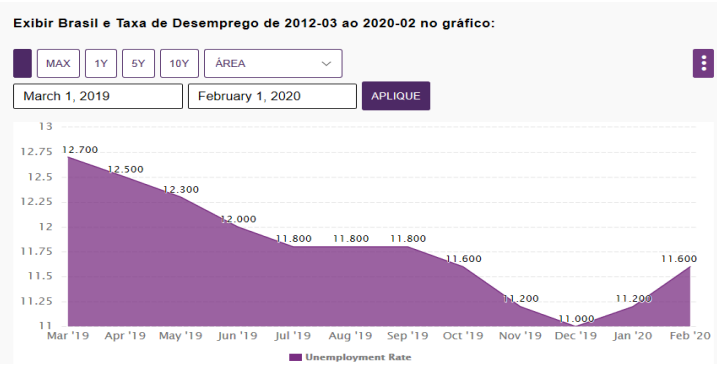

Fuente: (CEIC. Disponible en: https://www.ceicdata.com/pt/indicator/brazil/unemployment-rate).

\section{Hallazgos}

Desde los datos presentados en la tabla 1, puede ser visto un aumento en la taja de desempleo en el mes de febrero, lo que puede ser el comienzo de la crisis socioeconómica del país, puesto que mismo con el montante investido en la economía en el combate al Covid-19, no será el suficiente a resolver las consecuencias que van muy más allá de ese investimento junto con los 600 reales como un auxilio de urgencia a clase menos favorecida. De hecho, la pandemia reflete la desigualdad en términos de población afectada y de impactos en puestos de trabajos, la recesión es eminente ya en el primer semestre. Ya ha afectado a los más pobres, ha mostrado como es frágil el sistema de salud brasileño con problemas agravados delante de la pandemia, también los problemas 
sociales de las clases más bajas y además, que el Estado todo privatizado no puede resolver los problemas económicos de las medidas de precaución adoptadas en el intento de minimizar la difusión de Covid, ni el dinero invertido será suficiente para recuperar las empresas y solucionar el tema del desempleo y todas las consecuencias que vienen junto con ello. El tema es mucho más complejo y sencillo, necesitando más estudios.

\section{Referencias bibliográficas}

CEIC (2020). Brasil Taxa de Desemprego. Disponible en: https://www.ceicdata.com/pt/ indicator/brazil/unemployment-rate. Accedido el: 23 abr. 2020.

Heidegger, M. (1998). Ser y tiempo. Chile: Editorial Universitaria 


\section{CONCLUSIONES}

Este libro está constituido por documentos científicos desarrollados y expuestos en el espacio académico de interacción denominado Impacto del COVID-19 desde la perspectiva socioeconómica en el contexto global, que produjo un análisis, y reflexión crítica formalizada de un grupo de investigadores, que reconociendo su papel en la sociedad, decidieron de manera prospectiva, dilucidar los mayores impactos sociales y económicos que produce una pandemia declarada así por la Organización Mundial de la Salud (OMS) el 11 de marzo de 2020, en los diferentes escenarios.

De esta manera se sistematizaron los resultados expuestos desde diferentes tópicos y ejes temáticos y se resumen en las siguientes conclusiones:

- Los efectos de esta pandemia en torno a la desigualdad en América Latina en el cual se insiste en la creación de sistemas de salud inclusivos que sean oportunos y eficientes y que permitan el acceso a la protección de grupos vulnerables.

- En esta misma línea se contó con los hallazgos encontrados en el trabajo: El pueblo Wayuu discriminado por el gobierno de Colombia en el que se evidencia la carencia de un plan de acción claro y enmarcado en las condiciones y necesidades de esta población en el departamento de La Guajira.

- Con respecto a los efectos de esta pandemia sobre la organización familiar fueron dos los trabajos que se dedicaron a analizarlos, el primero titulado: Encuentros y desencuentros en la familia en el cual los autores destacan que durante este periodo se pondrán a prueba las herramientas y fortalezas de la familia ante la regulación de mantener una distancia física y una sana distancia emocional (necesaria) para permitir la reflexión y la atenuación de las emociones. El segundo, también preocupado por los mismos efectos en la organización social a partir de la dinámica y función familiar se enfoca en las consecuencias provocadas a nivel sicosocial tales como síntomas depresivos, ansiedad, estrés y miedo, irritabilidad hacia las personas con las que se convive, afectando la interacción entre sus miembros y posiblemente distorsionando la misión social de la familia. 
- $\quad$ En el sector educativo los aportes investigativos giraron en torno a cuatro tendencias, entre ellas:Las iniciativas de los estudiantes colombianos en la creación de videos, juegos, objetos virtuales y múltiples propuestas autodidácticas como un mecanismo de supervivencia ante el COVID-19, dando origen a una tendencia neurocognitiva que responde a las necesidades del entorno y que emergen como un proceso de transformación socioeconómica ante la crisis del COVID-19.

- En concordancia con las tecnologías, otro trabajo en esta misma línea lo representa Las competencias TIC para implementar la educación virtual ante la pandemia de la COVID-19 en el cual se deja constancia de las ventajas de estas herramientas, aunque los docentes no tiendan a promover procesos de innovación.

- Dentro de este mismo sector, pero a nivel universitario, se presentaron los hallazgos provenientes de los trabajos titulados: COVID-19 y la educación superior en América Latina: una aproximación hacia los efectos sobre docentes y alumnos y posibles respuestas y el segundo, La responsabilidad social universitaria: una herramienta de gestión organizacional centrada en el ser humano, en el primero se debaten los escenarios posibles, (1) el de habilidades futuras, (2) estudio multinstitucional en red, (3) "miuniversidad", (4) aprendizaje de toda la vida. en el segundo, se promueve el incesante cambio ante las tendencias globales que pueden transformar de una manera contundente el escenario universitario.

- En lo que respecta a la investigación, el trabajo: Perspectivas de investigación como consecuencias del COVID-19, sugiere un nuevo modelo para esta labor que considere el comportamiento humano vinculado con el institucional, teniendo como variables principales: flexibilidad organizacional, factores psicosociales, reacciones de comportamiento, salud emocional y balance vida- trabajo.

- Dentro del sector económico se ubicaron 10 trabajos, los cuales apuntaron hacia: La prospectiva de las barreras no arancelarias para Colombia ante una economía en tiempos de pandemia (COVID-19); Estrategia de negocios disruptiva como consecuencia de eventos globales: caso economía informal en Colombia; Oportunidades del cuadro de mando integral, después de que se levanten las restricciones del coronavirus; La 
suspensión de los contratos de prestación de servicios estatales por el COVID-19 en Colombia; Análisis de la planeación de prospectiva estratégica como herramienta para visualizar el futuro; Medidas económicas para lograr la reactivación de la economía colombiana ante la pandemia de la COVID-19 y el Impacto del COVID-19 sobre la industria del café en el Tolima, Colombia, traspasando las fronteras y dentro de este mismo sector se ubicaron los trabajos realizados en Honduras, México, Ecuador y Chile.

En el primer contexto se reportó el trabajo titulado: Inversión en capital humano en la manufactura intermedia, de la industria automotriz hondureña, y el efecto del COVID-19, en México; el Impacto del COVID-19 en el turismo de la ciudad de Pachuca de Soto, Hidalgo, México y en Ecuador se contó con el estudio que lleva por nombre: Impacto de la economía en tiempos emergentes, finalmente se concluye con el trabajo denominado: Efectos vinculantes post COVID-19: una mirada globalizante donde se enfatiza como la economía de la post pandemia, nos enfrenta al desafío de repensar los antiguos esquemas o bases en que se cimentaba la rentabilidad y se expone que la salida de esta crisis, importará parámetros nuevos, inversiones diferentes, seguridad, higiene, entre otros.

En síntesis es relevante destacar que con la reflexión aportada en todos los documentos científicos contenidos en este libro se pudieron vislumbrar los efectos en distintas áreas del acontecer social, pero se puede decir que la pandemia generada por CONVID-19 vino a mostrar la gran cantidad de debilidades y diferencias sociales que golpean a la sociedad de cualquier país, muchos serán los afectados pero no solo en su salud física sino también en su salud económica y muy especialmente en la mental pues la sociedad no sabe estar aislada necesita por naturaleza compartir una palabra, un apretón de manos, un abrazo, un ¡buenos días!

De estas reflexiones científicas se desprende que la situación a nivel mundial cambió, ya no se requiere que todos los trabajadores de una empresa estén presentes para que siga siendo productiva, no se necesita que los alumnos estén en un aula para que el profesor pueda dar su clase, pero también se pone a prueba la unión familiar al estar más tiempo juntos de lo que se estuvo en el pasado, los resultados de estas investigaciones reflexivas y críticas demuestran estos cambios y abren las puertas para la reflexión y el replanteamiento de los procesos. 
A su vez generan una gran cantidad de preguntas ¿Qué pasara? ¿Qué se puede hacer? ¿Se desplomará la economía? ¿Los nuevos profesionales estarán bien preparados? ¿Cómo se abordarán las investigaciones científicas? ¿En cuánto se elevará el nivel de pobreza? ¿Las familias permanecerán juntas? ¿Cuáles serán los efectos del aislamiento en los niños?, y como esas muchas más, queda de este grupo selecto, llamados, investigadores dar respuesta en sus futuras investigaciones.

Dra. Judeira Batista de Abreú. 
"Impacto del COVID-19 desde la perspectiva socioeconómica en el contexto global”, de la colección Unión Global. Publicación digital editada por el Fondo Editorial Universitario Servando Garcés de la Universidad Politécnica Territorial de Falcón Alonso Gamero, Santa Ana de Coro, estado Falcón, Venezuela, coedición Alianza de Investigadores Internacionales. S.A.S. ALININ, Medellín, Antioquia, Colombia. Con el respaldo de la Universidad Politécnica Territorial de Falcón Alonso Gamero (UPTAG), Falcón, Venezuela, la Alianza de Investigadores Internacionales (ALININ), Antioquia, Colombia y sus instituciones aliadas: Universidad Autónoma Chapingo (UACh) Sonora, México, Universidad Politécnica de Guanajuato (UPG), Celaya, México, Cuerpo de Bioeconomía y Biodesarrollo en organizaciones públicas y privadas de la Universidad de Guanajuato (UG), Celaya, México, el Centro de Investigación, Formación y Capacitación Tecnológica (CIFCAT) San Miguel de Allende, México, Zumaque Consultores (ZC. C.A.) Venezuela, Universidad Continente Americano (UCA), Celaya, México, Pontificia Universidad Católica del Ecuador (PUCE), sede Ambato, Ecuador, Universidad Surcolombiana (USCO), Neiva, Colombia, Corporación Universitaria Remington (UNIREMINGTON), Medellín, Colombia, Universidad Autónoma Latinoamericana (UNAULA), Medellín,Colombia y Universidad de La Guajira, Riohacha, Colombia bajo la supervisión del Fondo Editorial Universitario Servando Garcés de la Universidad Politécnica Territorial de Falcón Alonso Gamero, Santa Ana de Coro, Falcón, Venezuela. Este libro se diseñó en el mes de septiembre de 2020 . 
Este libro en versión digital se editó en septiembre de 2020 
Una publicación de :

Alianza de Investigadores Internacionales. SAS. ALININ

Fondo Editorial Universitario Servando Garcés

de la Universidad Politécnica Territorial de Falcón Alonso Gomero

\author{
EDICIÓN ÚNICA \\ COLECCIÓN UNIÓN GLOBAL \\ LIBRO RESULTADO DE INVESTIGACIÓN
}

\begin{abstract}
El libro "Impacto del COVID-19 desde la perspectiva socioescómica en el contexto global", de la colección Unión Global, es una publicación resultado de investigación, internacional, seriada, continua, arbitrada, de acceso abierto a todas las áreas del conocimiento, orientada a contribuir con procesos de la investigación científica, tecnológica y humanística. Todos los capítulos incluidos en la obra son resultado de proyecto de investigación desarrollado por sus autores. Con esta colección, se aspira contribuir con el cultivo, la comprensión, la recopilación y la apropiación social del conocimiento en cuanto a patrimonio intangible de la humanidad, con el propósito de hacer aportes con la transformación de las relaciones socioculturales que sustentan la construcción social de los saberes y su reconocimiento como bien público.
\end{abstract}

Cuenta con el aval de los grupos de investigación de: Universidad Politécnica Territorial de Falcón Alonso Gomero (UPTAG), Falcón, Venezuela, la Alianza de Investigadores Internacionales (ALININ), Antioquia, Colombia y sus instituciones aliadas: Universidad Autónoma Chapingo (UACh) Sonora, México, Universidad Politécnica de Guanajuato (UPG), Celaya, México, Cuerpo de Bioeconomía y Biodesarrollo en organizaciones públicas y privadas de la Universidad de Guanajuato (UG), Celaya, México, el Centro de Investigación, Formación y Capacitación Tecnológica (CIFCAT) San Miguel de Allende, México, Zumaque Consultores (ZC. C.A.) Venezuela, Universidad Continente Americano (UCA), Celaya, México, Pontificia Universidad Católica del Ecuador (PUCE), sede Ambato, Ecuador, Universidad Surcolombiana (USCO), Neiva, Colombia, Corporación Universitaria Remington (UNIREMINGTON), Medellín, Colombia, Universidad Autónoma Latinoamericana (UNAULA), Medellín, Colombia, Universidad de La Guajira, Riohacha, Colombia, así como diferentes grupos de investigación del ámbito nacional e internacional que hoy se unen para estrechar vínculos investigativos, para que sus aportes científicos formen parte de este libro que se publica en formato digital.

ISBN e: 978-980-7857-35-2

Fondo Editorial Universitorio Servando Garcés de la Universidad Politécnica Territorial de Falcón Alonso Gamero

\title{
Libro Resultado de Investigación
}

